Florida International University FIU Digital Commons

9-30-2008

\title{
Perceptions of Underprepared Community College Students regarding their Educational Achievement
}

Peter Barbatis

Florida International University, pbarbati@broward.edu

DOI: $10.25148 /$ etd.FI10022503

Follow this and additional works at: https://digitalcommons.fiu.edu/etd

\section{Recommended Citation}

Barbatis, Peter, "Perceptions of Underprepared Community College Students regarding their Educational Achievement" (2008). FIU Electronic Theses and Dissertations. 183.

https://digitalcommons.fiu.edu/etd/183 


\section{FLORIDA INTERNATIONAL UNIVERSITY}

Miami, Florida

\section{PERCEPTIONS OF UNDERPREPARED COMMUNITY COLLEGE STUDENTS REGARDING THEIR EDUCATIONAL ACHIEVEMENT}

A dissertation submitted in partial fulfillment of the

requirements for the degree of

DOCTOR OF EDUCATION

in

HIGHER EDUCATION

by

Peter Barbatis 
To: Interim Dean Kingsley Banya

College of Education

This dissertation, written by Peter Barbatis, and entitled Perceptions of Underprepared Community College Students regarding their Educational Achievement, having been approved in respect to style and intellectual content, is referred to you for judgment.

We have read this dissertation and recommend that it be approved.

Janice R. Sandiford

Glenda Musoba

Monika Shealey

Ann Nevin, Major Professor

Date of Defense: September 30, 2008

The dissertation of Peter Barbatis is approved.

$\begin{array}{r}\hline \begin{array}{r}\text { Interim Dean Kingsley Banya } \\ \text { College of Education }\end{array} \\ \hline \begin{array}{r}\text { Dean George Walker } \\ \text { University Graduate School }\end{array}\end{array}$

Florida International University, 2008 


\section{DEDICATION}

This dissertation is dedicated to my parents Gerris and Eva Barbatis who immigrated respectively from Greece and Cuba to the United States for increased opportunities and a better life. Despite their limited formal education, they understood the importance of school and valued learning. If it were not for their support and shared meaning of life, I would not be where I am today.

I also dedicate this work to my daughter Melissa. As a testimony of the impact an education can have, I hope I have instilled in her the love of life and the passion to learn. May she accomplish her life goals with much health, happiness, and joy.

Finally, I dedicate this dissertation to D. R. Mealy - a friend of the family, staunch supporter and an individual who cares for my success and happiness. Life should be comprised of close, supportive encouragers who share in our daily journey. 


\section{ACKNOWLEDGMENTS}

I wish to take this opportunity to thank my committee members, Dr. Glenda Musoba, Dr. Janice Sandiford, and Dr. Monika Shealey for their insights, encouragement and guidance. I most especially want to thank my committee chair, Dr. Ann Nevin for her knowledge, diligent dedication, and tireless efforts in helping me obtain this life-long achievement. She is a true mentor, coach, and selfless educator who believes in equal opportunity for the disenfranchised.

I also want to thank my colleagues at ABC for their support and encouragement as I continued my education. The College is committed to serving the residents of our county and making a difference in the lives of our students. I am honored to be part of the ABC family.

I want to thank Greta Jackson and Mareta Sizemore for their assistance and support in helping me locate our FYE students. Both colleagues are dedicated professionals who positively influence all with whom they come in contact. May their helping attitude and selfless service always be the prevailing outlook among faculty, administrators, and staff.

Finally, I would like to acknowledge our First Year Experience students and thank them for their generosity in sharing their life stories and experiences. Despite many challenges and obstacles, they enrolled in college and achieved the hopes and aspirations of their families and friends. It is for them that we should dedicate our professional lives and create success initiatives and programs. May we never lose sight of our mission and always have time to listen to their voices and concerns. In the true spirit of learning communities, administrators, faculty and staff may learn from students, too. 


\title{
ABSTRACT OF THE DISSERTATION \\ PERCEPTIONS OF UNDERPREPARED COMMUNITY COLLEGE STUDENTS \\ REGARDING THEIR EDUCATIONAL ACHIEVEMENT
}

\author{
by \\ Peter Barbatis \\ Florida International University, 2008 \\ Miami, Florida \\ Professor Ann Nevin, Major Professor
}

The purpose of this study was to understand the perceptions of underprepared college students who had participated in learning communities and who persisted to complete developmental classes and earned at least 30 college-level credit hours to graduate and the perceptions of their peers who had dropped out of college. The theories posed by Tinto, Astin, and Freire formed the framework for this case study. The 22 participants were graduates or transfer students now attending a public university, currently-enrolled sophomores, and students no longer enrolled at the time of the study. Semi-structured individual interviews and a group interview provided narrative data which were transcribed, coded, and analyzed to gain insights into the experiences and perspectives of the participants. The group interview provided a form of member checking to increase accuracy in interpreting themes. A peer reviewer provided feedback on the researcher's data analysis procedures.

The analysis yielded four themes and 14 sub-themes which captured the essence of the participants' experiences. The pre-college characteristics/traits theme described the students' internal values and attributes acquired prior to college. The external college 
support/community influence theme described the encouragement to attend college the students received from family, friends, and high school teachers. The social involvement theme described the students' participation in campus activities and their interactions with other members of the campus. The academic integration theme described students' use of campus resources and their contacts with the faculty. The persisters reported strong family and peer support, a sense of responsibility, appreciation for dedicated and caring faculty, and a belief that an education can be a liberatory means to achieve their goals. The non-persisters did not report having the same sense of purpose, goal orientation, determination, obligation to meet family expectations, peer support, campus involvement, positive faculty experiences, and time management skills. The researcher offers an emerging model for understanding factors associated with persistence and three recommendations for enhancing the academic experience of underprepared college students: (a) include a critical pedagogy perspective in coursework where possible, (b) integrate co-curricular activities with the academic disciplines, and (c) increase studentfaculty interaction. 


\section{TABLE OF CONTENTS}

CHAPTER

PAGE

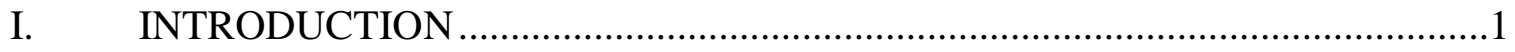

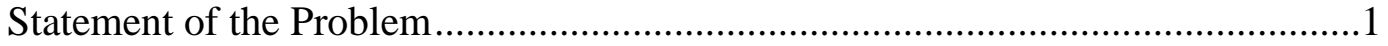

Purpose of the Study ....................................................................................

Research Question ..................................................................................6

Theoretical Framework ................................................................................6

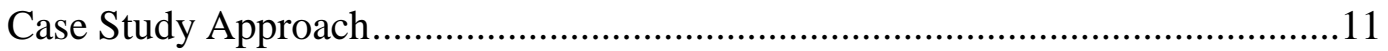

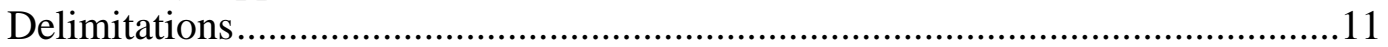

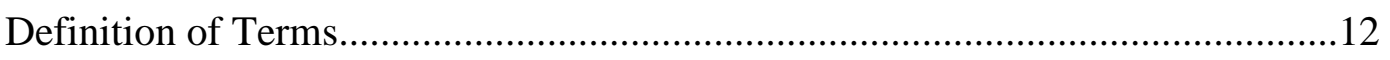

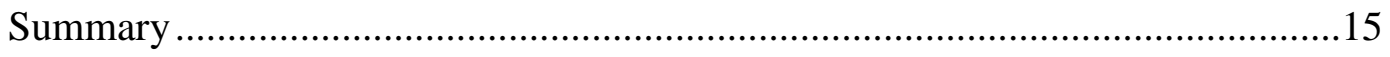

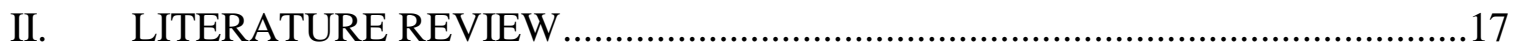

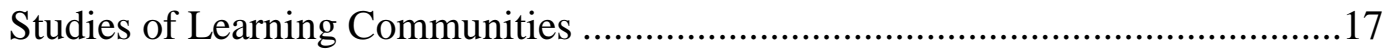

Factors Associated with Persistence of Community College Students .................34

Theories to Explain Retention and Persistence of College Students ....................43

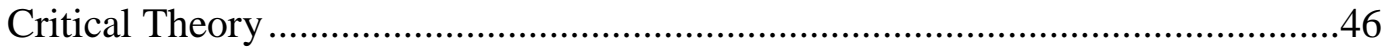

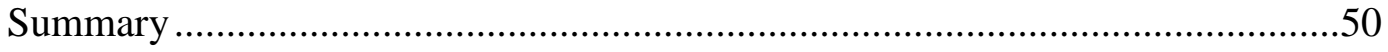

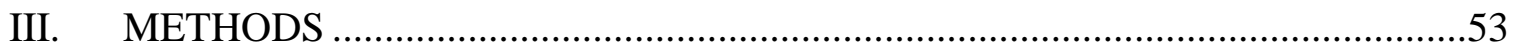

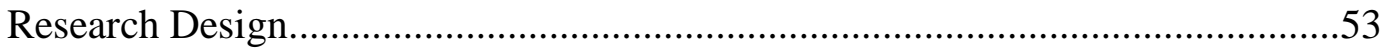

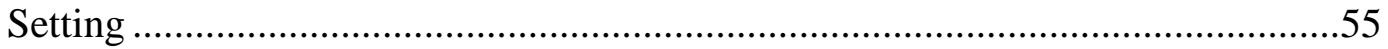

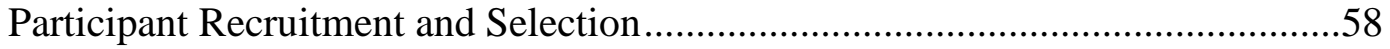

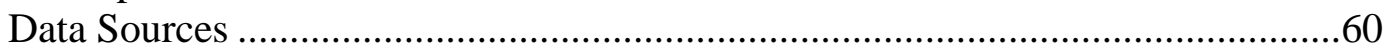

Data Collection Procedures............................................................................61

Researcher's Role, Autobiography, Assumptions, and Subjectivities..................64

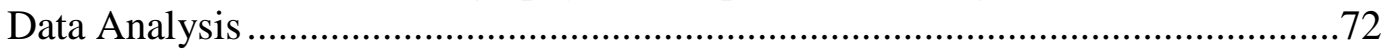

Procedures to Increase Validity and Credibility ............................................75

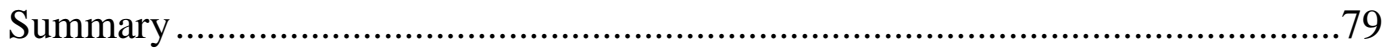

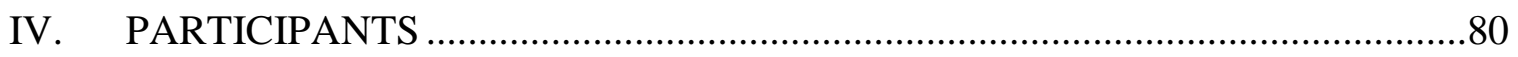

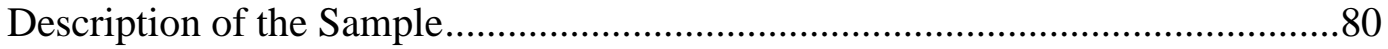

Learning And Study Strategies Inventory (LASSI) and GPA Results .................81

Study of Graduates, Persisters and Non-Persisters ..........................................82

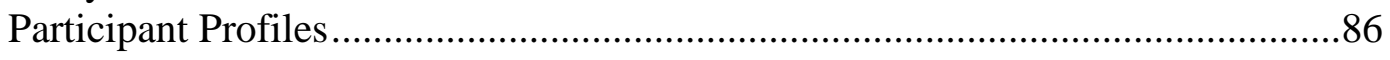

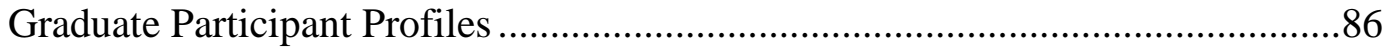

Summary of Number of Course Withdrawals and Failures for Graduates .............93

Persister Participant Profiles ............................................................................93

Summary of Number of Course Withdrawals and Failures for Persisters...........107

Non-Persister Participant Profiles ...................................................................109

Summary of Number of Course Withdrawals and Failures for Non-Persisters...113

Summary 


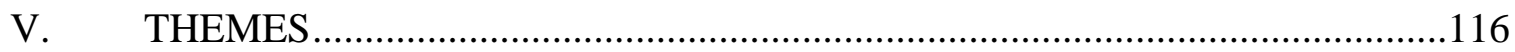

Member Checks to Verify Profiles and Themes.................................................116

Theme 1: Pre-College Characteristics and Traits ..............................................118

Theme 2: External College Support/Community Influences................................127

Theme 3: Social Involvement .........................................................................136

Theme 4: Academic Integration...................................................................139

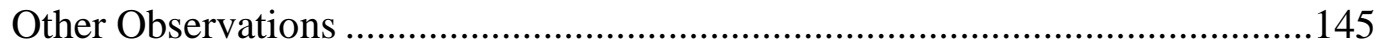

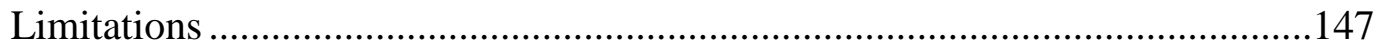

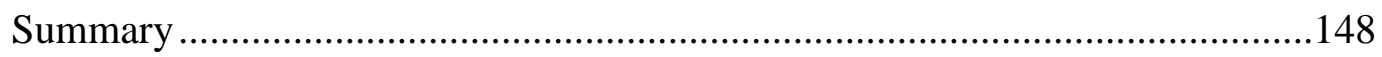

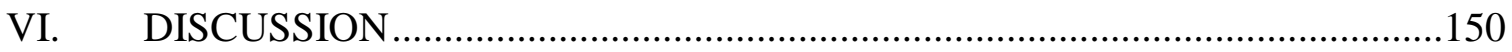

Summary of the Study ...............................................................................150

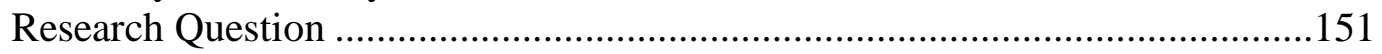

Emerging Model to Explain Persistence of Underprepared College Students ...154

Connection to the Literature Review ...................................................................157

Factors that Influence Underprepared College Students’ Persistence ..................159

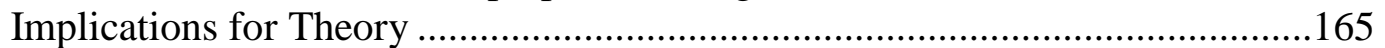

Implications for Community College Practice ..................................................168

Implications for Community College Policy …………........................................173

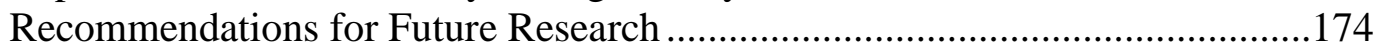

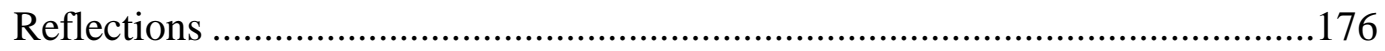

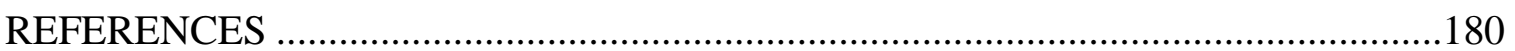

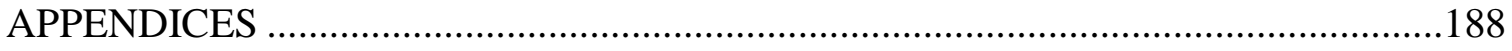

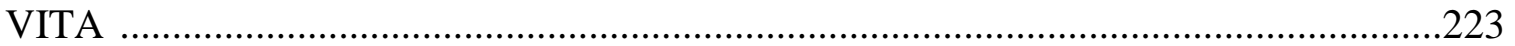




\section{LIST OF TABLES}

TABLE

PAGE

1. Empirical Studies of Learning Communities Published in Peer-Reviewed Journals

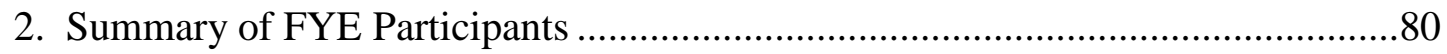

3. Demographic Profile of the Graduates ............................................................. 83

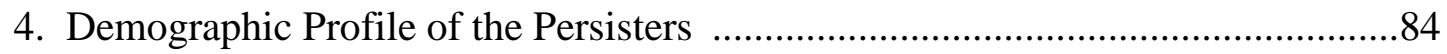

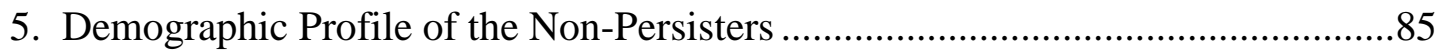

6. Summary of Number of Course Withdrawals and Failures for Graduates ............94

7. Summary of Number of Course Withdrawals and Failures for Persisters ..........108

8. Summary of Number of Course Withdrawals and Failures for Non-Persisters...113

9. Excerpts from the Individual Case Analysis of Participants in Three Groups ....115

10. Themes from the Cross Case Analysis 


\section{CHAPTER I}

\section{INTRODUCTION}

Postsecondary institutions such as community colleges place a great deal of emphasis on student retention. High levels of attrition may harm the interests of many constituents. For example, such interests include the long-term earning options of students, the economic vitality of communities needing skilled workers, and the institution’s curriculum development, faculty planning, mission, and political impact (Bragg, 2001). College administrators perceive student retention rates as indicators of academic quality and student success. In community colleges, this accountability measure is particularly disconcerting because the percentage of college students who leave within the first year is higher than from any other type of institution (McCabe, 2003). Furthermore, college students whose entry placement scores require them to enroll in remedial classes are most likely to have low persistence and graduation rates (Bers \& Smith, 1991; Burley, Butner, \& Cejda, 2001).

\section{Statement of the Problem}

This study explored the perceptions of underprepared college students who have participated in learning communities and who persisted to complete developmental classes and earn 30 college-level credit hours or graduate as compared to their peers who did not persist to complete their developmental classes and who have dropped out of college. The presence of over 3,600 public and private institutions may indicate the commitment to equal opportunity in the United States. Community colleges were founded with an open-door and equal-access mission (Bragg, 2001; Cohen \& Brawer, 
1982) where post-secondary educational opportunities are available to the disenfranchised and those who otherwise would not pursue additional education beyond the high school diploma. Moreover, community colleges offer programs for those who are underprepared (Brint \& Karabel, 1989). Nationally, approximately one-third of all students entering colleges or universities need remediation (Byrd \& McDonald, 2005); as many as $41 \%$ of all community college freshmen nationwide are enrolled in remedial (i.e., developmental or college preparatory) courses (Hoyt, 1999; McCabe, 2003). Differences between the underprepared college students and college-ready students include lower high school GPAs, lower ratings of confidence, and lower self predictions for completing their college education, which tend to perpetuate a cycle of minimal accomplishment and low self-esteem (Boylan, 1999; Boylan, Bonham, \& Bliss, 1994).

Nationally, $47 \%$ of students who require remediation graduate while only $24 \%$ of students who need three or more developmental courses complete their programs of study (Adelman, 1996). Attainment of pre-requisite knowledge and skills (failure to complete developmental classes) remains the stumbling block for student achievement but students who complete all developmental coursework achieve success rates similar to collegeready students (Boylan, 1999; Kraska, Nadelman, Manier, \& McCormick, 1990).

Compounding these challenges, the freshman year is already a critical time in the lives of students. During this period of change and adjustment, attrition is most likely to occur with approximately $40 \%$ of all students in a freshman class leaving before they complete their first year (Tinto, 1997). Students who are not connected to the campus community or who do not integrate their learning experiences across departmental lines 
and divisions are more likely to withdraw (Astin, 1996; Pascarella \& Terenzini, 1991; Tinto, 1997).

The national statistics were consistent with those for 2-year institutions in South Florida. For example, as reported in Achieving the Dream (2006), during the fall 2002 semester at the study community college, 3,629 students out of the 9,160 new incoming freshmen, required all developmental courses. Specifically, at the study site, 613 of 2,326 freshmen were underprepared in 2002. Of this number, approximately 5\% graduated; and less than $10 \%$ of those students who withdraw return within 4 years (Achieving the Dream, 2006).

Most research documented how college students who need developmental courses have high attrition and low completion rates, especially those with low socio-economic status, those from high schools that under-prepare their graduates for postsecondary education, and those who were first generation college students (Bers \& Smith, 1991; Boylan, 1999; Boylan, Bonham, \& Bliss, 1994; Burley, Butner, \& Cejda, 2001; McCabe, 2003; Roueche \& Roueche, 1999). Key factors to decrease attrition and increase retention included (a) structures that increase high levels of faculty-student interaction and integrate academic and social activities, (b) opportunities for involvement, (c) mentoring, (d) leadership experiences, (e) cultural and social support, and (f) use of campus resources and student services (Astin, 1996; Harvey-Smith, 2002; Roueche \& Roueche, 1999; Tinto, 1997).

Learning communities may provide key support to help retain students. Research on the impact of learning communities has focused primarily on college-ready students who participated in a learning community and their academic performance as compared 
to other college-ready students who had not participated and found that students in learning communities earn better grades and re-enroll in subsequent terms at higher rates than peers who take stand-alone courses (Tinto \& Goodsell, 1993; Tokuno, 1993; Zhao \& Kuh, 2004). Most studies in this genre were conducted at 4-year institutions or among certain naturally forming cohorts such as those enrolled in honors colleges or specific majors. For example, Tinto and Goodsell (1993) examined theme-based Freshmen Interest Groups (FIG) studies at the University of Washington. They found that participating students felt more connected to the campus and received higher grades than non-participants. In addition, 40\% of FIG participants graduated within 4 years as compared to $29 \%$ of non-participants. In another study, Zhao and Kuh (2004) analyzed 80,479 students from 4-year institutions in the United States $(N=365)$. They found that participation in a learning community is positively linked with engagement in active and collaborative learning, increased interaction with faculty members, and overall satisfaction with the college experience. At Bowling Green State University, Tokuno (1993) analyzed 10 learning communities and found that all programs were successful in promoting student retention, adequate grade point averages, and a substantial number of credit hours earned.

Still, a fundamental absence of understanding exists with respect to how learning communities might impact the retention to graduation rates of community college students who must enroll in multiple non-credit-generating classes (termed "underprepared students " in this study) to develop their English, reading and mathematics skills (termed "developmental or remedial courses" in this study). As of the time of the study, of the 284 institutions that registered their learning community 
programs with the National Learning Communities Directory (n.d.), 101 represented community colleges. Only 9 of these community colleges had implemented learning communities for underprepared students.

Previous studies of students at 4-year colleges and universities had relied on correlational studies, finding a positive relationship between learning communities and academic achievement and retention of students to graduation and, as noted in the section above, focused on studies of college-ready college students (e.g., Astin, 1996; Tinto, 1997). Some researchers studied the experiences of learning community college students (e.g., Singleton, Garvey, \& Phillips, 1998; Tinto, 1997). In studying Seattle Central Community College’s Coordinated Studies program, Tinto (1997) found that students in this metropolitan urban college reported a greater sense of community with faculty and peers and a greater appreciation of diversity because they had developed relationships with peers different from themselves. In another study, freshmen who participated in the College of the Holy Cross's First Year Program, located in Worcester, Massachusetts, expressed positive satisfaction and had more favorable experiences (Singleton et al., 1998). While the literature to date addressed many of the factors related to persistence of community college students, no studies were found that explain success and analyze the impact of learning communities on persistence and achievement of underprepared, ethnically diverse college students from the perspectives of those students.

\section{Purpose of the Study}

Because the ideals of learning communities are consistent with the values of community colleges within a democratic society (Harvey-Smith, 2002), studying the perceptions of underprepared ethnically diverse community college students who have 
participated in learning communities, may inform the field. If their experiences are better understood, perhaps more holistic initiatives can be implemented by community college administrators, faculty and staff to better support underprepared ethnically diverse community college students to achieve their success. The findings from this study may also offer important insights about the types and scope of institutional support that underprepared college students may require.

\section{Research Question}

The following question framed the study. How do underprepared community college students who participated in a learning community and completed their developmental classes, explain their experiences in having graduated (the graduates) or earned at least 30 credit-bearing college credits (the persisters) as compared to those who participated in a learning community, but have dropped out of college (the nonpersisters)?

\section{Theoretical Framework}

There were three major theoretical frameworks that guided this study: academic integration theory (Tinto, 1975); social involvement theory (Astin, 1985); and critical theory (Freire, 1970, 1992; Horkheimer, 1982; McClaren \& Hammer, 1989). The First Year Experience Learning Community implemented on the ABC Community College campus was created using the theoretical frameworks developed by Tinto (1975) and Astin (1985). However, Tinto (1975) and Astin (1985) did not address how the system functions for underprepared students. Thus, a third lens was necessary to explain why some students were successful in spite of a flawed educational system that did not 
prepare them for college. In this study, critical theory was used as the lens that framed the study of underprepared college students who participated in a learning community.

In the academic integration theory, Tinto (1975) asserted that students bring to college certain characteristics such as their ethnicity, level of family support, socioeconomic status, and secondary school achievement that influence their initial level of commitment to the institution, promote or inhibit persistence, and influence whether students eventually graduate. These initial pre-matriculation characteristics directly influence the degree to which students become integrated into the academic and social communities on the campus. The more students are integrated and feel themselves to be valued members of the campus, the more likely they are to persist (Tinto, 1975). Drawing on Dutch anthropologist Arnold Van Gennep’s (1960) study of the rites of passage that focused on a three-phase process of separation, transition, and incorporation as individuals move from youth to adulthood, Tinto (1975) argued that a student's academic and social integration at an institution are key contributors to whether he or she remains enrolled. Later, Tinto (1998) further argued that institutions should provide students with structured opportunities to form peer groups and to have interactions with faculty because the failure to establish academic integration may lead to feelings of isolation. A true balance must be achieved between individual student characteristics and attributes and the institution's expectations and culture (Harvey-Smith, 2002).

In contrast to the academic integration theory, Astin (1985) looked at persistence as a function of involvement rather than academic integration. Rather than change and assimilate to the institution's culture, college students maintain their individuality yet become socially engaged in programs and initiatives. In addition to participating in 
college activities, involvement can occur in the classroom, such as when working on class projects. Greater student involvement is associated with greater learning and personal development. Social involvement theory focuses less on the content of courses and more on what the students are actually doing as part of their assignments or class work. Astin (1996) found that frequent interaction with faculty was more strongly related to satisfaction than any other involvement.

In contrast to either academic integration or social involvement, critical theory asks how larger social systems might influence underprepared students’ experiences. Critical theorists such as Freire $(1970,1992)$ and Horkheimer (1982) reflected on ways in which race, class, and gender interact to influence an individual's experience. Freire (1970) proposed the concept of "liberatory intervention” (p. 7) where education results in an individual person's emancipation. This liberation is not only from previously held views of one's self. Liberation can also occur in the sense of becoming prepared to negotiate larger circles of influence, as when students learn new skills. This liberatory phenomenon or concept was an important aspect of the present study since the researcher hoped to uncover the perceptions of underprepared students regarding how the dominant academic culture may have treated them. Critical theorists have argued that the current educational system functions to reproduce class (e.g., Bourdieu, 1984). Many underprepared college students are first generation in college students with lower socioeconomic status, speak English as a second language, are women, and belong to racial or ethnic minorities. They may be blamed for being underprepared, and there has been little acknowledgment that perhaps the system had failed them. Students are expected to graduate with a high school diploma that signifies a mastery of basic English, reading, 
and mathematics skills. But once they enroll in the community college, they discover that they have been tracked into developmental courses, which they must complete with passing grades before being allowed to enroll in credit-bearing college classes. Because underprepared students do not elect the developmental coursework, it can be said that they are disenfranchised. Founded by German philosophers and social theorists in the Western European Marxist tradition known as the Frankfurt School, critical theory seeks "to liberate human beings from the circumstances that enslave them” (Horkheimer, 1982, p. 244). Critical theory offers an important perspective for understanding external influences such as power differentials and social justice issues within social and cultural contexts. Underprepared college students who enroll in developmental coursework may be in a new position to dispel the myths that surround their presumed deficits. Figure 1 summarizes the theoretical frameworks that guided the study of underprepared college students who participated in a learning community.
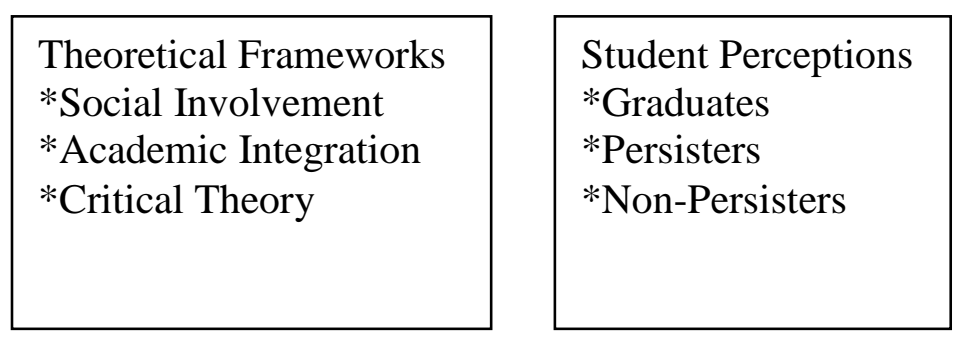

Outcomes
*Academic Achievement
of Underprepared
College Students

Figure 1. Theoretical frameworks that guided the perception interpretations of underprepared learning community college students concerning academic achievement. In the present study, through the process of recounting their experiences and explaining how they had overcome barriers and challenges they had faced in achieving their 
educational goals, they were able to add important insights into how the community college system functioned to support and/or to hinder them.

To summarize, the researcher applied a theoretical critical perspective to explore the perceptions of underprepared, ethnically diverse community college students who had completed the Freshmen Year Experience (FYE) Learning Community and their noncredit-generating developmental classes and their peers who had dropped out of college. The critical theory perspective was important with respect to underprepared college students, especially those who could be categorized as being on the oppressed end of the system that theories by Tinto and Astin did not address. Although theories by Tinto (1975) and Astin (1985) explained how the educational system functions for prepared students, they did not challenge how the system functions for underprepared students. The third theoretical lens was necessary to explain why some underprepared students were successful in spite of an educational experience that Tinto and Astin both agreed was far from perfect. For example, they acknowledged that adult students may not necessarily fit the schema outlined (Tierney, 1992). Theories by Tinto (1975) and Astin (1985) sought to explain why students attend and graduate from college. Their framework incorporates factors such as (a) parents or siblings who attended college, (b) yearly family income over $\$ 40,000$, (c) student race/ethnicity, (d) full time load, (e) academic and social engagement. However, these factors do not describe underprepared students. The theories by Tinto (1975) and Astin (1985) worked best to explain the experiences of prepared students from the White middle and upper class. In fact, Tinto has been challenged for not explaining the experiences of Native American and other minority students (Tierney, 1992). 


\section{Case Study Approach}

A case study research design was applied to gain an understanding of underprepared college students’ perspectives. Creswell (1998) stated that such a design is an exploration of a "bounded system" or a case (or multiple cases) over time through detailed, in-depth data collection involving multiple sources of information rich in context. The system is bounded by time and place so as to study the case - a program, an event, an activity or individuals. In this study, the case was comprised of underprepared community college students who had participated in a First Year Experience program. Participants in the study were encouraged to tell their stories in an effort to convey their lived experiences. The researcher then deconstructed and reconstructed their responses to make sense of their experiences within the larger context of the research study. In an attempt to identify experiences that have impacted their educational goals and achievement, in this study, the researcher engaged participants in an interview process where the participants described their lives as underprepared college students.

\section{Delimitations}

The study was delimited to a specific population of community college students. The participants of this study were students at one community college with a culturally diverse student body, located in an urban metropolitan area of the southeastern United States. Students' entry test scores required them to enroll in all three developmental courses (reading, English, and mathematics). Graduates completed their associate’s degree or successfully transferred to an upper division university. Persisters achieved passing grades and passed the statewide exit examination in all three developmental courses before enrolling in credit-bearing courses and earned at least 30 semester credit 
hours of college-level coursework. These students were in good standing at the college. Non-persisters had dropped out of college. Furthermore, each student had participated in the First Year Experience Learning Community.

The study was also delimited by the focus of the interviews. Topics explored with participants were confined to their experiences at one community college; thus overall generalization of study findings cannot be made to other populations.

Another delimitation was that the research focused on the students' perceptions of their experiences to the exclusion of administrative or policy factors. As an administrator within the community college system, the researcher was, of course, not unaware of the fact that the state provides incentives in the form of performance-based funding for students who complete their AA/AS/AAS or transfer to the upper division. However, findings concerning the lived experiences of underprepared college students have led to implications and/or recommendations for establishing different types of support to increase graduation and transfer rates.

\section{Definition of Terms}

At-risk. Students who had a higher-than-average probability of dropping out or failing schools were considered to be at-risk. Broad categories usually included innercity, low-income, underprepared students, those not fluent in English, and special-needs students with emotional or behavioral difficulties.

Cultural heritage. The legacy or tradition based on one's customary beliefs, social forms, and shared attitudes of a racial or ethnic group (Merriam-Webster's Collegiate Dictionary, 1993). Most of the study participants identified with their cultural background (e.g., Haitian, Jamaican) rather than race (e.g., Black). 
Developmental students. Also known as preparatory, compensatory, remedial or underprepared, developmental students were those who enrolled in college without the basic skills needed to complete college-level work (Higbee, Arendale, \& Lundell, 2005) and were required to take developmental courses in one or more subjects.

Ethnicity. Relating to large groups of people classified according to common racial, national, tribal, religious, linguistic, or cultural origin or background (MerriamWebster's Collegiate Dictionary, 1993). In this study, students whose parents emigrated from Latin America identified more with their ethnicity (i.e., Latino, Hispanic) than race (e.g., White).

First Year Experience (FYE). The First Year Experience (FYE) program was a learning community at ABC Community College. The FYE was designed to assist freshmen whose entry level test scores required remediation in three fundamental subjects (English, reading, and mathematics). Each year's cohort was limited to 25 fulltime students who together took a series of seven required classes over two semesters.

Graduates. For the purpose of this study, graduates were former First Year Experience Learning Community students who have graduated with their associate's degree or successfully transferred to the upper-division of a university.

Learning Communities. The term learning communities represents a variety of curricular models where faculty and administrators purposefully restructure the curriculum to link together courses or coursework during the same semester so that a group of students may experience greater coherence in what they were studying and may have increased intellectual interactions with faculty members and peers (Smith, 2001). Three general patterns or structural frameworks for learning communities exist. One 
pattern is unmodified courses where students are grouped based on shared academic interests or major and where they may enroll in an additional specialized course available only to learning community members (career exploration or orientation to college). A second pattern is linked or clustered classes where students co-register for two or more courses that are explicitly linked by content and include one or more integrated assignments. A third pattern is team-taught classes where students enroll in a program of study across disciplines that usually focuses on an integrative theme or question (Malnarich, 2005). While on some campuses, learning communities include a residential housing component, shared housing is not a part of the learning communities at $\mathrm{ABC}$ Community College.

Non-Persisters. For the purpose of this study, non-persisters were former First Year Experience Learning Community students who may or may have not completed their developmental courses and were no longer enrolled at ABC Community College.

Persisters. For the purposes of this study, persisters were students who successfully had completed their developmental courses and were enrolled in creditgenerating courses beyond 30 credit hours.

Preparatory. Although the term has a positive connotation in high school, preparatory may have a negative connotation at the college level. It is a label applied to students who need remediation in English, reading, and mathematics to prepare them to perform at the college level. Also called compensatory, developmental, remedial, or underprepared, preparatory programs or courses are designed to prepare students for college-level instruction. 
Race. A family, tribe, people, or nation unified by shared interests, habits or characteristics (Merriam-Webster's Collegiate Dictionary, 1993). Categories were obtained from institutional archived data.

Remedial/Remediation. Also known as developmental or preparatory, remedial courses or programs target both academic and noncognitive skills (attitudes, self-concept) and prepare students for college-level work (Higbee et al., 2005). Remediation as a term is no longer commonly used because of its negative connotation.

Student Success. In this study, student success has been defined as (a) maintaining a grade point average of 2.0 and (b) enrolling in credit-generating classes after earning 30 credit hours beyond developmental (non-credit generating) classes.

Summary

Acquiring a deeper understanding how underprepared community college students perceived their experiences in completing developmental coursework was the focus of this study. In the past 20 years, learning communities have appeared across a variety of postsecondary institutions. Most reviewed studies reporting the impact of learning communities indicated that this initiative strengthened student retention and academic achievement. There was a need for research that probed more deeply into the students' experiences, values and persistence, particularly for ethnically diverse students who were underprepared for college and had participated in a learning community during their freshman year.

In chapter 2, the researcher presents a critique of the literature relevant to this study. In chapter 3, the researcher details (a) the research design, (b) methods of data collection and analysis, (c) procedures to protect human subjects, and (d) methods to 
assure trustworthiness of the study. In chapter 4, the researcher describes the participants and their profiles. In chapter 5 , the researcher presents and describes the emergent themes. In chapter 6, the researcher (a) summarizes the study and interprets the findings, (b) provides recommendations for practitioners, and (c) suggests implications for practice as well as areas for future research. 


\section{CHAPTER II}

\section{LITERATURE REVIEW}

The following question frames the study. How do underprepared community college students who participated in a learning community and completed their developmental classes, explain their experiences in having graduated (the graduates) or earned at least 30 credit-bearing college credits (the persisters) as compared to those who participated in a learning community, but have dropped out of college (the nonpersisters)? The review of the literature is organized in four sections: (a) studies of learning communities, (b) factors associated with persistence, (c) theories of why community college students persisted, and (d) why critical theory is the selected lens within which to frame a study of underprepared community college students' persistence to complete their studies (i.e., the focus of the current study).

\section{Studies of Learning Communities}

In this section, studies of the impact of various learning communities are described and compared. The Wilson Web and Elton B. Stephens Company (EBSCO) databases were searched with the following keywords: learning community, retention of developmental students, coordinated studies, first year experience, freshmen cohort, persistence of community college students, developmental education pedagogy, and success of underprepared college students. All studies examining learning communities and published in peer reviewed journals are included in the literature review. The critique shows that some of these studies were more credible than others in terms of avoiding errors made by the researchers (Bogdan \& Biklen, 2003). 
Table 1 summarizes the studies of learning communities. Community college students who had participated in learning communities experienced higher academic achievement and lower attrition rates compared to students who did not participate (Singleton et al., 1998; Tinto 1997; Tokuno, 1993). Although many of the researchers examined outcomes such as grade point average, number of credits earned, timely progress toward their degree and graduation rates, other researchers focused on student attitudes and satisfaction. The studies are described and critiqued in chronological order so as to show the development of the knowledge base.

\section{Tinto and Goodsell (1993)}

Tinto and Goodsell (1993) examined Freshman Interest Groups (FIG) at the University of Washington in Seattle. In fall 1991, over 900 students, nearly one-quarter of the entering freshman class, were registered in 40 FIGs. The courses selected to make up a FIG were chosen to reflect a general theme of interest. Of the three courses taken by FIG students, two were large lecture courses ranging in size from 100-700 students. Once a week, students were grouped into quiz sections of 20-25 students led by a teaching assistant (TA). In quiz sections, the TA answered questions or provided an interpretation of the professors' lectures. The third course was a writing course in which students engaged in a peer review writing process where they wrote papers that linked the information and texts they were studying in the other two classes. In addition to courses, all FIGs included a weekly meeting for one hour with an undergraduate, upper class peer advisor. The researchers visited the campus for three one-week time periods, observing a total of 12 classrooms and interviewing 24 students. Findings indicated that students felt more connected by consistently seeing the same group of peers. In their interviews, some 
Table 1

Empirical Studies of Learning Communities Published in Peer-Reviewed Journals

Authors (Date) and Focus

Methods

Tinto and Goodsell (1993)

Freshmen Interest Group

University of Washington, Seattle

Observational and case study; three oneweek site visits, observations of 12 classrooms; interviews with 24 students.

Tokono (1993)

Freshman Interest Group University of Washington, Seattle

Tinto (1997)

Coordinated Studies Program Seattle Central Community College

Singleton, Garvey, and Phillips (1998)

First Year Program

College of the Holy Cross

Descriptive and causal-comparative study of 654 FIG participants and 3045 non-FIG participants; ANCOVA compared grade point averages.

Longitudinal multi-method causalcomparative and descriptive study; four CSP classes and 11 comparison classes were sampled; three 1-week site visits; two surveys administered in the fall quarter; 45 open-ended interviews with students and staff; 20 informal telephone interviews; and 36 formal student interviews averaging 40 minutes. During the following fall quarter, earned credits, GPAs, and fall-to-fall retention rates were compared.

Case study; measures included student evaluations and interviews; theme analysis

Descriptive and causal-comparative study using MANOVA to determine differences in pre- and post-scores on the Motivated Strategies for Learning Questionnaire.

Table 1 continues 
Table 1 (Continued)

Empirical Studies of Learning Communities Published in Peer-Reviewed Journals

Authors (Date) and Focus

Methods

Knight (2003)

10 separate learning communities ranging from 2 residential programs, 4 non-residential course-based programs and 4 special populations to include honors and minority students at Bowling Green State University

Brittenham et al. (2003)

Connections Program

Indiana University South Bend

Zhao \& Kuh (2004) National Survey of Student Engagement (NSSE) of freshmen and seniors from 365 4-year institutions

Raftery (2005)

Academic Improvement at Metropolitan Community College (AIM)
Descriptive and correlational study comparing the profiles of fall 1997 through fall 2001 freshmen (ages, gender, ethnicity, ACT composite scores, high school GPAs), outcomes (average retention rates, graduation rates, cumulative credit hours earned), BGSU New Student Transition Questionnaire, and NSSE for both learning community participants and nonparticipants.

Causal-comparative study comparing 40 students who participated in the Connections program and 42 freshmen in the control group; passing rates and student retention from fall to fall were examined as well as teacher observations to include social adjustment and class attendance.

Correlational study analyzing 80,479 freshmen and seniors; multivariate OLS regressions to determine relationship between learning community participation and student engagement.

Descriptive study comparing fall 1998 through fall 2004. Measures included average retention rates, graduation rates, cumulative credit hours, and GPAs for both AIM and non-AIM participants. 
students stated that had it not been for the FIG program, they would not have met anyone otherwise. Furthermore, students maintained they readily found others with whom to study. Tinto and Goodsell (1993) found that involvement in FIGs reduced the tendency to skip class. Peer pressure affected class attendance. Students valued the opinions of their peers rather than only respect the view of the professor. Although traditionally, postsecondary education can be highly individualistic, competitive and alienating, FIG seemed to support students by linking the academic and social aspects to create a more powerful learning experience. However, this study did not include the population of developmental students. The University of Washington has a selective admission policy and does not provide developmental courses for students who demonstrate a need for remediation. In addition, the researchers did not study internal and external influences that may affect student persistence and success.

Tokono (1993)

Tokono (1993) examined the same population as Tinto and Goodsell, but conducted a descriptive and casual-comparative study with respect to academic performance of the Freshman Interest Group (FIG) and non-participants at the University of Washington (UW). Using institutional data provided by the Office of Data Management at UW, 654 students enrolled in FIG were compared to freshmen who were not in the program $(n=3045)$. A freshman was defined as anyone who had less than 45 quarter hours completed. Tokono compared (a) grade point average using an analysis of covariance and (b) mean grades in specific courses using two-tailed $t$-tests with pooled variance estimates. He found that grade point averages were statistically significantly higher $\left(x^{2}\right.$ test showing $\left.p<0.01\right)$ for students in FIGs $(\mathrm{GPA}=3.04)$ as compared to non- 
participants (GPA = 2.88). Of the 27 courses studied (18 were excluded because of the grading system such as pass/fail, or limitations in enrollment such as honors), ten courses in which a $t$-test showed significant differences in mean grades. Of these, only FIG students in psychology showed a disadvantage. In the other nine courses, FIG students showed a higher mean grade, the average difference of 0.22 . In the longitudinal study, the differences in retention in the 1988 and 1990 cohorts was $8.4 \%$ and $6.9 \%$. These results indicate that more students who had participated in FIGs were retained compared to nonparticipants. Moreover, $40.3 \%$ of the FIG students had graduated in four years as compared to the UW average of 29\%. However, the University of Washington does not enroll underprepared students and does not offer developmental classes. All students in the study were enrolled in credit-bearing courses. Furthermore, the researchers did not extrapolate the impact of variables such as gender, race, ethnicity, and financial aid. Tinto (1997)

Tinto (1997) evaluated the impact of Seattle Central Community College’s Coordinated Studies Program (CSP) on students who participated in the CSP compared to those who did not. Using a longitudinal multi-method casual-comparative and descriptive research design, Tinto conducted observations of four CSP classes and 11 comparison classes via three 1-week site visits. He administered two surveys in the fall quarter and conducted open-ended interviews with 45 students and staff; 20 informal telephone interviews; and 36 formal student interviews averaging 40 minutes each. Measures of student engagement in and out of the classroom were derived from the Quality of Student Effort Scales (Pace, 1984), which assessed the quality of students’ effort, personal/interpersonal experiences, and college facilities. At Seattle Central, 121 CSP 
students co-enrolled in several cross-disciplinary courses organized in a unified theme and participated in cooperative learning activities as compared to 166 in the traditional curriculum track. CSP students reported a greater involvement in academic and social activities and a more positive view of the college. In addition, Tinto (1997) found that CSP students developed relationships with other students who were different from themselves, resulting in an appreciation for diversity. Their participation with peers in and out of classes helped to involve them more in the classroom and create a seamless interaction between academic and social activities (Tinto, 1997). The majority of CSP students reported a greater sense of community among peers and teachers and better grasp of the discipline. Although the researchers assumed that there were some students who tested into one developmental area (based on the number of community college students needing college preparatory coursework), they did not examine students who tested into all developmental courses.

Singleton et al. (1998)

In 1998, the College of the Holy Cross in Worcester, MA, clustered three general education classes from English, physics, sociology, psychology, philosophy, mathematics, and religious study with a 1-year seminar class around the general theme of “How Should We Live?” In the First Year Program (FYP), students read three books in common for all classes, participated in a variety of co-curricular events with faculty and fellow students, and lived with all other FYP students in the same residence hall. The researchers found FYP students were engaged, expressed positive satisfaction, had a favorable experience, behaved responsibly, and were more likely to assume campus leadership positions (Singleton et al., 1998). The feeling of community, generated by 
FYP, increased students' individual commitment to their education. Yet, the College of the Holy Cross, as a private, religiously affiliated institution, has a homogeneous student population. It is not representative of the diverse, at-risk student population enrolling in large, urban community colleges where entering students often bring a host of multiple developmental needs. Further, the residential component is not duplicable on most community college campuses.

Stefanou and Salisbury-Glennon (2002)

Stefanou and Salisbury-Glennon (2002) studied 172 Bucknell University firstsemester students who participated in a learning community during a six-week summer program that served as a bridge to the fall semester. Students completed the Motivated Strategies for Learning Questionnaire (MSLQ) as a pre- and post-test. The MSLQ (Pintrich, Smith, Garcia, \& McKeachie, 1991) is an 81-item Likert-type inventory measuring college students' motivational orientations and their use of different learning strategies. The MSLQ has 15 subscales representing six motivation dimensions: (a) intrinsic goal orientation (choice to engage in a task as a personal challenge or as curiosity), (b) extrinsic goal orientation (choice to engage in a task for competition or grades), (c) task value (relative value an individual places on engaging in a particular activity), (d) control of learning beliefs (student's perception of the locus of control for their learning behaviors and outcomes), (e) self-efficacy for learning and performing (student's expectation for success and ability to perform a certain task), and (f) test anxiety. Cronbach's alpha reliability coefficients for the MSLQ subscales ranged from .52 to .93 and there was evidence for predictive validity. 
A multivariate analysis of variance found that students' intrinsic and extrinsic motivation increased significantly and test anxiety decreased significantly as a result of participating in the program (Wilks' lambda $[75,895]=1.308, p=0.008$ ). Extrinsic motivation increased which seemed to indicate that students in the program valued the external judgments of their faculty and peers. The population for the study consisted of students who attended a private, expensive institution where the majority of the students come from higher socioeconomic families. None of these students were enrolled in remedial classes.

Knight (2003)

Knight (2003) reviewed ten learning communities ranging from residential types where students live together in a residence hall and learn through close interaction with each other and with faculty, to course-based programs that include a freshman seminar class, mentoring, and leadership development for specific student populations such as honors and minorities at Bowling Green State University. Descriptive profiles of fall 1997 through fall 2001 freshmen were examined that showed the demographic characteristics (age, gender, residency status, ACT composite score, high school grade point average) and outcomes (enrollment, cumulative grade point average, cumulative credit hours earned, and graduation rate) for both learning community participants and non-participants. Retention rates were higher for participants in most programs than for non-learning community participants. Multiple regression analyses were performed that included interaction between program participation and gender, race, and high school grade point averages. For example, women may particularly benefit from participation in the residential learning community, while minority students may be more likely to benefit 
from the learning community with a mentoring component, and students with higher high school grade point averages appear to be more likely to benefit from the honors learning community. To explore affective factors, two surveys were administered to include the BGSU New Student Transition Questionnaire (NSTQ) and the National Survey of Student Engagement (NSSE). Although the specific regression analysis results were not specified, they were reported as positive correlations at the $p<.05$ level of significance. For example, students who participated in a learning community showed significantly higher academic adjustment and university involvement. Students reported a stronger sense of belonging to a larger community with a sense of purpose. Knight (2003) noted that the retention rates were higher on average for learning community participants compared to non-participants; however, differences in participant characteristics such as gender and race were not analyzed. Two additional limitations of the study are (a) it was conducted at a 4-year institution with selective admissions procedures, and (b) it did not focus on underprepared students and the internal and external factors that influence their academic achievement.

Brittenham et al. (2003)

In the Brittenham et al. (2003) study, the outcomes for 40 students who participated in the Connections Program at the Indiana University South Bend (IUSB) were compared to those who did not participate. Students in the Connections program enrolled in open sessions which consisted of private and group study, teacher-student conferences, meetings with peer mentors and appointments with academic advisors and career counselors. Brittenham et al. (2003) found that $85 \%$ of students in the Connections program passed their developmental mathematics and writing classes as 
compared to $69 \%$ and $53 \%$ of participants who did not enroll in Connections. In addition, 74.4\% of the students in the Connections program returned the following fall semester as compared to $60.9 \%$ of all freshmen at the IUSB. Z- tests were conducted to examine where differences could be found between the pilot and control groups and the pilot and all groups, revealing a statistically significant difference between the pilot and control passing rates ( $p<.05$ and $p<.05$, respectively) and between the pilot and all groups passing rates $(p<.02$ and $p<.00006$, respectively) In addition, faculty reported that students in the Connections program showed less absenteeism, reported higher level of enthusiasm, and established informal working groups with peers that met on the weekends or other out-of-classroom times. Although these researchers examined students who needed remediation in more than one area, they did not indicate the ethnicity or other demographic characteristics of the participants.

Zhao and Kuh (2004)

Zhao and Kuh (2004) examined the relationships between participating in learning communities and student engagement in a range of activities of students from 4year institutions in the United States $(N=365)$. Like Knight (2003), they administered the National Survey of Student Engagement (NSSE) in spring 2002 to 80,479 freshmen and seniors. Of the freshmen, 29.6\% indicated they had participated in a learning community; $27.9 \%$ had not participated; and $42.5 \%$ were undecided. The NSSE specifically assessed student experiences in the following areas: (a) involvement in inclass and out-of-class activities; (b) amount of reading and writing; (c) participation in selected educational programs including study abroad, internships, and learning communities; (d) perceptions of the campus environment to include relationships with 
peers, faculty and administrators; and (e) student satisfaction with academic advising and their overall college experience. The researchers conducted a series of multivariate regressions (ordinary least squares) to determine relationships between learning community participation and student engagement.

Although the researchers did not interview the students personally or observe them in classes, the researchers conducted regression analyses showing that participation in a learning community is positively linked with (a) engagement in active and collaborative learning (standardized $r=.264, p<.001$ ), (b) increased interaction with faculty members (standardized $r=.299, p<.001$ ), and (c) overall satisfaction with their college experiences (standardized $r=.126, p<.001$ ). However, Zhao and Kuh (2004) studied students from 4-year institutions and included seniors. Although they examined such variables as gender, race/ethnicity, age, parent education, residential status, and fulltime/part-time enrollment, it is unknown whether any of the students were underprepared. Raftery (2005)

Raftery (2005) conducted a descriptive study of participation in a developmental learning community at Metropolitan Community College in eastern Nebraska. This study examined students who co-enrolled in a one quarter block of classes consisting of remedial reading, math, English, and personal development classes. Results showed that a) $10 \%$ more students in the Academic Improvement at Metropolitan (AIM) program successfully completed developmental English and reading, and b) a higher percentage of AIM students persisted for an average of five quarters with $74 \%$ retention after one academic year as compared to $65 \%$ retention rate for non-AIM developmental students. Although this was a longitudinal study, there were some limitations. First, the researcher 
did not conduct a statistical analysis to determine whether the results were significant perhaps because the sample size was not adequate. Second, assessment to determine student placement in developmental courses was optional which meant that not all students were required to enroll in remediation before taking credit-bearing courses. Therefore, the sample of developmental students is skewed towards representing a more highly-motivated student population which may have influenced the high retention rate for both AIM and non-AIM students. Third, as a campus, MCC does not represent an ethnically or linguistically diverse population. Finally, no information was collected about the students' perceptions and experiences.

Recent Dissertation Studies

Most of the studies found in peer-reviewed journals were dated. The most recent was published in 2005. In order to examine the most recent research concerning learning communities, to find emerging scholars in field and assist with methodology for this study, a search was conducted using ProQuest for recently completed dissertations in 2007 and 2008. Using the phrase "learning communities", 47 were found. Although the majority examined learning communities in $\mathrm{K}-12$, five investigated programs at postsecondary institutions. It was found that most studies no longer explored only the impact of learning communities on grade point averages, retention and graduation rates. Instead, researchers are studying student-faculty relationships, student attitudes about college, faculty professional developmental needs and fulfillment, and methods and practices used in planning learning communities.

Specifically, Wilmer (2008) at Old Dominion University examined the influence of social and academic interaction, demographic characteristics, social and academic 
adjustment, and learning communities on the satisfaction and achievement of developmental English community college students. Using the theories of Tinto, Astin, and Bean and the role of academic and social interaction on personal development, satisfaction, achievement and retention, nine purposefully developmental English classes at Virginia Western Community College were selected. One hundred and twenty students (50 were learning community participants and 70 were non-learning community particpants) completed a survey to measure institutional integration, classroom environment and student adaptation. The study concluded that learning community participants had higher perceived levels of interaction than non-learning community participants; demographic characteristics influenced individual's levels and types of interaction; academic achievement was influenced by satisfaction, with all other predictors having a weak relationship to achievement. The author further suggested that finding a strong relationship between any single influence and retention may be difficult due to the diverse individual characteristics and experiences learners bring to 2-year institutions.

Jacobson (2008) at University of the Pacific examined the methods and practices used in planning residential learning communities at University of Michigan, University of Missouri-Columbia and University of Oregon. The researcher interviewed the founders and initiators of the residential learning communities and examined archival documents. The researcher found four critical elements for initiating residential learning communities to include (a) the utilization of a representative planning committee; (b) shared values about faculty-faculty interaction; (c) campus champions with authority; and (d) expertise acknowledged by others and the willingness among the planning committee 
to adapt to changing circumstances. Furthermore, the initiators of residential learning communities were less influenced by formal institutional mission statements than by an immediate fiscal or student development concern.

Poindexter (2007) at the University of San Francisco explored how participation in a learning community impacted the attitudes of women from various ethnic backgrounds toward their academic experiences and the factors that encouraged them to remain in or drop out of college. In this qualitative, ethnographic study, the researcher interviewed 17 students and six community college faculty members, convened focus groups, and conducted classroom observations. The researcher found that (a) immediate family members’ support of their educational goals had more influence than ethnicity; (b) the collaborative environment of the learning community contributed to student academic success providing that the activities were related to the required tasks; (c) motivated and enthusiastic teachers who were interested in students' academic success helped them persist; (e) students rarely used college support services or participated in college activities.

Hodges (2008) at Michigan State University investigated the potential relationship between reasons for attending college and participation in a learning community. She used a mixed method approach which utilized both a survey and semistructured interviews to explore the 30 specific reasons students in the College of Natural Science attend college and their relationship to participation in MSU's residential learning community. Using chi-square test for independence, degree aspiration $\left(x^{2}=\right.$ 11.92, $\mathrm{df}=5, p=.04)$ and both mother's $\left(x^{2}=15.79, \mathrm{df}=9, p=.03\right)$ and father's $\left(x^{2}=\right.$ 14.94, $\mathrm{df}=9, p=.04$ ) educational attainment showed a significant difference between 
those who chose to participate in a learning community and those who did not. Further the researcher used the non-parametric Mann-Whitney U Test to find that students who were undecided about their degree aspirations $(p=.02)$ were more likely to participate in a learning community than students who planned to pursue a bachelors degree. Students who planned to pursue a medical degree $(p=.01)$ were more likely to participate than students who planned to pursue a bachelors degree. Also students who planned to attend medical school $(p=.01)$ were more likely to participate than students who planned to pursue a masters degree.

In analyzing the interviews, four themes were identified about the purpose of attending college: (a) preparing for life, (b) broadening horizons, (c) meeting new people, and (d) role modeling for others. Students' decisions to participate in a number of curricular, co-curricular, and extra-curricular activities were shaped not only by their reasons for attending college, but also by the perceptions they had about the value of the opportunities and preparing for medical and/or graduate school. Learning community participants indicated prestige and educational benefits while non-participants expressed concern about not experiencing diversity of thought and the extra courses that would be involved.

Strong (2008) at Michigan State University investigated the nature of and outcomes associated with out-of-class student-faculty interaction in a residential learning community. He interviewed 14 second-year undergraduates who were pursuing a B.S. in the sciences where 10 of the 14 students were members of the same residential learning community. His analysis found that students interacted with their faculty outside of class at two distinct levels (rudimentary and heightened) as interpreted through four primary 
variables: (a) frequency of interactions, (b) quality of interactions, (c) intensity of interactions, and (d) location of interactions. Students reported positive impacts on their academic, social, and personal development with the specific outcomes of increased student learning, motivation, self-worth, effort, and comfort level. The learning community was shown to have positive impacts on students in their academic, personal, and social development as well as their access to heightened-level interactions with faculty.

\section{Summary of Studies of Learning Communities}

In summary, the quantitative studies revealed the following factors: (a) students who participated in a learning community received better grades and had higher grade point averages than non-participants; (b) learning community students had higher persistence rates and made greater progress toward their degrees than non-learning community students; (c) learning community students had higher measures of intrinsic and extrinsic motivation and they valued the external judgments of their faculty and peers as compared to non-participants (Brittenham et al., 2003; Knight, 2003; Raftery, 2005; Stefanou \& Salisbury-Glennon, 2002; Tinto, 1997; Tokono, 1993). Three qualitative studies (Singleton et al., 1998; Tinto, 1997; Tinto \& Goodsell, 1993) revealed that learning community participation, hours studied per week, perceptions of their faculty, and involvement with other students are related to increased retention and persistence to completion of the community college program.

Specifically, however, no substantial quantitative or qualitative studies were found that focus on underprepared, ethnically diverse community college students who had persisted to complete their remedial classes and were enrolled in credit-generating 
classes. Considering the number of underprepared students who enter the community college (reported in chapter 1), there was a need for an exploratory qualitative study of the lived experiences of this population.

Factors Associated with Persistence of Community College Students

The majority of studies that identify factors associated with persistence (or factors associated with retention) were based on studies of students enrolled in 4-year colleges. Research that focused on the factors which affect 2-year students' persistence had produced mixed results. Bers and Smith (1991) surveyed 1,142 randomly selected students, from all those enrolled fall 1998 at a midsize suburban community college in the midwestern area of the United States. On the tenth day of that semester, students completed an annual self-administered questionnaire consisting of items about the student's objectives, future educational enrollment plans, and variety of demographic items. Embedded in the questionnaire was a 30-item scale developed by Pascarella and Terenzini (1980) to measure academic and social integration. The researchers found that academic and social integration of 2-year students in community college differed between persisters and non-persisters. Students' educational objectives, intent to reenroll, pre-college characteristics, and employment status may be more accurate predictors of persistence. They reasoned that the degree to which students might seek academic and social integration may be influenced by their objectives and initial level of commitment to the institution.

Amey and Long (1998) conducted a study of community college underprepared students to determine if selected input and environmental variables has an effect on the successful outcomes of degree-seeking students whose ASSET scores required placement 
in developmental English, reading, mathematics. For the purposes of this study, students who completed at least 24 credit hours or had earned a degree were considered successful; others were considered unsuccessful. A one-way multivariate analysis of variance (MANOVA) with a follow-up discriminate analysis was used.

High school grade point average appeared to make a significant contribution to the success of students as compared to unsuccessful students. As demonstrated in previous research (Astin, 1985; Pascarella \& Terenzini, 1991), this input variable was also highly correlated to the grade point averages of students in both developmental and non-developmental classes. Students in the successful group were more likely to enroll in their first developmental class during the first semester, whereas those in the unsuccessful group tended to wait until the second semester. Moreover, students in the successful group were more likely to enroll full-time (12 or more credit hours) during their first semester than were students in the unsuccessful group. The unique findings of this study underscore the importance of course sequencing and its relationship to the success of those students who took developmental courses prior to completing other courses compared to those who did not. The knowledge gained in developmental courses seemed to be fundamental to the successful completion of other college courses (Amey \& Long, 1998).

Student engagement was a factor related to retention and persistence as reported by researchers who have shown that frequency of social interaction is low among community college students (Maxwell, 2000; Roueche \& Roueche, 1999). Maxwell (2000) studied the frequency of peer relations and variation among students at a middleclass, suburban, ethnically-diverse community college in a large western city in the 
United States. Surveys were distributed in 19 courses including anatomy and physiology, biology, chemistry, English, health, math, philosophy, political science, psychology, and sociology at the beginning of the semester $(N=1,359)$ and mid-semester $(N=744)$. Using a 5-item Likert type scale ranging from almost never to two or more times per week, students rated their participation in study groups, student organizations, art, drama, or music activities, or informal interactions in the student center. Only $17 \%$ of students reported that they had shared in activities with other students at least once per week while $57 \%$ reported that they almost never interacted with other students and $78 \%$ indicated that they never participated in student clubs, organizations or student government, $80 \%$ almost never attended an artistic, dramatic, or musical activity on campus (Maxwell, 2000).

Interactions in the classroom and study groups seemed to provide the main point of contact for community college students. Collaborative learning pedagogy encouraged students to study together outside of class (Hagedorn, Maxwell, Rodriguez, Hocevar, \& Fillpot, 2000). This was an important consideration because the interpersonal environment of college students such as the frequency and nature of interactions with peers and faculty often had the greatest impact on attitudinal changes. An early study by Astin (1985) indicated interpersonal environments influence students' decisions such as the type of courses to take, how much to study, where to live, and how much to work. Pascarella et al. (1996) found that level of student engagement determined who studied the most and students who were most engaged with strong peer affiliations tended to have the highest levels of learning at the end of their first years in college. 
Student characteristics such as personality factors have been examined with respect to the success of underprepared learners (Ley \& Young, 1998; Smith \& Commander, 1997). Ley and Young (1998) interviewed 59 students (28 regular admission and 31 developmental) from an urban community college and rural residential university in the southeastern United States. Participants were asked what they would do with respect to 8 learning contexts. The researchers concluded that developmental and regular admission students differed in their self-regulating behavior; specifically, developmental students used fewer strategies and used them less consistently than their regular admission counterparts. Self-evaluation had the strongest relationship to selfregulation $\left[X^{2}(3, N=59)=14.2, p=.002\right]$.

College faculty and administrators place the responsibility for success on the student and self-regulating behaviors to indicate readiness for college. Smith and Commander (1997) observed a non-random sample of approximately 80 university students in two history classes, one paired with a learning strategies course for developmental students. They examined HIS113 - Introduction to American History for three weeks, noting student behaviors such as attending class, paying attention, being prepared, and using distributed learning materials. The researchers concluded that many students failed to exhibit day-to-day practical knowledge. They found that students lacked the tacit intelligence needed for success such as (a) attending class attendance, (b preparing for class, (c) using campus resources, and (d) collaborating with peers. In critiquing the observational study, the current researcher applied the criteria of resonance, that is, the results ring true with the researcher's own experience with underprepared 
community college students who do not appear to have the practical and tacit knowledge needed for success in college.

\section{Summary of Factors Associated with Persistence}

In summary, factors associated with the persistence of community college students included their educational objectives, such as degree attainment versus skill enhancement, and employment status (Bers \& Smith, 1991). Moreover, students who worked fewer hours continued their education unlike students who worked full-time. Students who enrolled in their developmental courses in their first semester significantly enhanced their chances for success (Amey \& Long, 1998). Student engagement was also important, but unlike their 4-year residential institution counterparts, the classroom served as the main point of contact for students (Maxwell, 2000). Interactions with peers and faculty were limited to academic activities. Finally, student behavior such as attending class, being prepared, and using distributing learning materials can impact retention (Smith \& Commander, 1997). For many underprepared students, these skills and familiarity with the academic culture were underutilized or unknown. Adjustment to College Life, Cultural Competence, and College Readiness

Another factor related to persistence and retention was that of adjustment to college life which required that students possess the skills and knowledge necessary to understand and navigate the culture. Bourdieu $(1977,1984)$ showed that students of higher socioeconomic standing have a type of cultural competence that helps them transition into postsecondary education (e.g., exposure to parents and relatives who have completed college or university studies). Campus culture can be traditional and represent accepted practices of teaching methods and assessment relevant to middle-class White 
students; yet these traditions may be unfamiliar and incongruent with minorities, immigrants, and working class students. Nontraditional students cannot call upon an accumulation of cultural capital to solve problems or make informed decisions (Lareau, 1987).

To study the cultural competence phenomenon, Valadez (1993) conducted a total of 47 in-depth interviews (12 with faculty, 7 with administrators, and 28 with students). They conducted observations of classroom interactions as well as formal and informal contacts between students and faculty at a small rural community college in a rural state where $68 \%$ of the population were classified as White, $31 \%$ were classified as AfricanAmerican and less than 1\% were classified as other racial/ethnic groups. The college enrolled 2500 students, 20\% of whom were African-American. The researcher interviewed non-traditional students, defined as minorities, immigrants, working class students, and students over age 25 . Students chosen for the study were enrolled in developmental courses in reading, English, and mathematics. During the interviews, faculty, students, and administrators were asked questions about their roles, the meaning of education in their lives, and their opinions of the academic achievement of minority students. Other questions focused on student expectations and goals and feelings about how the institution was providing the means for students to achieve their goals.

Valadez (1993) found that faculty attitudes were a dominant influence in shaping students’ perceptions about education. Students who reported positive educational experiences generally traced their success to the quality of their relationship with professors. Many students had not experienced much success in their K-12 environments, and the majority of the students had a history of low-paying jobs and unskilled 
employment. Improving their economic status was the primary motive for entering college. Many students needed an emotionally supportive environment to overcome feelings of inadequacy and bitterness. Valadez concluded that many developmental students did not seem to have the cultural capital to draw on previous positive experiences and did not seem to have family and friends for support.

Those professors who were group-oriented and used cooperative learning as part of their teaching methods seemed to engage students better than those professors who did not (Valadez, 1993). Although Valadez (1993) did not examine students in learning communities, the advantage of that study is that the interviewees were students who attended a community college where $20 \%$ of the students were African-American. Because smaller colleges may tend to generate skewed outcomes towards higher retention, it was important to study a larger urban college in a multicultural, multi-lingual setting and students who participated in a learning community.

Byrd and MacDonald (2005) conducted a qualitative analysis of students’ perspectives of college readiness through interviews of eight volunteers from a small urban university located in the Pacific Northwest who were juniors or seniors and had earned an Associate of Arts degree from a community college and were first-generationin-college. Ten themes emerged and were organized into three categories. Participants emphasized time management skills, goal-setting, and self-advocacy as essential for college readiness. Family factors often contributed to the participants' readiness for college. In addition, work experiences and career aspirations helped participants formulate a goal for college. Although this was a revealing phenomenological study of persisters, there are some limitations. For example, none of these students had 
participated in a learning community. Furthermore, all the interviewees were from the same program of study at the same small liberal arts college. Also, the researchers did not indicate what linguistic, ethnic, or racial diversity existed amongst the eight participants. Also, the researcher did not indicate whether these students placed into developmental courses before earning their AA degree.

\section{Studies of Pedagogy in Developmental Courses}

Three studies of pedagogy utilized by those who teach developmental courses were found: Thombs (1995), Kraemer (1997), and Lau (2003). Each is described below. In addition, each study is critiqued.

Many developmental programs narrowly focus on enhancing academic skills but ignore other affective issues such as motivation, long term goal setting, and self concept which may prevent a student from learning (Thombs, 1995). Thombs found that problem behaviors such as poor study habits were prevalent in all first semester freshmen and negatively impact college adjustment and academic achievement. In this study of 779 first semester college students from a public college in western New York, 57\% of the freshmen reported poor study habits and 54\% reported time management problems. These data reflect the need for strong support services, particularly at institutions where admissions standards are not highly selective.

Both the affective and cognitive realms were addressed by Kraemer (1997) who studied 217 students graduating from a private bilingual junior college in the Midwest. Students used a Likert-type rating scale (5-very often to 1-never) on 25 items that examine their affiliations with the academic environment and interactions with faculty and other students. Cumulative grade point averages were reported. The lack of academic 
integration (course relevancy, peer tutoring, study groups) and social integration (peer group interactions, involvement in organizations) were the most important predictors of student withdrawal.

Lau (2003) found cooperative learning pedagogy increased student retention, student satisfaction, and engaged participation. Lau (2003) suggested that the peer teaching or tutoring that often occurred during the cooperative learning experiences served to increase the student involvement in the learning process and enhanced the student understanding of the content of the course. Hagedorn et al. (2000) found that the cooperative learning model is favored among women and minorities who comprise a significant number of the community college student body especially in urban areas.

Grubb and Cox (2005) suggested that different instructors have different pedagogical approaches that may be inconsistent with the students' learning styles. In the conventional model, invisible disjunctions between students' and instructors' understandings became the students' responsibility. Educators were either entity theorists in which ability and intelligence were static and being good or not good at something was immutable and fixed, or incremental theorists in which intelligence and ability were changeable and contingent (Malnarich, 2005). As Smilkstein (2003) posited, learning was not about deficits, but was, instead, about potential. In a more collaborative model of teaching, part of the instructor's responsibility was to understand how students perceive the college, the curriculum, and learning outcomes. Practice and more practice over time was a key factor to moving from not knowing how to do something to becoming reasonably competent, and then to eventually achieving mastery. Learning was not held 
back until each step was mastered but was both developmental and reiterative (Malnarich, 2005).

In summary, important external variables for the persistence of underprepared college students included (a) social interaction with peers and faculty, (b) level of student engagement both in and outside the classroom, (c) students' self-regulating behaviors such as goal setting, note-taking, class attendance and preparation, and (d) the pedagogy used by the professors who teach developmental classes.

Theories to Explain Retention and Persistence of College Students Spady (1970) was one of the first theorists who attempted to explain dropout behavior. Harvey-Smith (2002) commented that Spady compared student attrition to Durkheim's (1961) work on cultural suicide and postulated that students would remain enrolled if they established comprehensive social systems. The interaction between the student and institution may encourage or discourage assimilation. The extent to which a student connects with the environment and establishes friends, determines social success. Academic success is characterized by good grades. When it is perceived that there are insufficient social or academic rewards, the student is likely to drop out (Harvey-Smith, 2002). Students may question why they should continue their schooling when they are confronted with limited achievement. Spady's work was considered groundbreaking and served as a foundation for subsequent retention studies.

\section{Theory of Integration}

Drawing on Dutch anthropologist Arnold Van Gennep’s 1960 study of the rites of passage which focused on a three-phase process of separation, transition, and incorporation as individuals move from youth to adulthood, Tinto (1975) created the 
integration model which asserted that students bring to college certain characteristics such as ethnicity, family support, socioeconomic status, and secondary school achievement that influenced the initial level of commitment to the institution and promote or hinder persistence and eventual graduation. These initial pre-matriculation traits directly impacted the degree to which students became integrated into the campus academic and social communities. The more students were integrated and felt valued as members of the campus, the more likely they were to persist. In a later study, Tinto (1998) suggested that institutions need to provide students with peer group and faculty interaction. Lack of integration can lead to incongruence and isolation. Tinto argued that a student's academic and social integration at an institution are key contributors whether he or she remains enrolled.

Bean (1980) developed a dropout prevention model which identified campus experiences and student beliefs that lead to their behavior. He compared college attrition to employee turnover in the workplace. He suggested that students leave school for the similar reasons that employees leave their jobs. Institutional factors such as creating routines, communication, commitment to goals, and institutional quality can impact or influence satisfaction levels and consequently influence student attrition rates, as organizational factors similarly affect employee turnover. In Bean’s theory, beliefs are affected by a student's experiences with overall campus quality, courses and friends. Such factors that affect student attitudes also affect student decisions during college and play an important role in a student's decision to drop out or persist. 
Theory of Involvement

Astin (1985) addressed persistence based on involvement rather than integration. Rather than change and assimilate to the institution's culture, involvement allowed a student to maintain his/her individuality, yet become engaged in programs and initiatives. In addition to participating in school activities, involvement can occur in the classroom, such as working on class projects. The greater the student was involved, the greater the learning and personal development. Students must invest effort and energy to bring about the desired outcome. Astin (1996) found that frequent interaction with faculty was more strongly related to satisfaction than any other involvement. Student involvement theory focused less on the course content material and more on what the students were actually doing.

Astin (1996) found that the three most effective forms of involvement included academic, faculty, and student peer group. The strongest single source of influence on cognitive and affective development was the student's peer group. Students who worked together on classroom material served as teachers to each other (Astin, 1984). The college classroom was the center of activity in higher education. Particularly for nonresidential institutions where students commute and balance family and work commitments, the classroom served as the conduit for academic and social involvement. The assessment of the applicability of these theories to students who were underprepared was much less developed than the research on traditionally admitted students. Theories by Tinto (1975) and Astin (1985) explained the experiences of White middle and upper class students; yet these students did not comprise the population of underprepared community college student. Critical theory was used to explain possible reasons students 
who have experienced limited academic success prior to enrollment, perform well after participating in a learning community.

\section{Critical Theory}

Why is it important to study retention of at-risk, under-prepared community college students within a critical theoretical framework? Critical theory provides an interpretive lens that is concerned with issues of power and justice (Lemeke, 1993;

McLaren \& Hammer, 1989). Critical theorists examine ways that race, class, gender, the economy, education, religion, and sexual orientation interact to construct a social system (McLaren \& Hammer, 1989). In their analysis, researchers who apply a critical theoretical perspective are interested in exposing power dynamics and oppression within the social and cultural experiences of the individual participants.

Lemeke (1993) argued that critical theory can help researchers understand marginalized individuals in a social context. In an attempt to develop a normative notion of "real democracy" (p. 247), Lemeke further argued that individuals could gain “conscious control” over social processes that affect them and their life chances. Critical inquiry is committed to social criticism and the empowerment of individuals and many critical theorists wished to ensure all voices are heard or at least effectively represented. Society should create conditions where all groups use their talents, express their feelings, and participate in experiences (Reid, 2004). Critical theorists advocate respect for group differences without oppression (Reid, 2004). Critical theorists envision social change as moving toward "a society that would develop individuality but shift the balance from individual rights towards the rights of the majority and the collective, and that would 
validate the pursuit of the common good rather than individual self interest” (Adamson, Briskin, \& McPhail, 1988, p. 101).

Critical theory may be particularly useful to community college professionals. Fundamental to its philosophy and commitment, community colleges were founded with the mission of an open door policy and equal access. The 2-year institution provides postsecondary educational opportunities to the disenfranchised and those who typically would have stopped with a high school diploma. Social justice is at the core of the 2-year college’s mission (Bragg, 2001). In fact, Bryant (2001) and Hilmer (1997) found that, regardless of family income level or academic ability or previous high school success, students could subsequently attend higher quality universities if they first attended a community college. Bryant (2001) found that over half of minority students and first generation in college students who enroll in postsecondary education, attend a community college. For many students, community colleges offer a good choice to begin their post-secondary studies. Thus, consistent with critical theory, community colleges may provide opportunities for the less fortunate.

Horkeimer (1982) argued that the ultimate goal of critical theory is to transform society into “a just, rational, humane, and reconciled civilization” (p. 244). This idea is echoed by Kincheloe and McLaren (2000) who promoted critical theory as a way to prepare individuals (a) to think critically about the forces that affect their daily lives, (b) to balance personal autonomy with societal solidarity, and (c) to counter discrimination due to factors such as gender, sexual orientation, race, and/or religious belief. McLaren and Hammer (1989) described how critical theorists appreciate individuals’ experiences, life histories and stories so as to emphasize unique contributions and perspectives. 
Slaughter (1989) believed that critical theorists are motivated by a desire for change in social institutions, structures and cultures. Many community college professionals may similarly view their roles as change agents, particularly in creating institutional support systems to help at-risk students achieve success.

However, there are also structures, systems, and individuals in the community colleges and state boards of education, which may have the effect of discouraging aspiring disenfranchised individuals (G. Musoba, personal communication, September 18, 2007). Critics of the functionalist view of the community college as an expression of democracy and access argue that 2-year institutions are reproducers of inequality and have a "cooling out" effect that serves to track students into vocational-technical programs (Clark, 1961). They have contended that community colleges represent a business dominated strategy to help manage the supply of labor. By cooling out the aspirations of community college students, the predominant working-class, minority, underprepared student populations are eventually tracked into low-wage positions in the economy (Anderson, Alfonso, \& Sun, 2006). Yet, some underprepared students successfully earn their associate degrees. It is important to learn more about the internal and external factors that influence their successes.

Freire (1970) provided a unique definition of student success. In Freire’s view, a critical pedagogy approach can result in an individual person's emancipation or liberation from possibly oppressive views of one’s self. Formerly disenfranchised individuals become empowered to negotiate larger circles of influence. Born in Recife, Brazil in 1921, Freire learned about poverty and oppression through the lives of the poor around whom he lived. Such experiences led to his vocation to work with and improve the lives 
of these marginalized people. His work with the Brazilian poor was viewed as subversive among the wealthy landowners and military. When the military overthrew the government in 1964, Freire was jailed for insurgent teaching. After serving a 70 day jail term, Freire was deported. He continued his work in Chile and later under the umbrella of the World Council of Churches (Kincheloe, 2008). In order to help students develop wider conceptual lenses to view their lives and social situation, Freire developed pictures and photographs depicting problems and contradictions in the world of his students. Freire asked his students to step back from these pictures and to think about what unseen forces are at work in these images shaping what is happening. In this context, his students were able to see their lives in a new way. They began to understand that the way things are presently was not the only option available. His students were motivated to gain literacy in order to take part in changing both their lives and society (Kincheloe, 2008). They knew they had to excel academically to overcome their oppressors. Understanding that schools can serve as impediments, Freire taught students to change inwardly. This liberation is a social dynamic that involves working with and engaging other people in a power-conscious process (Kincheloe, 2008). Freire (1992) wrote, "One of the tasks of the progressive educator is to unveil opportunities for hope, no matter what the obstacles may be” (p. 9).

This potentially liberatory effect was an important aspect of the current study. The researcher hoped to uncover underprepared community college students' perceptions regarding how the dominant academic culture had treated them. How were their perceptions similar to variables reported in the literature that are associated with lower completion rates or attrition of students who enroll in remedial college classes? What 
were the factors that helped them achieve success? In summary, critical theory offered an important perspective for understanding external influences such as power dynamics within the social and cultural contexts that exist in the community college. The critical theory lens was necessary in order to examine how the community college may function as both the oppressor and the liberator for underprepared students. Although Tinto's model and Astin's model were necessary because they are the most well accepted researchers in the literature related to college retention, neither Tinto nor Astin were sufficient to explain the experiences of underprepared college students. The theories of integration and involvement may have the effect of merely inserting underprepared students into a dominant cultural frame of reference that is transmitted within dominant cultural forms, leaving invisible cultural hierarchies intact (Tierney, 1992). A critical understanding of educational systems was thus an essential ingredient to the present study of the lived experiences of underprepared students.

\section{Summary}

This chapter provided a review and critique of the literature on (a) learning communities for community college students, (b) factors associated with persistence of community college students, (c) theories of persistence of community college students, and (d) critical theory as a framework for a study of the persistence of underprepared community college students. As stated previously, the quantitative studies in the literature revealed the following factors: (a) students who participated in a learning community received better grades and had higher grade point averages than non-participants; (b) learning community students had higher persistence rates and made greater progress toward their degrees than non-learning community students; (c) learning community 
students had higher measures of intrinsic and extrinsic motivation and they valued the external judgments of their faculty and peers as compared to non-participants (Brittenham et al., 2003; Knight, 2003; Raftery, 2005; Stefanou \& Salisbury-Glennon, 2002; Tinto, 1997; Tokono, 1993).

Some researchers had conducted qualitative studies of learning community college students (Singleton et al., 1998; Tinto, 1997; Tinto \& Goodsell, 1993). Three qualitative studies (Singleton et al., 1998; Tinto, 1997; Tinto \& Goodsell, 1993) revealed that learning community participation, more hours studied per week, positive perceptions of their faculty, and involvement with other students were related to increased retention and persistence to completion of the community college program. These studies did not include underprepared students who must enroll in three developmental courses.

However, there was no substantial literature that focused on underprepared, ethnically diverse community college students who had persisted to complete their remedial classes and were now enrolled in credit-generating classes. The scope of the problem with respect to the number of underprepared students who enter community college is as large as approximately $41 \%$ of all incoming freshmen (Hoyt, 1999; McCabe, 2003). The scope is reflected at the study institution where 3,629 out of 9,160 freshmen needed all three developmental areas. This study was undertaken to explore the lived experiences of underprepared college students. The researcher applied a theoretical critical perspective to explore the perceptions of underprepared, ethnically diverse community college students who successfully had completed the Freshmen Year Experience and their non-credit-generating developmental classes and had earned 30 credit hours, and the perceptions of their peers who had joined the FYE program but did 
not complete the non-credit-generating developmental classes and who dropped out of college. In the next chapter, the research design, methods of data collection and analysis, procedures to protect human subjects, and methods to assure trustworthiness are presented. 


\section{CHAPTER III}

\section{METHODS}

The following question frames the study. How do underprepared community college students who participated in a learning community and completed their developmental classes, explain their experiences in having graduated (the graduates) or earned at least 30 credit-bearing college credits (the persisters) as compared to those who participated in a learning community, but have dropped out of college (the nonpersisters)? College students who are required to enroll in remedial classes and who persist have been infrequently studied by researchers.

\section{Research Design}

The research design relied on a case study approach to understand the experiences of underprepared community college students. According to Bogdan and Biklen (2003), qualitative methods such as a case study approach can serve as the primary means of “giving voice” to the human experience (p. 201). Whether at the subconscious or conscious level, each individual interprets and analyzes experiences from within his or her boundaries and blinders. Hallmarks of qualitative research methods include the ability to study real-world situations as they unfold, the lack of predetermined constraints on outcomes, immersion in detail and data to discover interrelationships, exploring experiences through open-ended interview questions posed to participants (Patton, 2002). The researcher believed that the case study design was suited to the nature of the research question which sought to have underprepared college students share their experiences of 
attending college so as to gain a detailed view of their perceptions concerning influences on their educational achievement.

Within a case study design, the researcher explored how participants describe their lived experiences. In this design, the researcher focused on particular details of the participants' experiences of attending college, moving next to generalizations, which are clusters of meaning, while describing the context of the study and continually revising questions as meanings of the experience emerge (Creswell, 2001). The researcher focused on specific instances, or individual cases, deriving an in-depth study of each case, the study of the phenomenon of attending college as an underprepared student in its natural context, resulting in an understanding of the emic perspective of case study participants (Gall, Gall, \& Borg, 2003).

One purpose of case studies is to develop an understanding of a complex phenomenon as experienced by its participants. The intent reflects an interpretative stance. Case studies not only produce detailed descriptions of a phenomenon, but may also develop possible explanations of it (Gall et al., 2003). These explanations can be identified as patterns, meaning that one type of variation observed in a case study is systematically related to another observed variation. Cases can be chosen and studied because they may be instrumentally useful in understanding a particular problem or issue (Schwandt, 2007).

At the very heart of what it means to be human is the ability of people to symbolize their experience through language (Seidman, 2006). The use of language contains within it the paradigm of cooperative inquiry. Interviewing is a basic mode of inquiry (Seidman, 2006). The purpose of in-depth interviewing was not to get answers to 
questions, nor to test hypotheses. The goal was to understand how the underprepared student negotiated and made sense of the postsecondary educational experiences provided (Marshall \& Rossman, 2006). Using open-ended questions, participants were engaged to reconstruct and describe the phenomenon in an effort to convey their lived experiences. In addition to individual interviews, the group interview was structured to foster dialogue among the participants about their academic success. The purpose of both the individual and group interviews was to stimulate talk from multiple perspectives from participants (Bogdan \& Biklen, 2003).

\section{Setting}

The study community college was a large, urban 2-year institution in the southeastern United States that offered technical certificates and associate degrees. Recently, the state board of education authorized the college to offer baccalaureate degrees in certain majors. There were three campuses and four centers located throughout the county with approximately 65,000 credit and non-credit enrolled students. ABC was one of the largest community colleges in the country and served a diverse student population, particularly at the study site. Thirty-six percent of the students were Black, 39\% White, 22\% Hispanic, and 3\% Asian. Approximately one-third of all freshmen enrolled in all three developmental courses of reading, English, and mathematics. First Year Experience Learning Community

At the study site, a First Year Experience (FYE) Learning Community had been established based on current retention models (Astin, 1985; Tinto, 1997). As part of the Southern Association of Colleges and Schools reaccreditation self-study, ABC Community College created a cohort model for underprepared students whose scores on 
standardized tests require them to enroll into all three remedial courses (English, reading, and mathematics) to take their developmental classes in sequence to increase the number of completers. In addition to their classes in reading, English, and mathematics, students could earn 13 credits of college level courses toward their general education requirements. As part of the program, students declare a major by the end of the first semester; clarify personal values and attitudes; learn about and subsequently use campus programs and resources; and develop a connected and engaged community which provides support in their first and subsequent terms. In addition, the FYE program has helped (a) to increase the passing rates of traditional gate-keeper courses such as freshman composition and intermediate algebra; (b) to condense the number of terms needed to complete their developmental coursework; (c) to increase semester to semester retention rates; and (d) to improve graduation rates for this underprepared student population. The First Year Experience (FYE) Learning Community has been recognized as an innovative program for underprepared students.

Learning And Study Strategies Inventory (LASSI)

To ensure that there were no differences in attitudes and values among underprepared students, the Learning And Study Strategies Inventory (LASSI) was administered to all students. The LASSI is used to measure students' study skills and learning strategies, yield diagnostic information about students' self-perceptions of their study skills, and predict academic achievement and success (Flowers, 2003). The goal of the LASSI is to provide useful information regarding current study habits and learning strategies. Currently over 1700 colleges and universities have used the LASSI to assess students' study skills (Flowers, 2003). 
As described by Flowers (2003), the LASSI is comprised of 77 items with a response set of 5-likert type scale choices: "very typical of me," "fairly typical of me,” “somewhat typical of me," "not very typical of me," and "not at all typical of me," the LASSI is comprised of 10 scales, each yielding a separate scale score. Five scales measure emotional or affective traits (Attitude, Motivation, Time Management, Anxiety, and Concentration). Five other scales assess specific activities in which students engage while studying (Information Processing, Selecting Main Ideas, Study Aids, Self Testing, and Test Strategies). The Attitude scale assesses students' aspirations and rationales for attending college. The Motivation scale measures students' perceptions of their abilities to complete all coursework/assignments. The Time Management scale addresses students' knowledge and use of time management concepts. The Anxiety scale assesses students' feelings regarding their ability to succeed in college. The Concentration scale measures students' capacity to focus on studying. The Selecting Main Ideas scale measures students' ability to identify important ideas while reading or listening in class. The Study Aids scale assesses students' use of specific study strategies to help retain information. The Self Testing scale examines students' use of self-quizzing techniques to ensure information is learned. The Test Strategies scale measures students' perceptions of tests and quizzes (Flowers, 2003).

All students who met the requirements of the program were administered the LASSI at the beginning of new student orientation before information of the FYE program was shared. A statistical analysis of the LASSI scales between FYE and NonFYE participants and between FYE persisters and FYE non-persisters was conducted and is reported in chapter 4. The purpose was to show that FYE students (both persisters and 
non-persisters) and non-FYE students did not represent a design error of self-selection or other forms of conscious or unconscious bias in the selection process.

\section{Participant Recruitment and Selection}

Since inception of FYE in 2003, approximately 25 students per year volunteer to participate in the FYE program for a cumulative total $N=98$ (as of 2007). Of these, approximately 68\% persisted to complete remedial classes and enrolled in credit-bearing classes; less than $20 \%$ persisted to earn 30 or more credit hours. Seven students (7\%) graduated with an associate degree or transferred to a university. At the time of the study, 13 students were enrolled who had earned 30 or more credit hours; 27 students were enrolled who had earned 29 credit hours or less; and 51 students had withdrawn from the college. To compare the academic experiences of FYE students who had completed developmental classes and had earned 30 credit hours and were enrolled in credit-bearing courses towards their programs of study for the associate degree (persisters) and former FYE students who had dropped out and were no longer enrolled (non-persisters), all 13 currently enrolled students and 51 students who had dropped out of ABC Community College were invited to participate in the research study.

As Denzin and Lincoln (1998) stated, “All sampling activities were theoretically informed” (p.79). Although few developmental students persist to their sophomore year (perhaps being categorized as extreme or deviant cases), both the persisters and the nonpersisters were a homogeneous group of students who attended ABC Community College, participated in the First Year Experience, were day, full-time students, and, with the exception of one student, had recently graduated from high school. The non-persisters were former First Year Experience Learning Community students who may or may not 
have completed their developmental courses and were no longer enrolled at $\mathrm{ABC}$ Community College. The researcher selected similar cases in order to describe this subgroup of underprepared students in depth (Glesne, 1999). In this purposeful sampling, the participants were chosen so that the study sample represented gender and race demographics of the larger underprepared community college student body that were required to take developmental courses (Bogdan \& Biklen, 2003). Moreover, this type of sampling procedure was intended to identify information-rich cases for in-depth study of students who traditionally do not succeed. In other words, the FYE students formed the subject pool for this study.

The researcher had directory information on all FYE students that included each individual's address, phone number and email address. Initially, participants were mailed a letter detailing the study and subsequently were contacted by telephone to set up mutually convenient interview locations and appointments. For students whose phone numbers had been disconnected, the researcher used a snowballing sampling technique (Bogdan \& Biklen, 2003) where he asked interviewed students for contact information of an FYE peer who could not otherwise be contacted. Also, the researcher found other students on Facebook.com and emailed them.

Interviews were conducted face-to-face. Each participant signed two copies of an informed consent release form approved by the FIU Institutional Review Board (see Appendix B) in order for participants to keep one for their records. Each interview lasted approximately 1 to $1 \frac{1}{2}$ hours and was recorded with a digital voice-recorder. All interviews were transcribed by the researcher. To verify common themes, students also 
participated in a group interview. Students signed a promise of confidentiality regarding the focus group to encourage open discussion. The group interview lasted 2 hours.

\section{Data Sources}

Multiple sources of data were obtained. Each source is described in the following sections: individual and group interviews, archived data, and documents such as the researcher's log.

Individual and Group Interviews

An interview protocol derived from the literature review was developed to capture and explore individual differences among participants' experiences (including academic and social outcomes) so as to understand the meaning of their lived experiences (see Appendix D). Questions were phrased in an open-ended way to help participants tell the story of their experience. To understand the participants' subjective experiences, the researcher asked what something was like giving the students a chance to reconstruct their experiences according to their own sense of what was important (Seidman, 2006). When possible, students were asked to reconstruct rather than remember an experience. Reconstruction is based partially on memory and partially on what the participant now senses is important about the past event.

The group interview was held after the individual interviews had been conducted so as to provide the participants with an opportunity to review core categories and themes derived from the individual interviews. Because these themes emerged from the individual interview data, a detailed group interview protocol was established to substantiate the interview findings in terms of the interviewees' perspectives and to provide another source of data. 


\section{Archived Data}

Archived data were available on retention, grade point average, age, ethnicity, gender, first-generation-in-college status, financial aid award, and learning community participation of all full-time, day students who attended the study community college whose scores on standardized tests required them to enroll into all three remedial areas (English, reading, and mathematics). This information was used to provide background and demographic information about the participants and look for withdrawal rates and trends among disciplines.

\section{Researcher's Log}

During all aspects of the study, especially during the data collection and analysis phases, the researcher maintained a written journal. Notations in the journal included time and place. The researcher's log included reflective memos, thoughts and insights. Descriptions of participants, objects, places, activities, and conversations were noted. Confessions of mistakes, inadequacies, and prejudices were included. The researcher included speculations about what he was learning and what he planned to do next, thus showing how data collection and analysis were concurrent processes. The researcher's log also served as an audit trail to verify the rigor of fieldwork and confirm data collected (Glesne, 1999).

\section{Data Collection Procedures}

In this section, the procedures for the pilot study are described. In addition, the procedures for the full study are explained and the procedures undertaken for protecting the anonymity of the participants. 


\section{Pilot Study}

A pilot test of the interview protocol was conducted by inviting all seven First Year Experience Learning Community students who had graduated from the college with their associate degree or transferred to a university. Of the original seven graduates, the researcher was able to interview six former students. Only one student, who had transferred to a private, local university, chose not to be interviewed. The pilot study was conducted to serve three purposes: (a) to field test the interview protocol (b) to begin to identify themes that captured the experiences of underprepared college students who persisted to graduation from ABC Community College and (c) to serve as a comparison group to persisters and non-persisters in the full study. Subsequent to the analysis of the pilot study results, the interview protocols were changed slightly to include broader prompts so as to elicit free association from the participants. For example, the original question about peer support asked participants to name their five closest friends. Interviewees seemed to have difficulty finding "five" closest friends. The question was thus rephrased to ask participants to name their closest friends without placing a numeric value. An analysis of the pilot study interviews indicated that codes could be assigned and themes could emerge. The revised interview protocol was used in the subsequent interviews.

Full Study

In the full study, the goal was to interview students in order to obtain saturation. All possible attempts were made to contact and interview both persisters (who were currently enrolled) and non-persisters (students who had withdrawn). The researcher 
interviewed four non-persisters and 12 persisters. In addition, the graduates' interviews were included in the study.

According to research by Guest, Bunce, and Johnson (2006), saturation of themes can occur with fewer than six participants when the participants in the study share similar characteristics and experiences. Their research also indicated, although basic elements for meta-themes might be identified as early as six interviews, saturation in their study occurred within the first 12 interviews (Guest et al., 2006).

The group interview comprised the second phase of the full study. All interviewed students were invited to participate. Out of the 22 students who participated in the individual interviews, 6 persisters and 1 non-persister attended the group interview. The purpose of the group interview was to discuss the researcher's interpretation of the analysis of individual interviews and the identification of overall themes. Before the group interview, all participants received a copy of their verbatim transcript and a copy of the emerging models for persisters and non-persisters. The focus group promoted dialogue regarding aspects that the researcher needed to clarify from the results of the individual interviews. For example, one student suggested that the word "determination" be paired with the theme "persistence."

\section{Protection of Human Subjects}

Application for permission to conduct the study was made to Florida International University's Institutional Review Board (IRB). Upon approval from the IRB (as well as approval from Dissertation Committee, the College of Education Office of Research and Graduate Studies, the University Graduate College, and the study community college), in January 2008, the researcher began the recruitment procedures, conducted the pilot study 
to validate the protocol and then implemented the full study. Basic steps to protect anonymity and confidentiality were taken as per protocols required by the human subjects review boards at the respective institutions (see Appendix B).

Researcher’s Role, Autobiography, Assumptions, and Subjectivities

In this section, the researcher's role as participant observer is described. In addition, a brief autobiography and assumptions are included. Finally, the researcher’s subjectivities are revealed.

Researcher's Role as Participant Observer

As the main research instrument, the researcher asked questions, interacted with the study participants, and interpreted the results. Before conducting this study, the researcher had identified his assumptions, perspectives, and potential sources of subjectivity, a process that Peshkin (1988) suggested can lessen the impact of researcher bias. In addition, an external audit trail was applied to the researcher's log, verbatim transcripts of the individual and group interviews, the coding procedures, the identification of themes, and the text of the findings to ensure that the participants' experiences were accurately represented (Creswell, 1998).

Subjectivity can affect the results of interviews and research. Qualitative researchers point out that although subjectivity is consistently present, it is possible that one may not be necessarily aware of it (Bogdan \& Biklen, 2003). In the researcher’s personal quest to become a qualitative researcher, it was important for him to acknowledge personal biases and potential prejudices. As the researcher began this study, he needed to disclose those beliefs or assumptions which may have filtered, skewed, shaped, blocked, and potentially led to inadvertent misinterpretation of the results. Hence, 
via a self-reflection process similar to that suggested by Peshkin (1988), the researcher continuously confronted his opinions and articulated his assumptions as he engaged in the study.

Peshkin (1988) described the importance of recognizing one’s subjectivity, arguing that researchers should systematically seek out their subjectivity (potential sources of bias), before and while the study is in progress rather than retrospectively after the data have been collected and analysis is complete. Peshkin (1988) discussed his own subjective "I's" (identities) that were uncovered and monitored while conducting a field study. In the following section, the researcher describes his subjective "I’s" (identities). Autobiography

The researcher is an Hispanic, Greek-American. He is trilingual (English, Spanish, and Greek), 40-something year old man who is divorced and the father of a 20 year old daughter. Born in New York City, he is the only child of a Cuban mother and a Greek father. His family background, upbringing, and life events have certainly influenced his belief system and identity. His parents, both immigrants, chose to move to the United States to find better opportunities. Most likely, his maternal grandparents’ divorce, subsequent poverty and the effects of World War II compounded with Greece’s instability led to his parents’ desire and need for change. Both were risk-takers, highly independent, and resourceful. His parents were not afraid of working multiple jobs nor were they shirkers of responsibility particularly of family and those for whom they cared; his parents placed the needs of others before their own. Despite their limited formal schooling, they highly valued education. In the new country, his parents found employment, learned to drive, purchased a house and cars during a time and in a place 
when and where only English was spoken. They never sought welfare or assistance. They taught the researcher to have a strong Protestant work ethic and high expectations of self and others. Faith was also important. As Evangelical Christians, his parents, particularly his mother, made sure that religion and church service were vital parts of their lives. In their view, all obstacles could be overcome via the help of God.

These values permeate his life as a dean of student affairs at a community college where students from diverse ethnic and linguistic backgrounds have a chance to gain a college education. The choice to work in community college settings was influenced by his professors in his masters program at the University of Florida where the mission and philosophy of the community college were introduced. His current position as dean of students has enabled him to establish the First Year Experience program that has resulted in reducing student attrition and increasing the completion rate of developmental classes. These ideals resonate with his own experiences as a first generation college student. As an example, the following narrative written by a freshman who had attended the new student orientation illustrates the concerns about retention. He wrote:

As the first student in my family to go to college, I was nervous. In high school, I had heard about how mean professors were and how they wanted to see students fail. When I arrived to the new student orientation program, there were over 100 people in the auditorium. I sat in the back row and was terrified. There were only 126 students in my high school graduating class. The dean of the college welcomed us and spoke a little about the academic reputation of the school. He explained that the Community College is the eighth largest in the country. Can this school really be this big? He then talked about graduation and said $40 \%$ of us will not be back next semester. I was told I have to take something called "prep" classes to prepare me for college. I thought that's what high school was supposed to do. I'm beginning to wonder about my decision. What am I doing here? Will I be here next year?

(New student, Orientation Feedback, Fall 2006) 
Similar to this freshmen student, the researcher remembers attending his own new student orientation, feeling isolated and unsure whether he was ready to attend a large university. Assumptions

The researcher has several tenets by which he lives. Most have developed over years of watching his parents, church teachings, interactions with peers/friends, and personal knowledge. The best instruction came from the result of individual experience.

No one person is superior to another. All should identify with a part of society and belong. All individuals are created equally with the same potential for happiness and our personal definition for success. Although the metaphor may be a cliché, he believes that all are a part of a puzzle, balancing each other's strengths and deficiencies (or disinterests). As an undergraduate, he was a member of a fraternity. During those years, he developed strong friendships and social bonds which kept him motivated and in school.

It is important to appreciate diversity and respect others. His parents spoke limited English and many assumed, because of their language skills, they were unintelligent. This was far from the truth. Both were wise and caring. In his opinion, they accomplished more than most, emigrating from their native countries, learning a new language, and contributing to the community as engaged citizens.

Everyone deserves a chance. The researcher is a strong champion of the underdog and wished to see them succeed. In a previous career, he taught remedial mathematics. Realizing that this is often times the least popular discipline, he would always start the first day of class informing each student he/she had an "A.” He continued his remarks ensuring them he would do his part such as arrive on time and prepare for class, but they 
had to do their part by attending class, completing their homework, and asking questions to keep their grade.

Life should be fair and consistent. Discrimination and favoritism are unacceptable. As he ages, he realizes that "life is not always fair." Politics play a role in almost all relationships and settings. Still, where he has control, he wants to be fair. As the dean of students, when rendering a decision, he attempts to look at both sides of an issue, understanding that the truth is usually in the middle.

He strongly believes in an internal locus of control and responsibility. This psychological construct means that, for the majority of circumstances, human beings can influence change. He exercised this locus of control when he chose to work in the community college setting. He wants to assist young men and women exercise their locus of control by taking advantage of the opportunity to go to college. For the researcher, if it had not been for college, it is highly likely he would be working a minimum wage job, similar to many of his parents' friends' children. For these reasons, the community college exemplifies what the United States represented to many immigrants: a chance for a better life and future. This is what he does each day - he helps others to realize dreams and cultivate potential.

\section{Subjective Identities}

As a result of this reflective process, the researcher had identified four subjective identities or "eyes" with which he views the world: a family-social inclusiveness I, an ethnic-identity I, a justice-seeking I, and a professional role-dean-counselor I. These are described next. 
Family - Social Inclusiveness I. No one should feel excluded. It is important that students bond and experience a sense of community.

Ethnic - Identity I. Because of the discrimination he has experienced with respect to lower expectations for minorities, particularly Hispanics and recent immigrants, he looks for opportunities to find minority students who do perform well. He desires to transform those who favor the majority population.

Justice - Seeking I. It is important for students to have access to an education. Underprepared college students have the same right to postsecondary education as any other group.

Professional Role - Dean - Counselor I. To be successful in his job and experience positive job satisfaction, he wants the developmental learning communities to positively influence the college careers of students at his campus. He realizes that favorable results in student grade point averages and retention will positively promote the campus and college and ultimately result in additional funding and personnel. Furthermore, as a counselor, he wants students to realize their potential and make appropriate decisions for them.

As shown in Figure 2, the researcher believes that many of his identities overlap. For example, his Ethnic-Identity I, Justice-Seeking I, and Family-Social Inclusiveness I combine to form a commitment to bar discrimination and to advocate for all students within his Professional Role/Dean/Counselor Identity. During this reflective process, he was surprised to uncover his less humanistic, more selfish Professional Role/Dean/ Counselor Identity. This identity had a strong investment in wanting to see his college's program succeed and earn positive accolades on behalf of minority students. 


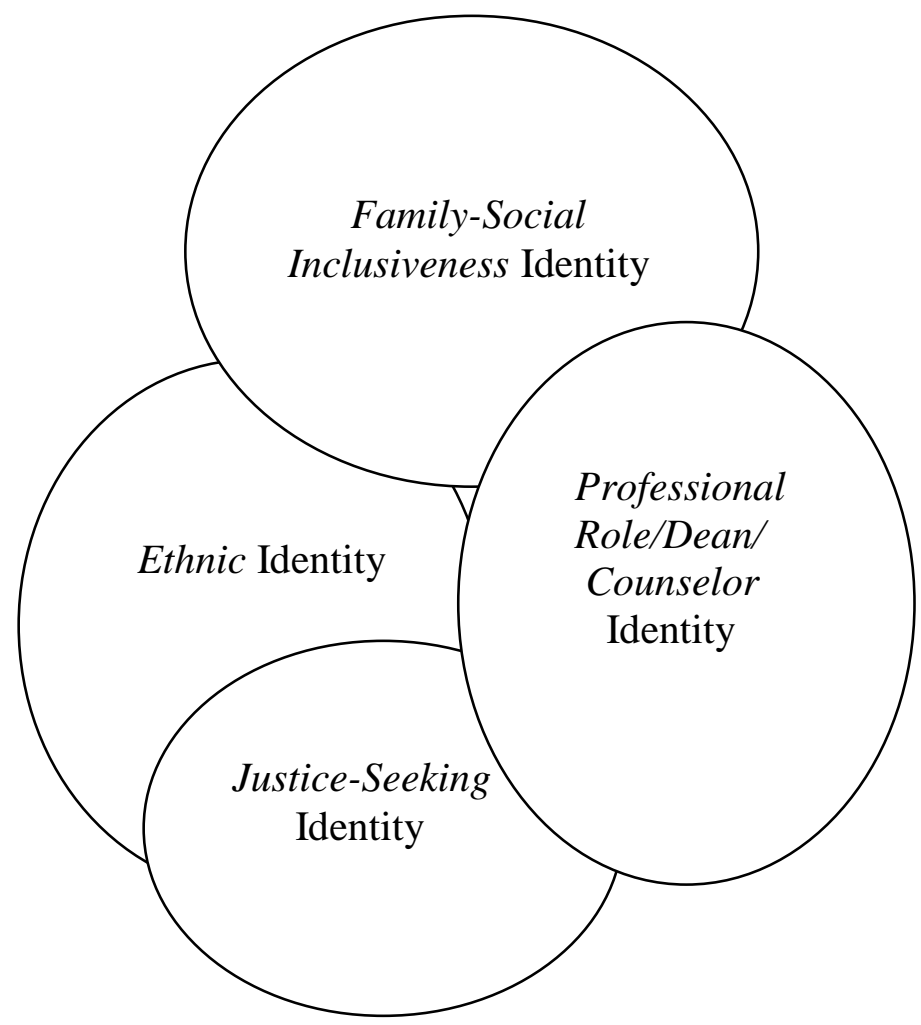

Figure 2. Overlapping identities and assumptions.

As a result of the articulation of the autobiography and assumptions which has shaped his life, his identified subjectivities formed the basis of his researcher's log in order to ensure that the subjective biases were less likely to affect the data collection, analysis, and interpretation procedures. In the end, this study was not an essay of quick impressions. Because qualitative research relies on collecting rich descriptions from those who are living the experiences, it was important to learn about how the underprepared community college student experiences their lives, hopes, and perceptions. In this study, he elicited the college students' perspectives as richly and detailed as possible.

Connected to issues of his subjectivity, observer effect concerned the researcher because of his role as dean of students. Students who were interviewed may have 
changed their behavior and responses to try to please the researcher. The researcher encouraged students to realize the importance of contributing their perceptions and the value of their true, honest insight. With the exception of one graduate and one persister who did not appear nor rescheduled her interview, the participants were more than willing to share their stories. In the process of establishing rapport for the individual and focus group interviews, the researcher verbally assured the students that the researcher was willing to hear their negative and positive experiences at $\mathrm{ABC}$ community college. For example, when recounting their experiences with the FYE program, participants were asked "how did the program fail or disappoint” as well as "how did it help.” In answering the question about average number of hours studied per week, most indicated 5 to 10 hours. However, four students admitted they only studied one hour per week or less. The researcher felt that participants who were trying to impress the dean would not have given such candid responses.

The reason that the researcher believed students were frank is that they had all participated in the Freshmen Year Experience where they had been encouraged to provide honest evaluations. Interview questions were designed to encourage participants to attest to both positive and negative experiences and recount both facilitators and barriers. Throughout the interview interactions, the researcher emphasized how important it was to attest to both sides of the record. Ultimately, the goal was to allow their voices to be heard with respect to the meaning they attached to their experiences. As expressed the researcher emphasized to all participants, he believed that their experiences could make a distinct contribution for other students. 


\section{Data Analysis}

The recordings of the interviews with participants were transcribed verbatim by the researcher. Participants’ files and interview transcriptions were coded by the researcher. So as to protect anonymity, participants were identifiable only by the code.

The researcher read through all interview transcripts and labeled passages. In the narrative description of the findings, participants; preferred pseudonyms were used to represent the participants' voices. If no preferences were stated, the researcher chose the pseudonyms. As part of the presentation of the findings, the researcher crafted profiles of each of the participants. From the copy of transcripts where important passages had been selected, the researcher put them together as a single narrative. Once again, he re-read with a more demanding eye to look for passages that were most compelling. Paired with archival data, the narrative was based on those passages to create the profile.

To search for themes within the verbatim transcripts of the individual and group interviews, the constant comparative method was employed for data analysis (Bogdan \& Biklen, 2003). It should be noted here that the questions on the interview protocol were informed by the literature review; thus, the literature provided a base for the themes that were identified based on participants' responses to those questions. The texts of the transcribed individual interviews were compared to each subsequent interview. Then the texts were analyzed across all individual interviews. In the cross-case analysis phase, the researcher searched for themes deductively using the information from the literature review. Thus, both the individual participant profiles and cross-case analysis were informed by the literature review. 
The group interviews provided an opportunity to verify the researcher's interpretation of themes with the participants, thus serving as a form of member check (Glesne, 1999). Researcher notes, conversations, and interviews were reviewed and compared as the researcher identified key issues. Data analysis did not focus exclusively on similarities, but instead sought to identify relationships that connected statements and events within the context of the participants. From the interviews of 6 of the 7 graduates, 12 of the 13 persisters, and 4 of the 51 non-persisters who participated in the study. core categories were identified until saturation of categories was achieved. This occurred within the first eight interviews, as per research by Guest et al. (2006) with respect to data saturation and variability.

Data analysis began immediately after finishing the first interview and continued until after the group interview. The researcher read through the entire set of interview transcripts and researcher's log, noting the general patterns that emerged in response to the interview questions that were derived from the literature review. In the next review, transcripts were examined using a different color highlighter as themes and subthemes were identified. If some of the data appeared to fit under more than one theme, the data were double-coded. For example, time management initially was coded under both precollege characteristics and academic integration while the topic of friends could be coded under both external college/community influence and social involvement. Subsequently, the researcher decided to place time management under academic integration because, for the majority of the students, it was a behavior they said they had learned in college. The researcher also chose to define "friends" as a support system established prior to college 
as compared to the peers whom they met at $\mathrm{ABC}$, which the researcher categorized as "peer interaction."

The researcher established meaning and coherence among the themes in the following manner. First, the researcher derived participant profiles which provided word pictures of the lives of the participants. Second, in the cross case analysis, the researcher examined the participants' perceptions deductively using the key factors identified in the literature review as a framework. The cross case analysis yielded four themes that were substantiated with rich descriptions using the participants’ words (i.e., "voice”) based on the verbatim transcripts of the interviews. Third, the researcher examined the themes from the perspectives of graduates, persisters, and non-persisters to see if there were any differences in the perceptions among the groups of participants. The researcher explored the students' perceptions of the conditions which may have contributed to or hindered their success. Finally, the researcher showed how the data addressed the research question and examined implications to theory, policy, and practice.

In summary, qualitative research is a process wherein the researcher derives categories and themes from the data. The researcher was actively involved in discovering categories of meaning that lead to developing themes which subsequently led him to identify areas that needed further investigation. In the study, the researcher read the transcriptions to determine key phrases used by the participants. Referred to as emic analysis (Creswell, 1998), concepts came from the participants themselves who shared their perceptions and beliefs in response to the interview questions, which the researcher derived from the literature review. The researcher examined the transcriptions for recurring words or concepts. The peer reviewer checked the accuracy of these recurring 
words and concepts with the researcher. The researcher also searched for themes based on the factors identified in the literature review.

To address the research question, interview questions and probes were identified that helped extract perceptions about what students believed had contributed to their college experiences and academic achievement (see Appendix D). Although the interview questions had been derived from the literature and were intended to reflect various theoretical frameworks (i.e., Astin, 1985; Freire, 1970, 1992; Tinto, 1975), there was no intention on the part of the researcher to force participants to answer in any way that deviated from their personal perspectives.

\section{Procedures to Increase Validity and Credibility}

To address the potential limitations of this study, the researcher implemented procedures to address potential researcher bias. The researcher acknowledged sources of potential bias. As the Dean of Student Affairs, the researcher had worked with the administration to establish the learning community at the study community college. In addition, the researcher had worked with the students as an advocate and believed they have a right to be members of postsecondary education communities. In critical research, Glesne (1999) noted that researchers have been instrumental in disputing the presumed requirement that one needs to be distant and removed from the object being studied. The credibility of the findings, therefore, depends on careful attention to spending sufficient time with the research participants and establishing methods to assure trustworthiness of the data. As the time spent with the student increases, the Hawthorne (observer) effect where subjects change their behavior to impress or please the researcher, is reduced. 
The procedures to establish trustworthiness of the data helped the researcher keep in mind the iterative nature of the research procedures between data collection, data analysis, and outcomes. Three of the eight verification procedures discussed by Creswell (1998) were incorporated in this study. The researcher selected these procedures so as to verify the trustworthiness of the study at three important points: (a) the data collection process (triangulation of data sources), (b) the researcher's steps to analyze the data (external audit trail), and (c) the themes that emerged from the analysis (member check).

Triangulation is an iterative process in which the researcher continued to review the transcripts, researcher log, and archived data. Triangulation of data sources required that the researcher (a) look at themes as they emerged from the analysis of the interview transcripts and (b) then look for confirmation of the themes from other sources (e.g., researcher log, archival data, or other participants' interviews).

The audit trail was conducted by a peer who was asked to provide feedback on the researcher's data analysis procedures. The peer was a recent doctoral graduate from Florida International University who conducted a qualitative dissertation on foster care children. He worked at a nearby school district in the Department of Research, Evaluation, and Accountability. The peer reviewer provided feedback on the researcher's data analysis procedures. Examining the researcher's records, the peer reviewed (a) transcripts of interviews for one graduate, one persister and one non-persister; (b) the researcher log; and (c) archived data. He followed the procedures detailed by the researcher in tracing the themes to the data sources. The peer reviewer provided positive comments and found many of the same themes as the researcher. However, the peer reviewer used different words; for example, the peer reviewer used the word "resolution" 
as compared to the researcher's use of the word "persistence.” In addition, he suggested that the sub-themes of time management and self-reliance/independence be under precollege characteristics. After he spoke to the researcher and learned that FYE students enrolled in the student life skills course where time management and study skills were taught, he understood that these two traits, although personal characteristics, were learned or emerged while students were in college, thus fitting better as a sub-theme under academic integration. Also, the researcher indicated that the sizes of the circles in the emerging model of persistence were not as pronounced. As a result, the researcher changed the sizes of the circles to visually represent the relative strength of the themes that seemed to have a stronger impact on the participants (i.e., external college support/community influence).

In addition to Creswell's procedures, the researcher relied on his dissertation committee chair and a member of the dissertation committee, an expert in qualitative research, as reviewers who acted as an external check of the research process. The reviewers offered feedback on the researcher's interpretations of themes. In addition, a summary of the transcripts and findings were provided and they assisted in verifying the researcher's development of themes to capture the essence of the data.

Member checking is a procedure where the participants were asked to examine rough drafts of the researcher's conclusions. Creswell (1998) argued that participants should play a major role directing as well as acting in phenomenological research. To ensure that ideas and thoughts accurately represented the students, the researcher took data, analyses, and interpretations back to them in order that they might offer feedback on the accuracy and credibility of the account. This was done individually through email 
contact with each participant after the interview as well as through the group interview. In the event that the member check revealed disagreement with the researcher, that disagreement was noted as part of the record and changed. For example, two students provided clarification as to the year they moved to Florida or their place of birth. Instead of the traditional approach of studying those who fail to persist, the researcher focused on those underprepared community college students who had persisted or had graduated. It was important to identify those students’ experiences so as to attest to both similarities and differences within each group and across the groups. In addition, clarification of the researcher's biases is an important aspect for qualitative research. The researcher continued to reflect and monitor his own subjectivity so as to minimize its impact in the inquiry process.

External validity refers to how findings from particular research studies can be generalized to other groups (Firmin, 2006). Rich, thick description allows the reader to make decisions regarding transferability (Creswell, 1998). Considering that purposeful sampling was used, the researcher matched study participants to the greater population in gender, race, ethnicity, and test scores. The greater the degree of similarity, the greater will be the degree of external validity (Firmin, 2006). Describing in detail the participants and setting enables the reader to determine whether the information and findings can be transferred to other settings because of shared characteristics.

In deriving universal statements of general social processes, there is an assumption that human behavior is not random or idiosyncratic (Bogdan \& Biklen, 2003). Thus, findings related to how these underprepared, ethnically diverse community college students overcome academic deficits may be applied to other settings such as how non- 
English speaking, ethnically diverse immigrants cope and adapt in the United States and become contributing members of society only to the extent that readers can resonate with the descriptions of their experiences. By exploring the experiences of the study's underprepared students who participated in a learning community, the researcher hopes to generate a deeper understanding of the phenomenon of college life as this student body experienced it.

\section{Summary}

The design of the study was based on a case study approach within a critical theory framework. The researcher used the purposeful case sampling method (Glesne, 1999). The study sample, therefore, was selected to represent gender and race demographics of the larger underprepared community college student body. The researcher interviewed 18 learning community college students who have completed college remediation (English, reading, and mathematics) and have earned at least 30 college credit-bearing hours or had graduated/transferred to the upper-division. In addition, four students were interviewed as learning community non-persisters (those who dropped out of college prior to completion of their programs). Participants were interviewed about their perceptions of their college experiences and their academic achievement. Semi-structured interviews were conducted with the participants. Although all 22 students were invited, six persisters and one non-persister returned to participate in a group interview. Data derived from the individual interviews were analyzed using the constant comparative method and are reported in chapter 4 . Themes that emerged from the cross-case analysis are reported in chapter 5. 


\section{CHAPTER IV}

\section{PARTICIPANTS}

The purpose of this chapter is to describe the participants of the study. First, a description of the sample is presented and comparisons of grade point averages are provided. Next, the individual profiles of the participants in each of the three groups are shared so as to introduce the students to the readers.

\section{Description of the Sample}

As shown in Table 2, from 2003 to 2007, 98 students joined the First Year Experience (FYE) developmental learning community including 50 Black, 23 WhiteNon-Hispanic, 3 Asian, 22 White-Hispanic students; 29 men and 69 women; and 59 (60\%) first generation in college. From the original number, seven students graduated

Table 2

Summary of FYE Participants

\begin{tabular}{|c|c|c|c|c|c|c|}
\hline $\begin{array}{l}\text { Cohort } \\
\text { Year }\end{array}$ & Black & $\begin{array}{l}\text { White } \\
\text { Non-Hispanic }\end{array}$ & $\begin{array}{l}\text { White } \\
\text { Hispanic }\end{array}$ & Asian & M & $\mathrm{F}$ \\
\hline 2003-04 & 10 & 7 & 4 & 2 & 6 & 17 \\
\hline 2004-05 & 8 & 8 & 7 & 0 & 8 & 15 \\
\hline 2005-06 & 16 & 4 & 5 & 0 & 4 & 21 \\
\hline 2006-07 & 16 & 4 & 6 & 1 & 11 & 16 \\
\hline TOTAL & 50 & 23 & 22 & 3 & 29 & 69 \\
\hline
\end{tabular}


with their associate's degree programs or transferred to an upper division university; 13 were currently enrolled with 30 hours or more; 27 were currently enrolled having earned 29 hours or less; 51 had withdrawn. All students were contacted by phone. To protect anonymity, pseudonyms were chosen for all participants.

Learning And Study Strategies Inventory (LASSI) and GPA Results

To ensure that there were no differences in attitudes and values among students and to support the notion that FYE students (both persisters and non-persisters) and nonFYE students did not represent any errors of self-selection or other forms of conscious or unconscious bias, the Learning And Study Strategies Inventory (LASSI) was administered to all students. The LASSI is used to measure students' study skills and learning strategies, yield diagnostic information about students' self-perceptions of their study skills, and predict academic achievement and success (Flowers, 2003). Its major goal is to provide useful information regarding a student's current study habits and learning strategies. Among both FYE persisters and non-persisters and those who chose not to participate in the FYE program, there were no significant differences on any of the ten LASSI scales based on independent $t$-test analysis at the .05 level. It is important to note that running these ten $t$-tests created the risk of inflated type-1 error due to the multiple comparisons without a conservative correction factor such as Bonferoni. It can only be concluded, therefore, that the two populations of students were homogeneous for the traits measured by the LASSI, such as motivation, study skills, etc.

The overall grade point average for the learning community students were reported for those who persisted. The GPA for FYE participants across 2 years was 2.2. 
In contrast, the overall grade point average across the students who did not participate in the learning community and who persisted across 2 years was 1.9.

When institutional policy defines a grade point average of 2.0 as its success indicator, and defines any average less than that as its criteria for academic warning, suspension and dismissal, even the slight difference of .3 on a grade point makes the difference between remaining in college or being dismissed. Meehl (1996) noted that sometimes the smallest differences, although not statistically significant, can have great impact on decision making processes and on life outcomes.

Study of Graduates, Persisters, and Non-Persisters

The researcher had identified all students who had completed the FYE program and who had completed their developmental courses, and had graduated, earned 60 credits or transferred to the upper division of a 4-year institution. Table 3 shows the demographic information of the six graduates (of seven possible interviewees) who participated in the study. The graduates included six women and one man. Although six students were categorized as Black and one student as Asian on ABC College's student mainframe system, they self-identified by their cultural identities. Two students identified themselves as Haitian (Frieda and Sara), two as Jamaican (Janice and Nekee), one African-American (LeLe), and one as Indian (Absum). One student graduated within five semesters and transferred to a large state university; one student graduated within six semesters and transferred to a local state university; two transferred to a local state university with over 60 hours, only needing to complete math or the math portion of College Level Academic Skills Test (CLAST); one transferred to a local proprietary college and graduated with an AS in Physical Therapy Assistant and one student recently 
graduated and was working full-time as she contemplated her options of 4-year institutions.

Table 3

Demographic Profile of the Graduates

\begin{tabular}{|c|c|c|c|c|c|c|c|}
\hline Name & $\begin{array}{l}\text { Year in } \\
\text { FYE }\end{array}$ & $\begin{array}{l}\text { \# of Credits } \\
\text { Earned } \\
\text { at ABC }\end{array}$ & Age & Gender & $\begin{array}{r}\text { Race/Ethnicity } \\
\text { Self-Identity }\end{array}$ & Major & $\begin{array}{r}\text { Overall } \\
\text { Cumulative } \\
\text { G.P.A }\end{array}$ \\
\hline Absum & 2004-05 & 60 & 23 & M & $\begin{array}{l}\text { Asian } \\
\text { Indian }\end{array}$ & Engineering & 2.76 \\
\hline Frieda* & 2005-06 & 60 & 20 & F & $\begin{array}{l}\text { Black } \\
\text { Haitian }\end{array}$ & Psychology & 2.55 \\
\hline Janice** & 2003-04 & 41 & 23 & F & $\begin{array}{l}\text { Black } \\
\text { Jamaican }\end{array}$ & $\begin{array}{l}\text { Physical } \\
\text { Therapy } \\
\text { Assisting }\end{array}$ & 2.65 \\
\hline LeLe & 2004-05 & 64 & 22 & F & $\begin{array}{l}\text { Black } \\
\text { African } \\
\text { American }\end{array}$ & $\begin{array}{l}\text { Special } \\
\text { Education }\end{array}$ & 2.89 \\
\hline Nekee* & 2003-04 & 68 & 23 & $\mathrm{~F}$ & $\begin{array}{l}\text { Black } \\
\text { Jamaican }\end{array}$ & Business & 2.48 \\
\hline Sara & 2005-06 & 60 & 20 & $\mathrm{~F}$ & $\begin{array}{l}\text { Black } \\
\text { Haitian }\end{array}$ & Business & 2.52 \\
\hline
\end{tabular}

*Transferred to the upper division before earning AA degree

**Transferred after 41 credits to earn PTA degree at a private proprietary college

The researcher identified 13 students who had completed the FYE program and had earned 30 credits or more. Many of the currently-enrolled participants were within one or two semesters of graduation. Table 4 shows the demographic information of the 12 persisters who participated in the study. The persisters included nine women and three men. Seven students were Black and self-identified by their cultural identities - that is 
Table 4

Demographic Profile of the Persisters

\begin{tabular}{|c|c|c|c|c|c|c|c|}
\hline Name & $\begin{array}{l}\text { Year in } \\
\text { FYE }\end{array}$ & $\begin{array}{c}\text { \# of Credits } \\
\text { Earned } \\
\text { at ABC }\end{array}$ & Age & Gender & $\begin{array}{l}\text { Race/Ethnicity } \\
\text { Self-Identity }\end{array}$ & Major & $\begin{array}{r}\text { Overall } \\
\text { umulative } \\
\text { G.P.A. }\end{array}$ \\
\hline Addison & 2006-07 & 37 & 20 & M & $\begin{array}{l}\text { Black } \\
\text { African- } \\
\text { American }\end{array}$ & $\begin{array}{l}\text { Business } \\
\text { Management }\end{array}$ & 3.04 \\
\hline Andye & 2006-07 & 35 & 46 & F & $\begin{array}{l}\text { Black } \\
\text { Jamaican }\end{array}$ & $\begin{array}{l}\text { Radiation } \\
\text { Therapy }\end{array}$ & 3.15 \\
\hline Caridad & 2005-06 & 42 & 20 & F & $\begin{array}{l}\text { Hispanic } \\
\text { Guatemalan }\end{array}$ & Journalism & 2.83 \\
\hline Dora & 2004-05 & 63 & 21 & F & $\begin{array}{l}\text { Hispanic } \\
\text { Costa Rican }\end{array}$ & Nursing & 3.46 \\
\hline Joseph & 2005-06 & 33 & 21 & M & $\begin{array}{l}\text { White } \\
\text { American }\end{array}$ & $\begin{array}{l}\text { Atmospheric } \\
\text { Science }\end{array}$ & 3.14 \\
\hline Juanita & 2006-07 & 32 & 19 & $\mathrm{~F}$ & $\begin{array}{l}\text { Hispanic } \\
\text { Puerto Rican/ } \\
\text { Dominican }\end{array}$ & Nursing & 3.20 \\
\hline Kyla-Renee & 2004-05 & 36 & 22 & $\mathrm{~F}$ & $\begin{array}{l}\text { Black } \\
\text { Jamaican }\end{array}$ & Nursing & 1.52 \\
\hline Melissa & 2005-06 & 53 & 21 & $\mathrm{~F}$ & $\begin{array}{l}\text { White } \\
\text { American }\end{array}$ & Education & 3.03 \\
\hline Nettie & 2005-06 & 46 & 23 & $\mathrm{~F}$ & $\begin{array}{l}\text { Black } \\
\text { Haitian }\end{array}$ & Pre-Med & 2.03 \\
\hline Robert & 2004-05 & 61 & 22 & M & $\begin{array}{l}\text { Black } \\
\text { Haitian }\end{array}$ & Accounting & 2.57 \\
\hline Star & 2005-06 & 49 & 22 & F & $\begin{array}{l}\text { Black } \\
\text { Bahamian }\end{array}$ & $\begin{array}{l}\text { Travel/ } \\
\text { Tourism }\end{array}$ & 2.83 \\
\hline Tridi & 2005-06 & 51 & 21 & F & $\begin{array}{l}\text { Black } \\
\text { Haitian }\end{array}$ & Accounting & 2.59 \\
\hline
\end{tabular}


three students identified themselves as Haitian (Nettie, Robert, and Tridi), two as Jamaican (Andye and Kyla-Renee), one as Bahamian (Star), and one as AfricanAmerican (Addison). Three students were Hispanic and self-identified by their cultural identities - that is Costa Rican (Dora), Dominican/Puerto Rican (Juanita), and Guatemalan (Caridad). Two participants were White-Non-Hispanic (Joseph and Melissa). Although most of students were in their early 20s, one student (Andye) was 45 years old, interviewed in the spring of 2008. Three of the 12 persisters planned to complete their associates degree by December 2008 or prior. The other students were enrolled in health science majors where programs of study required 70 - 84 credit hours. In addition, the researcher identified 51 students who had participated in the FYE learning community, but had dropped out. Table 5 shows the demographic information of the non-persisters. Table 5

Demographic Profile of the Non-Persisters

\begin{tabular}{lccccccr}
\hline Name & $\begin{array}{c}\text { Year in } \\
\text { FYE }\end{array}$ & $\begin{array}{c}\text { \# of Credits } \\
\text { Earned } \\
\text { at ABC }\end{array}$ & Age & Gender & $\begin{array}{c}\text { Race/Ethnicity } \\
\text { Self-Identity }\end{array}$ & Major & $\begin{array}{r}\text { Overall } \\
\text { Cumulative } \\
\text { G.P.A. }\end{array}$ \\
\hline Aleida & $2004-05$ & 27 & 21 & F & $\begin{array}{l}\text { Hispanic } \\
\text { Cuban }\end{array}$ & Radiography & 2.92 \\
Anna & $2003-04$ & 44 & 23 & F & $\begin{array}{l}\text { Black } \\
\text { Jamaican }\end{array}$ & $\begin{array}{l}\text { Criminal } \\
\text { Justice }\end{array}$ & 2.47 \\
J.R. & $2003-04$ & 16 & 22 & M & $\begin{array}{l}\text { Black } \\
\text { Haitian }\end{array}$ & Business & 1.62 \\
Sacha & $2006-07$ & 4 & 19 & F & Black & Nursing & 0.91 \\
\end{tabular}


Non-persisters included 3 women and 1 man. Three students were Black and all selfidentified by their cultural identities, that is, as Haitian (J.R. and Sacha) and Jamaican (Anna). One student was Hispanic of "Cuban descent” (Aleida). With the exception of Anna who worked part-time, the remaining non-persisters who were interviewed worked full-time or were responsible for young children.

In summary, the 22 participants included 17 women and 5 men who ranged from 19-46 years of age. They participated in the FYE at ABC in various cohorts: 4 in the 2003 cohort; 6 in the 2004 cohort; 8 in the 2005 cohort; and 4 in the 2006 cohort They included 7 Black Haitians, 5 Black Jamaicans, 2 Black Americans, 2 White Americans, 1 Black Bahamian, 1 Hispanic Guatamalan, 1 Hispanic/Costa Rican/Italian, 1 Hispanic Puerto Rican/Dominican, 1 Hispanic Cuban, and 1 Asian Indian.

\section{Participant Profiles}

In conducting the individual case analyses, the researcher constructed an individual profile for each participant based on the interviews and the archived data. In the profiles below, representative verbatim quotes from the interviews are included to illustrate key points about how each participant experienced their programs of study at ABC Community College. To protect the anonymity of participants, two participants selected pseudonyms while the researcher chose pseudonyms for the remaining participants.

\section{Graduate Participant Profiles}

The researcher interviewed six of the seven graduates (Absum, Freida, Janice, LeLe, Nekee, and Sara). Their profiles are presented in alphabetical order using a pseudonym. 
Absum "Just keep going, keep going”

"Absum" is a 23 year old, Indian-American senior at a large state university majoring in Civil and Environmental Engineering. He and his family immigrated to the United States from India when he was a senior in high school. He is the middle child. His older brother, who resides in India, attended college and is an accountant. Absum's younger sister moved to the United States in 2002 as a high school junior and is currently a student at $\mathrm{ABC}$ Community College pursuing an Associate in Science degree in nursing. Unlike the other FYE graduates, both of his parents graduated from college. His father is an engineer and his mother has a technical degree. Absum is also unique as he was the first of all FYE students to graduate (May 2006) since the inception of the program and the only student to transfer to a 4-year institution outside the immediate area of ABC Community College.

He joined the 2003-04 cohort and graduated within seven semesters. Further, he is the only male graduate. He is also the only graduate who enjoyed mathematics. When asked to describe an item in his wallet or backpack that best represents him, he answered, "My TI89 calculator because I'm really good at math...and I like something I can prove.” He maintained a 2.76 grade point average. While attending ABC Community College, he worked full-time at various places and was not involved on campus. At the state university, he works part-time in the computer lab and is involved in the engineering club.

Of all the graduates, Absum is the most independent and goal oriented. He remarked, “[My parents] didn’t want me to work, they wanted me to go to school - finish school and were willing to pay for my degree. But I wanted to work and go to school at 
the same time. I paid for my own tuition.” He is a true utilitarian who considers postsecondary education as a means to achieve his goal. He chose ABC Community College because "it was the closest” and “just to take classes.” His advice to new freshmen was, “Make sure you know where you're going. Just don’t pick random classes. That wastes too much time. Just know where you're going.” Absum intends to graduate in December 2008 and "be successful, earn money and live a happy life."

Frieda "Education is number one"

"Frieda” is a Haitian-American, 21 year old New York native. She moved to the state in 2001 as a high school freshman. An only child, she lives with her mother and stepfather and visits her father who resides in nearby city at least once per month. Her mother graduated from college and is a registered nurse. Her father graduated high school. She is the only graduate engaged to be married; she met her fiancée in high school. She participated in the 2003-04 FYE cohort and transferred to a local university in January 2008. Frieda had attended ABC for six semesters. Majoring in psychology, she needed one more math class to complete her associate in arts degree. While attending ABC Community College, she was active on campus, serving as president of the Dynamic Soul Dancers.

She maintained a 2.55 grade point average before transferring to the upper division. However, math was difficult for her. While at ABC, she withdrew or failed Elementary Algebra, Intermediate Algebra, and Statistics, for a total of four times. Initially shy and a little reserved, Frieda revealed, “FYE helped me make friends. With all the classes we had each other, I overcame my fear of public speaking.” One of her best friends, whom she met in high school, also attended ABC and joined FYE. Neither 
student knew of the other’s intention. She claimed, “I consider her to be closest to me. We have a lot in common.” Frieda’s family served as a source of motivation. Frieda elaborated, "My mom works really hard. She pays for my education and that motivates me to just keep working harder and harder so she can see that her money is well spent and that it was worth it.” Frieda’s goal is to “finish my bachelor’s degree. My fiancée and I are engaged to be married after I graduate.” She provided the following advice to peers:

Take your first semester, the first year of college very seriously. I mean, it's a new experience and of course, you're going to be excited about it, but the grades you get in the beginning affect you. That starts your GPA and that will affect you later down the line. If your GPA is a little low, it takes a lot to bring it back up.

Janice “Do something”

“Janice” is a Jamaican-American, 23 year old graduate of a local professional college. She moved to the United States from Jamaica when she was nine years old. As an only child, she is extremely close to her mother. She noted, "It was just me and my mom all the time.” When talking about the importance of staying connected, she stated, “I'm not really on the phone all the time with friends, but I'm always on the phone with mom.” She resided at home. Her mother did not attend college; she worked two jobs and as Janice emphasized, “She doesn’t force me in helping her out. My concentration is on school."

Janice completed her associate of science degree in Physical Therapy Assistant and is studying for her state board examination. She participated in the first FYE cohort, (2003-04) and completed 41 hours. While attending ABC, she was active on campus, serving as president of the Peer Educators Club and Student Ambassador. She maintained a 2.65 grade point average before transferring. Although initially declared as a nursing 
student, she changed her major to PTA and transferred to a local professional college because of her difficulty with mathematics courses at the community college. She attempted Pre-Algebra two times. The only other class from which she withdrew was National Government. Ultimately, her goal is to begin working in field and later pursue her doctorate in physical therapy at the university. She asserted, "I have the motivation and I have the strong will. I have my goals that I'm striving for. Nothing at all is going to get in my way. It's all about school. Until I'm done, there's only one picture that I'm focusing on.” As a student born outside the United States, she further explained,

Being the fact that I'm not a born American, you have something even more to work for. Your family don't come to America to just do nothing, otherwise, why? You come for a better life - to get an education. I'm going to do something with my life.

\section{LeLe "Open to new experiences"}

"LeLe" is a 22 year old, African-American ABC Community College graduate. Interested in working with children with special needs, her major is special education and, at the time of the study, she had not yet decided whether she will continue her education locally or transfer to a historically Black college. She indicated, "I think one of the reasons I want to go there is because it's a Black college. I've never had that experience. I want to get a different aspect of my culture.” She joined the 2004-05 FYE cohort and attended for nine semesters. She completed her associate in arts degree in December 2007. She earned a 2.52 grade point average and withdrew or failed for a total of 8 courses, 4 of which were for several math classes including Elementary Algebra, College Algebra (twice), and Statistics. Subsequently, she passed Liberal Arts Mathematics I and II. LeLe was active on campus. She joined Intervarsity Christian 
Fellowship and worked in Student Life. She boasted of attending several leadership retreats and participating in several trips.

Born in Florida, she described four siblings - two older brothers, one older sister, and one younger sister. She was the second in her family to graduate from college. Her older brother attended Kent State University. Her mother was attending ABC. LeLe describes a close relationship with her mother, father, and particularly older brother. He provided both encouragement and financial support. She recounted, "If I needed anything for school...if it was clothes or shoes or book bags, he'd get it no matter what. I'd say, 'I'll pay you back and he would say don’t worry about it.' He's like the role model.” She provided the following advice to fellow students:

Be open. There's so much. If you fail at ABC, you fail because you choose to fail, not because you didn't have the opportunity. Don't let anyone let you feel less of anything because you're going to a community college. Things you can experience somewhere else, you can experience at a community college. There's so much that they do here, that it's ridiculous.

\section{Nekee "Be proud of me"}

"Nekee" is a 23 year old Caribbean-American junior at a local university. Born in Jamaica, she immigrated to the United States with her family when she was eight years old. She described her older sister who did not attend college and a younger brother who was currently enrolled at a state university. She and her family were U.S. citizens. She emphasized, "America gives you a lot. It provides for you."

She participated in the 2003-04 FYE cohort and was active in the Student Ambassadors and Dynamic Soul Dancers. Nekee chose to participate in FYE as a result of her mother's encouragement. She stated, "Because we had the same people in the class, you worked together more and you helped each other out...I'm still friends with 
people.” She transferred to the local university in January, 2008, majoring in Business Administration with a specialization in management. She only needed to pass the math portion of the College Level Academic Skills Test (CLAST) to earn her AA degree. She had earned 68 credit hours and has maintained a 2.48 grade point average. She was enrolled in College Algebra and intended to receive her AA in May 2008. The first in her family to attend college, Nekee reported strong family support. She explained,

My parents influenced it [my college experiences] a lot. I felt like I had to prove something to them. I had to strive to do better in my life - to get an education so they'd be proud of me. 'Cause they did not have that opportunity, I should take advantage of it.

Sara "I want to be successful"

"Sara" is a recent ABC graduate and FYE participant. She is a 20 year old junior at a local university majoring in Business Administration with a specialization in Management. Born in New Jersey, her parents immigrated to the United States approximately 25 years ago from Haiti. When she was four, they moved to South Florida. She is the eldest of three children; she has two brothers. She is the first in her family to graduate from college. She indicated, "My parents never got the education they wanted. When they came here, it was really hard for them. My father always wanted my brothers and I to get the education, do our homework. Even if we didn't do well, he always encouraged us to try harder and do better.”

Sara reported strong family support and a peer network and talked about her parents, brothers, grandparents and friends. She shared, “I really didn’t have that many friends growing up. Even though I'm a girl, usually boys don't look up to their older sister, but they look up to me and I look up to them also.” One of her closest peers whom 
she met in high school also participated in FYE with her. A participant of the 2005-06 FYE cohort, Sara recently graduated in six semesters from ABC. Originally declared as a pre-occupational therapy major, she withdrew from three classes: chemistry, biology, and biology lab. As a highly responsible individual who had cared for her brothers since the age of nine, she said her worst experience in education was "dropping chemistry 'cause I didn’t want to drop any classes. It was really hard for me.” She graduated with a 2.52 grade point average. She shared the following advice: "Have faith, be strong. Find either one or two friends that you know, probably have the same values will help you out and not lead you down the wrong path.”

Summary of Number of Course Withdrawals and Failures for Graduates

The researcher used archival data to track the number of withdrawals and failures for the graduates. As shown in Table 6 on the next page, the graduates enrolled in a variety of courses that were difficult for them to pass, particularly math, sciences, and writing. Inspection of the table indicates that the graduates attended from 5 to 12 semesters before completing their respective programs of study and/or transferring to a local proprietary college or the upper division. On average, the graduates withdrew from three courses and failed two courses. The majority of them later repeated failed courses for grade forgiveness in order to improve their grade point averages.

\section{Persister Participant Profiles}

The researcher interviewed 12 of the 13 persisters (Addison, Andye, Caridad, Dora, Joseph, Juanita, Kyla-Renee, Melissa, Nettie, Robert, Star, and Tridi). The persister profiles are presented in alphabetical order. 
Table 6

Summary of Number of Course Withdrawals and Failures for Graduates

\begin{tabular}{|c|c|c|c|c|}
\hline Name & $\begin{array}{l}\text { \# of } \\
\text { Semesters } \\
\text { at ABC }\end{array}$ & $\begin{array}{l}\text { \# of } \\
\text { Withdrawals }\end{array}$ & $\begin{array}{l}\text { \# of } \\
\text { Failures }\end{array}$ & $\begin{array}{l}\text { Courses (Grade) in which } \\
\text { Participants Withdrew or } \\
\text { Earned a Grade less than "C" }\end{array}$ \\
\hline Absum & 7 & 1 & 2 & $\begin{array}{l}\text { Biology (W) } \\
\text { Preparatory Reading II (F) } \\
\text { Trigonometry (F) }\end{array}$ \\
\hline Frieda & $6^{*}$ & 2 & 2 & $\begin{array}{l}\text { Elementary Algebra (W) } \\
\text { Intermediate Algebra (W, F) } \\
\text { Statistics (D) }\end{array}$ \\
\hline Janice & $5 * *$ & 1 & 2 & $\begin{array}{l}\text { Pre Algebra (D) } \\
\text { Pre Algebra (F) } \\
\text { National Government (W) }\end{array}$ \\
\hline LeLe & 9 & 5 & 4 & $\begin{array}{l}\text { Astronomy (W) } \\
\text { Elementary Algebra (D) } \\
\text { College Algebra (W, F) } \\
\text { Statistics (D) } \\
\text { Western Civilization (W) } \\
\text { Biology (F) } \\
\text { Environmental Science (F) } \\
\text { Short Story: Fiction (W) }\end{array}$ \\
\hline Nekee & $12 *$ & 4 & 3 & $\begin{array}{l}\text { Pre Algebra (W, F) } \\
\text { College Algebra (D, F) } \\
\text { Statistics (W) } \\
\text { Liberal Arts Math (W) } \\
\text { Biology Lab (W) }\end{array}$ \\
\hline Sara & 6 & 3 & 0 & $\begin{array}{l}\text { Biology (W) } \\
\text { Biology Lab (W) } \\
\text { Chemistry (W) }\end{array}$ \\
\hline
\end{tabular}

*Transferred to local state university before earning A.A. degree

**Transferred to local proprietary college to complete A.S. degree 
Addison "My father, he's a big influence"

"Addison” is a 21 year old African-American student. Born in Jacksonville, Florida to an upper middle class family, he has one older brother. His father has a strong influence on Addison. Having worked for IBM as a computer engineer, he expects much of his son. Addison claimed, “College is expected.” Initially, his father expressed reservations about enrolling in a community college. Addison shared, "He [my father] wanted me to go straight to a 4-year university. I think the reason he was opposed, he pictured ABC to be like a high school. He didn’t think it would be a good atmosphere. I wouldn't get the right exposure that I would get at a university. FYE changed that...surprisingly, he said he liked the FYE program and how they came in and made sure you had the right classes and help guide you through your first year. He convinced me to do it.” Addison is majoring in business administration and intends to transfer to a local university. Someday he hopes to start his own business. He said, "I chose business because it's in the same field [my father] did. Also, I want to see what I can do. So, I know if I manage something and it’s successful, I know I did that, not somebody else.” Addison has earned a 3.04 grade point average, the highest among the minority men. He is highly motivated to make money and focused to perform well. He does not consider himself typical. He explained,

I guess people expected me to be like every other stereotypical Black male - loud and obnoxious. I'm more calm and collected. I'm different because usually I don't say much. I heard this all throughout high school. Why don't you talk or why don't you smile? I'm thinking to myself, why do I owe it to you? You haven't done anything for me to open up. My dad says the same thing because he doesn't open up. 
He gave the following advice to new students: "Make sure you're ready for it...make sure you have the time to put in that you need to put in. Don't try to overlook time and always keep yourself focused.”

Andye "You gotta stick with school"

"Andye" is a 45 year old sophomore at ABC Community College majoring in Radiation Therapy. Born in Jamaica and 1 of 12 siblings, she has lived in the United States for the past 12 years. As the only married student in the FYE cohort, she described her three sons - one college sophomore enrolled at a local university and two high school juniors who were dual-enrolled at ABC Community College. All three children lived at home. She had attempted to return to school before, but waited until her younger sons started high school. She stated, “Now that they're older and can take care of themselves. It's my time. I've done my part.” As the oldest student in the FYE program, she said that fellow students often called her "mom.” Determined, helpful, and focused, she joined the 2005-06 FYE cohort because: "The classes were selected for me and it seemed reasonable. It was a challenge and I like challenges.” She worked part-time at a local home improvement center and was active on campus serving as a campus ambassador. She maintained a 3.15 GPA, majoring in Radiation Therapy. Attributing reasons for her success, she indicated,

I was more serious. I guess more mature and more focused. Some of them face money interest. I have a family...the less I have, the happier I am because I don't have the pressure to spend. And if you earn less now, it will be better later. I say you gotta stick with school.

Andye reflected a strong sense of responsibility and seemed to know what needed to be done. She provided the following advice to new students: 
Be prepared to read and be prepared to keep up with your schedule - the syllabus. Tests can surprise you and it's not a good feeling to know that you're not thinking about the test and all of sudden it's here. You feel exposed. Find the time to dedicate to school.

\section{Caridad "Your goals are attainable"}

“Caridad” is a 20 year old Hispanic sophomore at ABC Community College.

Born in Providence Rhode Island, her parents and two older sisters immigrated from

Guatemala. She was the first in her family to attend college; however, her oldest sister attended a technical school to become a paralegal assistant. She moved to Florida when she was 16 years old and lives with her mother. Her parents were divorced and her father resided in a northern state. Her sisters were married with children. Caridad credited much of her success to her mother who worked three jobs. She explained, "I want a better life for my mom, cause she raised three kids on her own...I want something better.” Very energetic and outgoing, she planned to major in journalism. She had maintained a 2.83 grade point average and has earned 42 credits. She intended to transfer to a local state university. Her favorite activity was writing. She noted,

My high school English teacher helped me discover what I was good at. Because, I was always good in English, but I never really had a passion for something until I met her and she introduced me to Maya Angelou and Shakespeare...I like to write essays and once the pen hits the paper and I have a thought and I just flow with it. So, it just became a main focus for me. So I started reading more - writing more poetry, sonnets, everything. Similar to her peers, her least favorite class was mathematics. She had attempted intermediate algebra twice and, at the time of the study, was currently enrolled for a third time. She chose to participate in FYE because, in her words,

I don't know if a lot of kids admit it, but I was scared. I was scared about coming to college. I didn't know how to do anything and we're sitting in orientation and they said, we're conducting this program called "First Year Experience” and you basically get to matriculate with the same 
people. So, I thought what if I don't make any friends being alone. So, this kinda gives you a little bit of a boost because they help you pick your classes and it kinda shows you how everything is your first year in college. So, I figured it would be a little bit easier than just getting - I kinda pictured it as an ocean, but rather than being dumped in the middle, I had a boat.

She offered the following advice to new students,

When I came to school, I didn't think it was going to be hard. I honestly thought it was going to be like high school. The teachers would always be on you, so, I would say, yeah it gets really, really hard sometimes and you think, okay, this is it - I don't want to do this anymore, but strive for your dreams. Your goals are attainable. They're not as far as you think they are.

\section{Dora "Be prepared”}

“Dora” is a 21 year old sophomore at ABC Community College. Although Dora was born in New York, her father had emigrated from Costa Rica and her mother was born in Italy. Although most of her family lives abroad, she described her family as a close-knit, religious family. According to Dora, "We speak mostly Spanish. My father speaks to my mother in Spanish and she talks back in Italian. Me and my brother talk to them in English. It's like a circus.” Her family moved to Florida 12 years ago when she was in elementary school. Originally she majored in pre-medicine, and, at the time of the study, she was majoring in nursing, planning to transfer to a large state university to earn her Bachelors of Science in Nursing. She remarked,

I remember telling my parents that I changed my major. My mother started crying. She said I really want you to be a doctor. I told her that I can't be a doctor right away - that I need to study something else first. She accepted that answer. I think she still thinks I'm going to be a doctor.

She reported that her father worked two jobs to help pay for school tuition. As she explained, "School is the priority. My job is school.” She joined the 2005-06 FYE cohort. Of all the FYE students, she maintained the highest grade point average of 3.46. Not only 
was she first generation in college, but was also the first to graduate from high school.

When asked about her best educational experience, she replied,

I was the first one in my family to graduate from high school and then go

to college. The whole family came to the [high school graduation

ceremony] - my mother, my father, brother, even my grandmother from

Italy came. It was a big deal and everybody was proud of me.

She provided the following advice to new students: “Don’t be shy...ask a lot of questions and go for help. There are people that care, but they can't read your mind to know what you need.”

Joseph "You can't give up right away"

“Joseph” is a 20 year old White man at ABC Community College majoring in atmospheric science. Originally from Massachusetts, he lived with his mother, stepfather, eight year old brother, and grandparents. They moved to Florida when he was an infant. Joseph has had little contact with his biological father. He said, “I don’t talk to him.” He reported that he had a strong relationship with his stepfather who advised him saying: "It’s hard if you do not go to college, so just get through it.” In high school, he was part of the Exceptional Student Education (ESE) program, but ultimately he graduated with a standard high school diploma. He remembered, "I had to repeat the math FCAT twice and the reading three times.” His best educational experiences were in high school when he won several ESE social studies and science awards.

He joined the 2005-06 FYE cohort and has earned a 3.14 grade point average. As one of the few White men to join, he chose to participate in FYE because, in his words, "Having the same people in the same classes and the professors get to know their people...it gets you used to the flow of college.” Also, unique to Joseph and unlike the 
majority of his peers, his favorite subjects were mathematics classes. Introverted and reserved, he reported that he was not involved in student clubs and organizations. He explained, “They look fun and all that, but I didn’t have the time and been busy doing other stuff.”

After completing his associate in arts degree in December 2008, he planned to transfer to a large state university and join his friends from high school. As one of the few men who persisted and maintained a high grade point average, he attributed his success to goal-setting. He indicated, “I have a plan and know where I want to go.” He advised incoming freshmen: “Join FYE because it was great. It helped me to get where I am right now. It helped me get more comfortable and I'm doing well as a result.”

Juanita “Don't regret what you do, regret what you don't do"

“Juanita” is a 19 year old Hispanic, sophomore at ABC Community College majoring in nursing. She indicated, "I want to help people. I remember when I was little, I used to walk into the hospital and I want to help them. Like, I want to go over there and pick something up for them or do something. I want to help them out.” She joined the 2005-06 FYE cohort. She had earned a 2.52 grade point average. Born in Puerto Rico, she had lived in Florida for the past 15 years. She was the oldest of three children; she has one brother and one sister. Her mother was born in Puerto Rico and her father immigrated from the Dominican Republic. She was the first in her family to attend college. She emphasized,

They're glad - they're so happy because I'm the first one. They're like, you have to show an example to your sister and brother. If we couldn't do it, you can do it so, I'm doing it because I want to and because of my sister and my brother and my parents. 
She explained that her parents had recently purchased a car for her. She chose to attend ABC Community College because,

Everyone says the university is better than the [community] college. I really didn't know. I didn't care. I just wanted to become a nurse. It's basically the same thing. They have like 200 kids - students in one class and I have like (pause) twenty-something. I get A's, they get C's.

She attributed her success to FYE. In her words, “If it wasn’t for FYE, I wouldn’t be here right now. Thank God, cause it helped me a lot and I know where to go.” Open to new opportunities, she explained, “I don’t regret anything I do, but I regret what I haven’t done!” She offered the following advice to entering peers:

Ignore what other people say because I guess that's why I was nervous and scared. 'Cause I thought college is for older people. You need to be smart. It's hard. I think I would have thought that if I didn't join the FYE program.

\section{Kyla-Renee "I know I can do better"}

“Kyla-Renee” is a 22 year old sophomore at ABC Community College. Born in Jamaica, she has lived in Florida for the past 15 years. She reported that she had one younger brother. She and her family immigrated to the United States from Jamaica because, in her words, “There are better opportunities...it's harder back there.” She is the first in her family to attend college. According to Kyla-Renee, she experienced pressure among her extended family to succeed. She explained, "Usually when we have family gatherings and stuff, they know that I'm in college. They ask me, 'How are your classes? When are you going to graduate?' So, it makes me feel like they care.” She chose to major in nursing because, as she explained, "When I was in high school, I was in the health science program and I like it, even though I'm a little bit scared of blood. We had days we'd go to the hospital and I like that.” 
She joined the 2005-06 FYE cohort. She explained why she decided to participate, "When I found out about the activities and stuff, I thought maybe this is going to be different than just going to school and just studying.” Despite performing well her first semester, she had difficulty in mathematics and science classes. Although she attempted 51 credit hours, she only earned 36 credit hours. However, she admitted to only studying one hour per week. Of all the persisters, she had the lowest grade point average (1.52) and was currently under academic probation. She noted, "I guess when I see my GPA, sometimes, it makes me - because I know I can do better. But then I'm thinking, I have another chance next term. I'm going to do better. I'm going to study more." She offered the following advice to new students, "Sometimes it’s boring and you don't want to do it, but you have to do it. We have all the opportunities in the world to do things like go to school...just take your classes and study.”

Melissa "ABC - it's home"

"Melissa" is a White, 20 year old sophomore at ABC Community College. The oldest of three children, she was born in New Jersey and moved to South Florida when she was four. She reported that she has a passion for working with children and is majoring in Elementary Education. She emphasized, "I always wanted to be a teacher. I love kids. I love the whole aspect of seeing them grow.” At the time of the study, she had earned 53 credits and maintained a 3.03 grade point average. She is scheduled to graduate in May 2008 and transfer to a local university. She participated in the 2005-06 FYE cohort and is highly active on campus serving as a student ambassador. She chose to participate in the FYE program because, 
My mom made me. She was here with me at orientation and they were telling us about it and I was like, ugh, I don't know about this and [my mom] was like, just do it. It will be fun. I'm glad she made me do it.

She remembered her first day in college.

When I found out I had to take the prep classes, I was discouraged intimidated because you go through high school and then a lot of it is straight from high school and you don't really get the credit for it. It pushes people away.

Reflecting on her persistence, she added, "Why would you drop out of school, if you already make it through [developmental] classes? If you made it through the prep classes, you might as well keep going." She credited her success to being involved with campus activities. She explained,

I think that's one of the main reasons that I'm finishing up now was because I was so active on campus. I think that probably had the biggest role to do with anything - being active and constantly being here. I'm here more than I'm at my jobs or at home. Most of my time, I'm here at ABC.

Nettie "I'm not a quitter. I'm proving to my mom I can do it"

"Nettie" is a 21 year old student from Haiti. Shy and reserved, and perhaps a little lonely, she described her two younger siblings; she lived at home with her father and stepmother. They immigrated to the United States before she started ninth grade. She described language acquisition as the most difficult aspect of moving to the United States. She observed, “Especially the first week when you have no idea what they're saying, but you want to be successful. So, like my first three years when I got here, I have to be in the library a lot. That was my home." She worked approximately 25-30 hours a week at a local arts and craft store, usually during the weekend. Not particularly close to her father and stepmom, she indicated, “I don't even think that they know I’m going to be graduating.” 
She attributed much of her success to the memory of her biological mother who passed away when she was 12 . For that reason, she said that she worked hard to continue her education. She remarked, “I never think about quitting. I'm proving to my mom I can do it.” She planned to graduate in August 2008, and intended to transfer to a local university to continue in a pre-medicine curriculum. She had maintained a 2.03 grade point average. She joined FYE because,

I graduated out of high school and I wasn't sure about anything - what classes to take and stuff. And then to get somebody to explain everything to you and just give it to you like that, it was a pretty good thing. That's what I needed to motivate me to stay in college.

She provided the following advice to new students:

Take advantage [of opportunities] and ask questions. Don’t just go to school and go back home. Find out what's going on. If you just come to class and go home, you have no idea what's going on. I know that there's a lot of help out there. Get the help. Don't just say that I'm failing my classes and college is not for me. That's not true!

Nettie exemplified the mission of the community college, when she stated, "College is for everybody if you stick your mind to it.”

Robert "My goal is to be the first college graduate"

"Robert" is a 22 year old sophomore at ABC Community College majoring in Business Administration with a specialization in accounting. Although originally, a computer engineering major, he had difficulty in the sciences and higher level mathematics courses. Born in Haiti, he moved to Florida as a ninth grader. His mother continued to live in Haiti and his father, who has remarried, brought him to the United States. He said he is the first in his family to attend college. He stated,

My dad and sister encourage me to stay in school because they don't really have a good job. I am the first one in my family to go to college and 
I don't want to mess that up. My parents would be more than happy to see me graduate.

Highly responsible, soft-spoken and a little shy, he reported that he sends money to his mother. He mentioned, “I’m the only child on my mom’s side. I’m the one that has to provide for her. So, I have to send her money every two weeks or every month.” He worked part-time at a local supermarket and was very proud to be a student at ABC. He said, "When people ask about you and you tell them that you're in college, they give a lot of compliments - like, keep going, do something with your life.”

Robert joined the 2004-05 FYE cohort. He explained, “I chose to participate in FYE because what I've been told - the information they gave me... it would be a great experience in my life and since it was my first time in college, it was worth it.” He was a member of the Roots Club and Computer Club. He commented, "It was a good experience.” His goal was to graduate in August, 2008, and to transfer to a local university. He earned a 2.57 grade point average. He provided the following advice to new students: "When you come to college, do not procrastinate. Always try to do your work ahead of time, 'cause if you don't, everything's going to start piling up and that's when you're going to fail.” Star "I've come too far to give up"

A 21 year old international student from the Bahamas, "Star” is majoring in Travel and Tourism at ABC Community College. She and her sister came to the United States by themselves during her senior year of high school. Unlike many high school students, she stated,

My sister was out of the house at 16 and I was gone at 17 . My mom pushed us to be independent at a very early age. She would have friends or 
family who would say, "Oh, you're sending them over to live on their own and you have two girls - that's scary.” But [my mom] believed in us and we believed in ourselves.

Despite her independence, she frequently visited the Bahamas to see her mother, fiancée, and other family members. She intended to graduate in summer, 2008, and to transfer to a local university to continue her studies in hospitality management. Dedicated, focused, and mature, she maintained a 2.83 grade point average. She was a member of the 2006-07 FYE cohort and chose to participate because, as she noted, "Coming out of a very small high school - about eight kids graduated in the senior year, I decided that the FYE program - it's smaller classes and everyone sticks together for about a year and the classes seemed pretty manageable for me.”

Star was extremely patriotic. She explained,

I decided to major in tourism simply because my mom works in the tourism industry for about 15 years. And I saw how it would go up and it would go down, but basically in the Bahamas, that's our number one industry. I feel like I would be a great asset to my country...to give back and to be able to succeed and make the industry number one. I want to be able to go back home and give back and help the Bahamian people.

\section{Tridi "I enjoy being a student"}

"Tridi" is a 20 year old sophomore at ABC Community College. Born in the Bahamas, her family is originally from Haiti. They immigrated to the United States when she was in elementary school. She shared, "We came for a better future." She described her large family of 20 siblings (her father had 18 children from another marriage) and many cousins - all were living nearby. She resided at home with her mother and younger brother and sister. She is the first of her mother's children to attend college although she has one older brother who graduated from college. She worked at a local supermarket and 
attended ABC Community College full-time. Tridi joined the 2005-06 FYE cohort because, as she said,

A lot of my friends went off to universities and different colleges and it was just me and two of my other friends who attended $\mathrm{ABC}$ at the time, so, I wanted to be in a program where I could interact and meet other people and get to know the school better.

Working as a custodian and holding two jobs, she attributed much of her success to her mother. She explained, "My mother, she told me that she'll work three or four jobs just to get me through school cause she doesn't want me to end up like her. She’s a pusher. She won't let you quit.” Maintaining a 2.59 grade point average, she was majoring in accounting and planned to continue her education at a local university. She chose accounting because, she said, "I love interacting with people. I like traveling. I like numbers.” One of 3 FYE students who enjoyed math, she was the only woman to have taken and passed calculus. Tridi gave the following advice to new students:

Don't go to college being narrow-minded, assuming it was a certain way due to what other people have to say. Go to college with an open mind. Experience things. Allow yourself to join programs, meet new people, 'cause you'll end up gaining a lot from it. 'Cause I sure did.

Summary of Number of Course Withdrawals and Failures for Persisters As shown in Table 7, the participants enrolled in a variety of courses that were difficult for them to pass. Inspection of the table indicates that the students attended ABC Community College from 4 to 12 semesters. Only three persisters did not need to repeat any courses. In other words, Addison, Joseph, and Melissa completed all courses attempted. Consistent with the graduates, the majority of the persisters had difficulty in completing math courses. In addition, many persisters experienced difficulty in completing science courses. 
Table 7

Summary of Number of Course Withdrawals and Failures for Persisters

\begin{tabular}{|c|c|c|c|c|}
\hline Name & $\begin{array}{l}\# \text { of } \\
\text { Semesters } \\
\text { at ABC }\end{array}$ & $\begin{array}{l}\text { \# of } \\
\text { Withdrawals }\end{array}$ & $\begin{array}{l}\text { \# of } \\
\text { Failures }\end{array}$ & $\begin{array}{l}\text { Courses (Grade) in which } \\
\text { Participants Withdrew or } \\
\text { Earned a Grade of less than "C" }\end{array}$ \\
\hline Addison & 4 & 0 & 0 & None \\
\hline Andye & 6 & 0 & 1 & Elementary Algebra (D) \\
\hline Caridad & 7 & 0 & 3 & $\begin{array}{l}\text { Elementary Algebra (D) } \\
\text { Intermediate Algebra (D, D) }\end{array}$ \\
\hline Dora & 8 & 1 & 2 & $\begin{array}{l}\text { Accounting I (F) } \\
\text { Anatomy I Lab (D) } \\
\text { Statistics (W) }\end{array}$ \\
\hline Joseph & 5 & 0 & 0 & None \\
\hline Juanita & 5 & 0 & 1 & Elementary Algebra (F) \\
\hline Kyla-Renee & 9 & 1 & 6 & $\begin{array}{l}\text { American History (W) } \\
\text { Anatomy I (F) } \\
\text { Elementary Algebra (F, F) } \\
\text { Intermediate Algebra (F) } \\
\text { Logic (F) } \\
\text { World Religion (F) }\end{array}$ \\
\hline Melissa & 7 & 0 & 0 & None \\
\hline Nettie & 8 & 0 & 6 & $\begin{array}{l}\text { Biology I (F) } \\
\text { Chemistry I (F) } \\
\text { College Algebra (D. F) } \\
\text { Philosophy (F) } \\
\text { Statistics (F) }\end{array}$ \\
\hline Robert & 10 & 1 & 4 & $\begin{array}{l}\text { College Algebra (W, F) } \\
\text { English I (D) } \\
\text { Pre Algebra (D) } \\
\text { Pre Calculus (D) }\end{array}$ \\
\hline Star & 6 & 1 & 2 & $\begin{array}{l}\text { Elementary Algebra (D, F) } \\
\text { English II (W) }\end{array}$ \\
\hline Tridi & 8 & 0 & 6 & $\begin{array}{l}\text { Accounting II (F) } \\
\text { Economics I (F) } \\
\text { Health (F) } \\
\text { Intermediate Algebra (F, F) } \\
\text { Preparatory Reading II (D) }\end{array}$ \\
\hline
\end{tabular}




\section{Non-Persister Participant Profiles}

The researcher interviewed 4 of the 51 non-persisters (Aleida, Anna, J.R., and Sacha). Two students were members of the 2003-04 FYE cohort, one student participated in the 2004-05 cohort, and one student joined the 2006-07 group. The profiles for the non-persisters are presented in alphabetical order.

\section{Aleida "Life doesn't always turn out like you always expect”}

“Aleida” is a 21 year old former student. She is an only child and lives with her grandmother. Her parents emigrated from Cuba in the early 1980s; she was born in the United States. Her parents divorced when she was a junior in high school after which time she lived with her mother. Neither one of her parents graduated from high school or attended college. She is the first to graduate from high school and attend post secondary education. She chose to attend ABC because "[It] was right down the street from my mom's house. A lot of [high school] kids went to ABC. It was the next step.” Her major was radiography. She left school because she had a son in February 2006. She was part of the 2004-05 FYE group. She worked at a local supermarket as a cashier. Her goal was to return to school once her son begins pre-K; she described her intention to change her major to elementary education. She explained, “I did okay at ABC. I would have stayed in school if I didn’t get pregnant. I can still go to school when Alex [son] starts school.”

While enrolled at ABC, she maintained a 2.92 grade point average. She indicated, "I had like a 3.4, before that last semester I got like a .75 or something. I had to stop going because I was pregnant and sick all the time.” She provided the following advice to new students: “I learned that if you don’t care about your work no one else would. If you believe in yourself then teachers will help you reach that goal and help you anyway they 
can.” She added, "You gotta enjoy being a kid because when you grow up it’s about working, dealing with tough bosses, paying bills, buying diapers and stuff. I'm always on the go. It's constant.”

Anna "It's just me"

"Anna" is a 23 year old who participated in the 2003-04 FYE cohort. She dropped out because of math. Like many of her peers, she had attempted elementary and intermediate algebra multiple times. She exhausted her attempts at ABC and was required to take the math courses at another institution. Initially she pursued an associate in arts degree in pre-law; currently she reported that she intends to return to $\mathrm{ABC}$ to continue her education in criminal justice. She earned a 2.31 grade point average while at ABC.

Born in Jamaica, she and her parents moved to the United States when she was 10 years old. Although neither one of her parents attended college, one older sister attended ABC. Anna said she preferred structure and needed a prescriptive program of study. When asked what would have kept her in school, she answered, "If I was still in the FYE program and was told, here, go do these classes, that would be good.” She described her typical professors and her college experience this way:

I had some teachers that it was up to you if you come to class, and you would sit there. I won't say they won't teach you anything, but they will talk about everything but what's going on in the book. And, then you'd have to leave and learn all on your own and expect to know what's on the test. That's what I hate.

\section{J.R. "I failed myself when I didn't choose which dream I wanted to pursue"}

"J.R." is a 22 Haitian-American former student who had attended ABC

Community College from 2003-2004 for a total of five semesters. He maintained a 1.62 grade point average while he majored in business administration, and, at the time of the 
study, still owed \$185 in outstanding fees to the college. Highly religious, he described that he was the oldest of three boys. Both of his brothers were currently enrolled at ABC.

His parents emigrated from Haiti when he was a one year old child. His father was the general manager of a store associated with a national chain. After dropping out of ABC, J.R. moved out of the house at the age of 19. J.R. continually referred to his maturity; he was most proud of his independence and self-sufficiency. He worked fulltime as a pharmacy technician II at the same store his father managed. Recently, J.R. earned a real estate license and was studying to become a mortgage broker. He hoped to return to $\mathrm{ABC}$ to earn his $\mathrm{AA}$ degree; yet, at this time, his first priority was real estate. J.R. described an extremely close relationship with his father who, he claimed, is his motivation. He explained,

My main motivation to succeed was my father. When he first came from Haiti, he came with nothing. Now he's a manager. Anything my dad wanted, no matter how hard it was, how far the obstacle - if it had to do with his family, he was going to achieve that goal.

He joined FYE because his father indicated he needed the structure. J.R. shared that he doesn't work up to his potential unless he is interested. Despite his interest in business ventures and real estate, J.R. said that his first love was art. He noted, "I wanted to do computer animation, art design. I was a very good artist. My teachers felt I should pursue it, but I believe I was chasing a dream that I would never catch.” He left college because “I didn’t realize what I wanted. It’s something you have to want. Unless you want to be here, you'll never get anything from it. Until you're able to open your eyes and get around yourself, you won't succeed in life.” He gave the following advice to new students, 
No matter what your excuse is - no matter how you feel when you get up in the morning, take the time to look at yourself in the mirror. Realize your goals before you step foot in the classroom. Realize what you want to do. Don’t ever say the words, “I can’t do something.”

Sacha "Go to school because you want to go"

"Sacha" is a 19 year old Haitian-American former ABC Community College

student. Born in Massachusetts, she moved to live with her grandparents in Haiti during elementary school. She reported that she had one older sister and one younger brother and sister. Her grandmother was a doctor in Haiti and both of her parents attended college. Her father was an engineer. As the first among her siblings to attend college, Having completed all of her high school graduation requirements with the exception of the Florida Comprehensive Achievement Test (FCAT), Sacha was admitted to college under the "ability to benefit" policy. She attended ABC Community College for one semester and earned a 0.91 grade point average. In February, 2008, she passed the FCAT. Sacha planned to return to $\mathrm{ABC}$ to pursue a career in nursing. She worked at a store representing a major chain. She joined FYE because, as she said,

When I first came here, they told me that FYE was good, and I'm like, okay, it's good and it will help me out. So, I joined and it was actually wonderful. It was my first semester. I thought it was going to be scary. I thought it was going to be a repeat of high school, but it wasn't. It was way better. The teachers were open. The classmates were wonderful. I had no problem raising my hand to ask questions - to be helped.”

She left college because, as she described, "I had to go to another school to take English, reading, and math. It was a little bit too much for me, so that's why I took a little bit of time off to study for that.” Reflecting on her religious views, Sacha noted, "I always believed in God and Jesus because it’s helped me through a lot.” Sacha offered the following advice to new students, "Pass all your classes and never give up.” Sacha also 
emphasized the importance of choosing your friends. She said, "Do not follow the kids that do not want to be here - that all they come here for is partying or their parents wanted them to come. Go to school because you want to go.”

Summary of Number of Course Withdrawals and Failures for Non-Persisters As shown in Table 8, the non-persisters enrolled in a variety of courses that were difficult for them to pass. Inspection of the table indicates that the majority of nonpersisters had to repeat a variety of courses, including algebra, science, and English.

Table 8

Summary of Number of Course Withdrawals and Failures for Non-Persisters

\begin{tabular}{|c|c|c|c|c|}
\hline Name & $\begin{array}{l}\text { \# of } \\
\text { Semesters } \\
\text { at ABC }\end{array}$ & $\begin{array}{l}\text { \# of } \\
\text { Withdrawals }\end{array}$ & $\begin{array}{l}\text { \# of } \\
\text { Failures }\end{array}$ & $\begin{array}{l}\text { Courses (Grade) in which } \\
\text { Participants withdrew or } \\
\text { Earned a Grade less than "C" }\end{array}$ \\
\hline Aleida & 4 & 1 & 3 & $\begin{array}{l}\text { Anatomy I Lecture (W) } \\
\text { Anatomy I Lab (F) } \\
\text { Intermediate Algebra (D, D) }\end{array}$ \\
\hline Anna & 6 & 4 & 4 & $\begin{array}{l}\text { American History (W) } \\
\text { Environmental Science (W) } \\
\text { Geography (W) } \\
\text { Health (W) } \\
\text { Intro Computers (F) } \\
\text { Pre Algebra (F) } \\
\text { Intermediate Algebra (F, F) }\end{array}$ \\
\hline J.R. & 5 & 4 & 6 & $\begin{array}{l}\text { Accounting I (W) } \\
\text { Computer Applications (F) } \\
\text { Macro Economics (W, W) } \\
\text { Prep English II (D, W, F) } \\
\text { Pre Algebra (F) } \\
\text { Speech Communication (F) } \\
\text { State/Local Government (W) }\end{array}$ \\
\hline Sacha & 1 & 0 & 2 & $\begin{array}{l}\text { Preparatory English II (F) } \\
\text { Preparatory Reading II (F) }\end{array}$ \\
\hline
\end{tabular}


One of the non-persisters attended only one semester yet also had the lowest grade point average (0.91).

\section{Summary}

The researcher identified all students who participated in the FYE program. A total of 22 students participated in the study: six of the seven graduates; 12 of the 13 currently-enrolled students who had completed 30 or more credits; and 4 of the 51 students who had dropped out. Furthermore, $82 \%$ of the participants were either first generation in college or first generation in the United States or both.

The participants in the current study included seven Black Haitians, five Black Jamaicans, two Black Americans, two White Americans, one Black Bahamian, one Hispanic Guatemalan, one Hispanic Costa Rican/Italian, one Hispanic Puerto Rican/Dominican, one Hispanic Cuban and one Asian Indian. With the exception of one student, all students were single, in their 20s, and attended ABC directly out of high school.

The majority of the participants majored in education, business, or the health sciences. Although all graduated from an American high school, many expressed difficulty in passing $\mathrm{ABC}$ courses in mathematics, science, and writing. The narrative profiles of the participants emerged from the researcher's interpretation of interview transcripts integrated with archival data.

Table 9 displays representative excerpts of the individual participants by group. As shown in Table 9, the excerpted quotes from the individual profiles revealed a number of important aspects of the participants. The graduates and persisters seemed to 
emphasize what they can do to influence their achievement in college. The representative quotes for the non-persisters, in contrast, seemed to have a less optimistic perspective.

Table 9

Excerpts from the Individual Case Analysis of Participants in Three Groups

Graduates (6 of 7) Persisters (12 of 13) Non-Persisters (4 of 51)

\begin{tabular}{|c|c|c|}
\hline $\begin{array}{l}\text { Absum “Just keep } \\
\text { going, keep going” } \\
\text { Frieda "Education is } \\
\text { number one" } \\
\text { Janice "Do } \\
\text { something” } \\
\text { LeLe "Open to New } \\
\text { Experiences" } \\
\text { Nekee "Be proud of } \\
\text { me” } \\
\text { Sara "I want to be } \\
\text { successful” }\end{array}$ & $\begin{array}{l}\text { Addison "My father - he's a big } \\
\text { influence" } \\
\text { Andye "You gotta stick with } \\
\text { school" } \\
\text { Caridad "Your goals are } \\
\text { attainable" } \\
\text { Dora "Be prepared" } \\
\text { Joseph "You can't give up right } \\
\text { away" } \\
\text { Juanita "Don't regret what you do, } \\
\text { regret what you don't do" } \\
\text { Kyla-Rene "I know I can do } \\
\text { better" } \\
\text { Melissa "ABC - it's home" } \\
\text { Nettie "I'm not a quitter. I'm } \\
\text { proving to my mom I can do it" } \\
\text { Robert "My goal is to be the first } \\
\text { college graduate” } \\
\text { Star "I've come too far to give up" } \\
\text { Tridi "I enjoy being a student" }\end{array}$ & $\begin{array}{l}\text { Aleida "Life doesn't } \\
\text { always turn out like you } \\
\text { always expect" } \\
\text { Anna "It's just me" } \\
\text { J.R "I failed myself when I } \\
\text { didn't choose which dream } \\
\text { I wanted to pursue" } \\
\text { Sacha "Go to school } \\
\text { because you want to go" }\end{array}$ \\
\hline
\end{tabular}

In chapter 5, the researcher presents the themes as related to the research question. In chapter 6, the researcher summarizes the study, discusses the findings, provides recommendations for practitioners, and suggests implications for practice as well as areas for future research. 


\section{CHAPTER V}

\section{THEMES}

The purpose of this chapter is to present the themes derived from the cross case analysis and how the themes addressed the research question. The following question framed the study. How do underprepared community college students who participated in a learning community and completed their developmental classes, explain their experiences in having graduated (graduates) or earned at least 30 credit-bearing college credits (the persisters) as compared to those who participated in a learning community, but have dropped out of college (the non-persisters)?

Member Checks to Verify Profiles and Themes

To verify the accuracy of the profiles constructed from the interviews and archived data reported in chapter 4, the researcher contacted each participant via email. Each participant received a copy of the profile and was asked to review the profile to ensure that the participant agreed with the content. Twenty students accepted the profile as written; two students added details about their background, The researcher incorporated their information in their final profiles.

In addition, the thematic analysis was mailed to the participants for their feedback. All students were invited to the group interview. Six persisters and one nonpersister attended the group interview where ideas and overall themes were discussed and examined as to how they fit or did not fit within the participants' experiences. One of the participants had suggested the additional theme of “determination” for pre-college characteristics and "high school faculty" as a source of external support. Although some 
of the participants identified more strongly with some of the themes (for example, the women identified more with their mothers than the men), all agreed that the themes reflected their experiences.

The researcher reviewed verbatim transcripts of each participant's interview individually to identify recurring concepts and to code the transcript. Then the researcher reviewed all 22 transcripts to search for common concepts and codes across all interviews. Using the constant-comparative method and the information from the literature review, the researcher deductively identified four themes, organized as follows: (a) pre-college characteristics, (b) external college support/community influences, (c) social involvement, and (d) academic integration. As shown in Table 10, each theme also contains several sub-themes, which provides further detail in interpreting the experience. Table 10

Themes from the Cross Case Analysis

\begin{tabular}{|c|c|c|c|}
\hline $\begin{array}{l}\text { Pre-College Characteristics } \\
\text { and Traits }\end{array}$ & $\begin{array}{l}\text { External Support and } \\
\text { Community Influence }\end{array}$ & $\begin{array}{l}\text { Social } \\
\text { Involvement }\end{array}$ & $\begin{array}{l}\text { Academic } \\
\text { Integration }\end{array}$ \\
\hline $\begin{array}{l}\text { Sense of Responsibility } \\
\text { Goal Oriented } \\
\text { Resourcefulness } \\
\text { Determination } \\
\text { Cultural \& Racial Self- } \\
\text { identification } \\
\text { Faith }\end{array}$ & $\begin{array}{l}\text { Parents } \\
\text { Familial } \\
\text { Relationships } \\
\text { Peers } \\
\text { High School Teachers }\end{array}$ & $\begin{array}{l}\text { Student Life } \\
\text { Peer Interaction }\end{array}$ & $\begin{array}{l}\text { Time Manage- } \\
\text { ment } \\
\text { Faculty } \\
\text { Campus Re- } \\
\text { sources }\end{array}$ \\
\hline
\end{tabular}

Although the themes were not pre-selected from the literature review, the terminology chosen (i.e., Pre-College Characteristics, Social Involvement, and Academic Integration) 
aligned with previous research studies. In the following sections, each theme is described with supporting verbatim quotes from the participants to explain the theme.

\section{Theme 1: Pre College Characteristics and Traits}

The pre-college characteristics and traits theme was used to describe those attributes students bring to college - internal factors. It included six sub-themes of (a) sense of responsibility, (b) goal oriented, (c) resourcefulness, (d) determination, (e) cultural and racial self-identification, and (f) faith. The graduates and persisters shared internal characteristics that they believed may have contributed to educational achievement.

Sense of Responsibility

The first sub-theme in the pre-college characteristics and traits theme is a sense of responsibility. Several of the graduates talked about "knowing what needs to be done" and “following through.” LeLe and Sara emphasized the expectations from their families that they would be responsible. For example, from a young age, LeLe felt responsible. She explained,

I've always had that in me. Even as a child. My mother had my little sister when I was six years old, and I thought that was just the greatest thing because I learned to help take care of a baby and everything. I've always done has been around children. Some of my first jobs were babysitting.

Similar to LeLe, Sara shared, "From the time I was nine, I was taking care of my brothers, so I'm very responsible. I would take care of them, especially at 9 years old. From then I'm very responsible"

The persisters, too, described a sense of duty and responsibility. Addison, Robert, Dora, Nettie, Juanita, Andye, Star, and Caridad articulated how this sense of duty and 
responsibility affected their success. Having recently immigrated to the United States,

Robert indicated,

College is important cause out there is not easy. You have to try everything you can and college can teach you all that. I am the first one in my family to go to college and I don't want to mess that up. My parents would be more than happy to see me graduate and continue my education.”

Despite her young age, Dora also felt a sense of duty. She emphasized,

I see what [my family] has been through - coming to the United States and learning another language and culture. They want it better for me and my brother. They make all kinds of sacrifices. My father works two jobs. I have to do my part. As they say, my job is school now. Plus, I have to be an example for my brother. It's expected.

As the oldest former FYE student, Andye noted,

I have a family, so I make provisions for schoolwork during the night time. I sacrifice some sleep." She added, "I'm in school because when I see my boys with such potential and they want to go to UF, I realize I have to do something in order to get myself in a position to help them financially.

Star not only reported a clear sense of responsibility, but a patriotic duty to her country.

She explained,

I feel like I would be a great asset to my country - to give back and to be able to succeed and make the industry number one. Even though there are times I want to stop this, I look back and say my job is college. I want to be able to go back home and give back and help the Bahamian people.

The non-persisters (Aleida, J.R., Sacha, and Anna) did not seem to express the same sense of duty or responsibility to attend college. For example, Aleida referred to her priorities in raising her son while J.R. noted, I didn’t have to choose my classes. They were pre-set for me, which was a terrific thing. From my father's aspect, I didn’t have to do much.” He added, “I never gave my 100\%. I never really had to study.” 


\section{Goal-Oriented}

The second sub-theme in the pre-college characteristics and traits is goal-oriented. Graduates shared the importance of having a plan and explained their goals to gain an education to prepare for a specific career. For example, Absum wanted a civil engineering degree; LeLe wanted to become a teacher and Janice wanted to become a physical therapist. In contrast, Frieda wanted to provide for her future family. Sara spoke of her goals: "My mom owns a cleaning business. I want to take that over, but I also want to open up a franchise.” She added, “I just want to be successful. I want to be able to...seeing what my parents went through...they weren’t really able to either afford it... when I have kids, I want to give them things that they need.”

Similarly, the persisters had concrete goals and objectives. They too realized that a college education would lead to more opportunities. Melissa justified her goals this way: "Pretty much nowadays you hafta have an education no matter what you're doing." Joseph elaborated about his plans:

I have a plan and know where I want to go. Ever since I was a kid I was interested in the phenomenon of weather. Like when I was five years old, I lived through Hurricane Andrew and I asked, 'What is that?' And the first time I saw a tornado in a movie, I was, like, whoa, I need to study this. And I've been interested since I was a kid.

Caridad was clear about her goals: "A year from now, I want to write for the newspaper or magazine.” She explained,

I want a better life for my mom. 'Cause my mom raised three kids on her own and she worked three jobs. I want something better for me. I don't want the same thing. I want have a husband and children, you know, I want have my career first. I also want to supply my mom with some happiness while she's still alive. I want to give her a house and to buy her a car and I can't do that if I'm getting paid 9 or 10 dollars an hour. I have to be getting paid top notch.” 
The non-persisters seemed to express unclear, less specific goals even though they had declared majors. Aleida and J.R. were unclear about their goals. Similarly, Anna stated, “When I was younger, I wanted to be a lawyer, but right now, I don’t know. I thought about going towards correctional officer. It seems interesting. I chose it from T.V. - not a good way to pick a career.”

\section{Resourcefulness}

The third sub-theme in the pre-college characteristics and traits theme is resourcefulness. Despite encountering challenges, many of the participants petitioned committees or found support from various resources. Frieda and Janice transferred without earning an AA degree. Frieda petitioned the academic standards committee at the university for admission. Janice transferred to another college and graduated with an Associate in Science in Physical Therapy Assistant to avoid completing college level math at ABC. She noted,

I just figured I was getting tired after awhile and there was one particular class I couldn't pass and I was getting frustrated (laughter) and I feel like I'm going to be stuck, you know. I needed a change after two years. I just felt like I'm going to be continuing, you know, taking classes and classes. I just felt like I wasn't going to get anywhere, really.

LeLe found financial and academic support from an unexpected connection:

When I first started [at $A B C$ ], one of the students in the FYE program played for the basketball team [who told me], oh, the coach for the basketball team is looking for a babysitter to babysit her son. It's only going to be for like an hour, and since you're out here anyway, you might as well talk to her...I was able to see more and understand more [about $\mathrm{ABC}$...like, that's the science building, that's the English building...was able to see much more by working for her...there was just so many things that I was able to experience...I've gotten two computers from ABC. 
Several of the persisters expressed their resourcefulness as well; they found venues in which to accomplish their goals (Joseph, Robert, Star, Nettie, Tridi, and Caridad). Tridi suggested, "If you need any kind of help, you can always find someone to help you. Any questions answered, you can always find it.” Several persisters referred to being resourceful in getting help, such as, Joseph who noted,

When I couldn't pass the reading portion of the Florida Comprehensive Achievement Test (FCAT), I got help. I found out about this Saturday program at another high school. So, for nine straight Saturdays, I got tutored. It wasn’t the best way to spend my Saturdays, but I had to do it.

Others referred to the demands of acquiring English as a new language (e.g., Nettie and Robert). For example, describing when she first moved to the United States in ninth grade, Nettie explained,

Learning English was hard, especially the first week when you have no idea what they're saying, but if you want to be successful...so, like my first three years when I got here, I have to be in the library a lot. That was my home - the library, downtown.

In comparison to the graduates and persisters, the non-persisters did not seem to be resourceful in finding inventive ways to continue their college programs. None of the non-persisters mentioned that they used specific resources or strategies to accomplish their goals and instead depended on others for assistance and direction. For example, J.R. was dependent on his father. He expressed,

I got tired of everybody else doing something for me. It was kinda like being a grown baby. I didn't have enough gas in the car, so, [my father] would put gas in my car...before, I would never go to my checkbook to see how much money I had. I would keep swiping, swiping my card thinking that it was infinite and that's because no matter what happened, if I ran out of money, I had a safety net, a parachute. [My dad] got me my first job which I still have as a pharmacy technician. He was the manager at the time. 


\section{Determination}

The fourth sub-theme in the pre-college characteristics and traits theme is persistence/determination. Sara said, “I’ve been through trials and tribulations throughout my college experience, I knew what I wanted and I was striving for that.” Despite several challenges, graduates and persisters stayed in school (Frieda, Sara, and Janice). In talking about grades, Absum indicated,

Getting a bad grade doesn't disappoint me. It just makes me work a littler harder. I know that I can do better and I guess, I'm more disappointed in myself. When I do good, it just makes me feel like I accomplished something. Makes me feel like I should keep going.

His favorite motivational quote is "I tell myself that everyday is a new day. Whatever you did yesterday, it doesn’t matter, just keep going. Keep going.”

Frieda described her challenges:

I'm a very resilient person. This past semester at ABC, was my hardest semester - the last one - and I had so many obstacles, but I kept telling myself, I'm determined to further my college career. I did it and I felt like I'm never supposed to give up on anything. I was taking two math courses. I was taking college algebra and statistics at the same time. It was just so many different things going on in the beginning of the semester. My fiancée got into a car accident and that was stressful and I got into a minor car accident. I don't let other obstacles discourage me. It just pushed me to keep working hard. I couldn't see myself not in school.

Consistent with the graduates, determination was a common sub-theme among the persisters (Tridi, Addison, Dora, Joseph, Andye, and Nettie). As Dora said, "I was taught not to give up easy.” Addison noted,

Determination. That pretty much sums it up. I always try to keep myself motivated because otherwise I fail. My father drilled in me - always maintain your focus and your drive. 'Cause if you ever lose it, you'll probably not be anything. 
Similarly, Joseph explained,

If you don't succeed, try, try again. You can't give up right away. Sometimes it takes people the second or third try to get it. There was this one time in high school, I couldn't pass the FCAT and I said to myself, "I'm finished, I'm finished." And then, it wasn't the math FCAT I couldn't pass. It was the reading FCAT. I'm not very good at reading. So, the last time I took FCAT, I got a 301 on the reading portion. I just passed it by the skin of my teeth. And I was like, whoo hoo! That's what motivated me to go on. I was like, I know I can do this if I just put my mind to it. I had to repeat the math FCAT twice and the reading three times. I just said to myself, "I can do this - pass the math first and then pass the reading. Strength and then weakness.

Unlike other participants, Nettie lost her mother at a young age. She explained the impact of that loss this way, "My mom died when I was 12. Before she died, she told me to make sure I am something. She wanted the best for me.” She added, "I just want to continue until I finish.” Interestingly, despite limited chances for success, she persisted. Nettie maintained a 2.03 grade point average and, as a pre-medicine major, had difficulty in biology and chemistry, yet she emphasized, "Quitting is never an option for me, so I don’t see myself as a quitter or dropping out of school. This is something I want to do. No matter what, I will stick with it.” Similarly, despite her low grade point average, Kyla-Renee claimed,

I never think about giving up. Just being able to see that some people can't do it and to know that I have all the opportunities in the world to do things like go to school, you know, stuff like that, just knowing that I'm able to do it that I can do it. I'm still here because I want to take it all the way to the end. I want to finish. I don't want to start, go through all this and all I have to show in life is my high school diploma. I want to show I can do more.

In comparison to the graduates and persisters, the non-persisters did not seem to be determined to finish their college programs. Obstacles and other life events seemed to stop them from completing their college education (Anna and Aleida). For example, 
Anna noted, “I stopped again because of math. I just couldn’t do it.” J.R. explained, “My favorite saying is from the Lion King - Hakuna Matata - no worries.”

\section{Cultural and Racial Self-Identification}

The fifth sub-theme in the pre-college characteristics and traits theme is cultural and racial self-identification. Eighteen of the 22 participants were either born in another country (e.g., Bahamas, Haiti, India, Jamaica) or were first generation in the United States. Their perceptions revealed how their respective cultural heritages influenced their views about the importance of an education and the concept of hard work leading to success. The cultural heritages of the graduates included Asian, Haitian, Jamaican, and African-American. For example, Absum, who emigrated from India, explained,

I think the Indian culture, they're more toward education. Basically, my dad says when you're in school, you do what you're supposed to do. You study hard and you don't mess around and you live life later on.

Similarly, Frieda referred to her Haitian heritage when she stated,

Actually in the Haitian culture, school is number one. I can't speak for other nationalities or cultures, but I feel like in the Haitian culture, education is a very important factor. If you don't have an education, what do you have?

Janice described her Jamaican culture: "When I was nine years old, I moved from Jamaica. Being the fact that I'm not a born American, you have something even more to work for - my family, my mother. We're here to do something for ourselves.”

Cultural and racial self-identification was a consistent sub-theme among the persisters as well. The majority of the persisters mentioned some aspect of their race, ethnicity, or familial cultures: Black (Addison, Tridi, Andye, Kyla-Renee, Robert, Star, and Tridi), Hispanic (Caridad, Dora, Juanita). 
Perhaps Dora's words best capture the ideas about the importance of their respective heritages and cultures. She explained,

I've been very lucky to have parents who are immigrants. This is how this country was founded. I think immigrants come to this country for a better life. Why else would they come and have to start all over by learning a new language, customs and stuff? So, education is important. Most kids who have parents from other countries expect a lot of them. So, I think that since my parents were born outside of the United States, that influenced me more than being Hispanic or a girl.

Similarly, Kyla-Renee referred to the Jamaican culture when she said, "I think they're more strict on education...like, you have to go to school, even if no one else went to college. You need to go to college. You need to do this. You need to have an education.”

The non-persisters did not indicate that their race, culture, or gender had an influence on their education. For example, Anna, of Jamaican descent, claimed, “I’ve seen no issue with it...I think we're pretty equal.” J.R., whose parents emigrated from Haiti, asserted, “I wouldn’t say my race had anything to do with [my education]. Aleida noted, “I don’t think race or gender affects school. In high school, everybody was Hispanic, Black or something. Nobody cares about that.”

Faith

The sixth sub-theme in the pre-college characteristics and traits theme is faith. Although not consistently mentioned among all participants, nine spoke of their religious convictions and quoted the Bible (four graduates, seven persisters, and two nonpersisters). For example, when faced with challenges, Nekee referred to the verse, "I can do all things through Christ who strengthens me,” Similarly, Sara stated, "I have a strong faith in Jesus Christ and whenever I feel like giving up... I have to pray, even if I don’t feel like it. I pray and that gives me motivation and I think I can do anything.” 
Faith was also mentioned among the persisters (Addison, Dora, Kyla-Renee, Tridi, Star, and Robert). Speaking of her motivation, Tridi affirmed, "I would say God is my motivation, because I have a very strong religious background so, God is the biggest helper I could possibly get.” When asked to show something in her purse or backpack that represented her, Dora shared,

My Bible, because my pastor once told the youth group that we should never go anywhere without our Bible. It represents my faith and being a Christian. My belief in Christ is important to me. It's who I am. I believe that no matter what, God has a plan for each of us and we should not be discouraged.

Star said,

Definitely, God is important, because I feel that if I don't have God on my side, I don't think I'd be able to make it this far. I put him first and then so much things I've been through (pause) I have to continue to pray and God will be with me.

Similar to the graduates and persisters, some of the non-persisters expressed a strong faith (Sacha and J.R.). J.R. pointed out,

My faith has always been there. I got saved at a young age, like 12. My faith has always been there no matter what obstacles I face. If I want something, I'll pray about it first. If I'm meant to receive it, I will receive.

Theme 2: External College Support/Community Influences

Participants attributed their success to supportive families who include parents, (mothers were named more often than fathers), siblings, grandparents, cousins, and fiancées. In addition, friends developed in K-12, as well as high school teachers had an influence on decision to attend and persist in college.

Parents 
The first sub-theme in the external college support/community influences theme is parents. Because the majority of the students are relatively young and straight out of high school, their parents may have had a stronger influence than if the students were older. Although many of the parents had no or little post secondary education, they tried to help them with school work. Mothers were more frequently mentioned than fathers, although all the men mentioned their relationships with their fathers or stepfathers. Several parents of the participants directed them to join FYE. For example, Absum noted,

They kept pushing me that I need to graduate and I need to get my degree, so I guess that helped me a lot. Coming from India, education is stressed in my family. Both my parents went to college. First of all they didn't want me to work. They wanted me to go to school, finish school and they were willing to pay for my degree, but I wanted to work and go to school at the same time. So, I started part-time, working 20 hours, but then I thought I can handle it so I worked full-time and went to school full-time. I think my family - they had a great impact on me. They never let me quit. They kept pushing me.

As an only child, Frieda described her family's influence:

Well, my mom, she influences me the most because she's like, really, she's the type of person that wants me to do very well with school - like, school's number one. And, umm, my father, as well. He always pushes me. My stepdad's there whenever I need to talk to him about anything that has to do with school. Yeah, they influenced me a lot.

In addition, her mother is a role model who attended college and graduated to work as a register nurse. Freida explained,

She reminds me that, you know, at the end, it's going to be all worth it 'cause I do want to be a psychologist and I know it takes a lot of schooling, but I know it's gonna be worth it. My mom is always pushing me hard and says, "Study, study, study."

The persisters mentioned their parents as well. Tridi spoke of her mother saying, 
My mother, she told me that she'll work three or four jobs just to get me through school 'cause she doesn't want me to end up like her. She wants me to have the best future I can possibly have.

When wanting to quit, she remembered how her mother supported her:

It was the first year I was attending ABC, but during the summer I failed 2 classes and I was like really discouraged...I think I'm going to take a semester off and just get my life straight. I think I didn't have the intention of coming back but my mom [said], “Oh, no, you can’t quit right now. You just started school. It will be shorter than you think.” She was telling me that there was no reason for me to quit. That she'll help me or get one of my cousins to help me.

Family is very important for Dora. Being first generation born in the United

States, she explained,

College was expected in my family. My parents don’t speak English extremely well and they only expect A's from me and my brother. I think they think a "B" means "bad" (light chuckle). When I was in high school, my mother used to help me study for advanced vocabulary and my science classes. She would sit with me at the dining room table and quiz me at night. She had no idea about what I was studying and couldn't pronounce the words, but she helped me. My father definitely wanted me to go to college. He works two jobs to help pay for school and they don't want me to work during the school year. I work at [city] Parks and Recreation during the summer. School is important. Neither one graduated from high school. They want me and my brother to have what they didn't have more opportunities...my dad used to drive me on his way to work and then my mom would pick me up in the afternoon. This Christmas, my parents bought me a car. They see I need one when I go to [state university].

Juanita agreed that her parents were important to her success:

Yeah, [my parents] are glad. They love it. They're so happy because I'm the first one. They're like, you have to show an example to your sister and brother. If we couldn't do it, you can do it. So, I'm doing it because I want to and because of my sister and my brother and my parents. They help me with everything for school, they're willing to do anything and everything so I can just stay in school and study. They pay. They pay for everything and to get around. That's the whole reason why I got my car. 'cause they're like, you're almost done. You're doing it! I see it. I'm proud. So, they got me a car. 
Several of the participants indicated they wanted to take care of their parents,

particularly their mothers as they become older. Tridi expressed,

My mother, she's a hard-working woman. She works two jobs just to take care of us, so, I would love to graduate from college with at least my masters, so, I could end up to take care of her, so she can stop working so hard.

Jillian added,

I really had something to go on, which I said is my mom. Some people don't have that and they're like, whatever, I just gave up. I can't say that. Giving up is not an option. It's in me. It's a choice to make a difference in my life, so, if I want to do something big. I always tell my mom, "Mom, I going to buy you a mansion. I'm going to buy you a Ferrari.”

In memory of her mother, Nettie emphasized, “[My mom] always tell me to succeed in life. You need an education. This is something I need to do. I like to show her I can do it.”

The non-persisters talked about their mothers and fathers as well. In some cases, the non-persisters had made decisions counter to what their parents wanted, for example, by dropping out of college. Similar to the graduates and persisters, the non-persisters' parents supported the pursuit of higher education. For example, Anna explained, My mother, she's always constantly on me. Like, if I'm not in school, she asks, when am I signing back up? What's going on and what not. If I'm not in school, she'd like ignore me 'cause this is where she thinks I should be. I don't think she likes her job that much and she expects me to do better.

Sacha said, "College is a big thing in my family. Actually my dad pushed me to go to college. He just wants me to go to school.” 
J.R. noted, "I wanted to do computer animation, art design. My father told me to think about doing business - getting my AA in business and since he was very successful and being a manager ...so it kinda derailed me.”

\section{Familial Relationship}

The second sub-theme in the community influences theme is familial relationships to include siblings, a spouse, cousins, and other family members. Beyond the parents, the extended family emerged as an important influence.

When asked about quitting school, Nekee stated, “I don’t remember a time when I almost quit. I'll say maybe when like I failed a couple of my classes, I may have thought about quitting and then I thought about my family and I didn’t want to do it.” She described her younger brother who is attending [a state university]:

Yeah, he's very smart. Like, he's smarter than all of us. He gets good grades and all these scholarships and stuff. He's always motivated me, and he's the younger one. He's always motivating me...oh, you need to take this class, you need to pass this class. Even though he's the younger one, he always trying to motivate me to do better.

Although there are six siblings, LeLe primarily described her relationship with her

older brother who told her, “If you don’t start now, you'll never start.” LeLe continued:

So, he was kinda the one that pushed me to start school and I was really grateful for that. My brother is one of those people that motivates me the most. There were times when my financial aid didn't give me as much money as I thought it would and I would call him and he would say, “That's fine, don't worry about it. I'll pay for your books.” If I needed anything for school, if it was clothes or shoes or book bags, he'd get it no matter what.

Sara described her relationship with her grandfather:

My grandfather, he passed away last year. He was someone very close to me. He used to always tell me, if you can't do it, if you try your hardest, than at least you know you tried. Even if you didn't succeed at it, at least 
trying it sometimes is better than succeeding. That's something I'll always remember.

Many of the persisters spoke of siblings and other family members as well.

Speaking of her extended family, Tridi claimed,

They definitely do - always pushing me. They don't want me to fail. They don't want me to suffer, so they're always pushing me and encouraging me. Sometimes I do need it because I get discouraged and tired, so they're like, oh, you'll be okay. You'll survive. It's not that bad. It's not that hard. I'll help you. So, that helps me look forward to succeeding and doing well. I have cousins who are teachers and I have some who work in the business field so, whenever I need help like answering questions or homework, especially when it came to math, they'll always be there to help me and, you know, show me examples to help me out.

Andye cited the support from her sons: "My boys help me. They’re doing a portion of work. If they see me reading the newspaper they say, 'Did you finish your homework?' They encourage me.” Kyla-Renee shared the importance of her extended family:

Whenever I talk about the nursing program, they're always telling me that nursing is a good field, you know, stuff like that. They're like, make sure you stay, do it, even though it's hard, don't give up. Just try. They're a good motivation.

Caridad described how her sisters help her:

My sister actually helps me study (light laughter). She can't say half the words on my study guide. She'll help me study and she'll be like, no, you got this wrong, no, you got that wrong. My oldest one is always asking me, "How's school? What are you learning?” They always check in.

Three of the four non-persisters did not provide examples of how their extended families supported their educational endeavors. Although brothers and sisters were mentioned, some of the participants were unaware of their siblings' educational achievement and enrollment in college. For example, Anna described her family: "I have an older sister who attended ABC. She's 30 now. I believe she graduated.” When asked if 
her sister had an influence on her education, Anna responded, "No, I did it on my own." Similarly uninformed about his siblings, J.R. said, "I am the oldest of all my brothers. Two attend ABC - one, I believe, [at one campus] and one, I believe, [at another campus].” Aleida indicated, “I don’t have a large family. I have some cousins down in Miami, but I don’t know them too much. After [Hurricane] Andrew, my parents moved. They live their life, I live mine.”

\section{Friends}

The third sub-theme in the community influences theme is friends. Participants indicated positive peer influences to enroll and continue in college. Overwhelmingly, all the participants described relationships with peers that were developed in elementary, middle and high school. Tierney (1992) critiqued Tinto's theory that the concept of integration suggests abandoning the old culture which would be to abandon the underprepared student’s support network. Although Tinto uses Van Gennep’s “rites of passage" idea, in which an individual moves from childhood to adulthood or transitioning from one developmental stage to another, these rites of passage occurred within a specific culture, not between cultures as the transition from high school to college. For many underprepared students in this study, stepping foot on a college campus was experienced as a disruptive cultural experience not because college is a rite of passage but because it is culturally distinct from their native cultures. Starting anew was not acceptable; thus, many participants reported that they had kept their former friends. To describe their friendships, participants cited such attributes as being supportive and encouraging as well as sharing common interests (e.g., attending college) and being from the "right crowd." For example, Frieda shared, "Overall, my friends have a lot in common, we all have the 
same goals, we all want to be successful, we all are in school; we all complement each

other.” Janice spoke about her friend this way:

I was always kinda [sic] with the right crowd (laughter). With [my friend] being at a university, she kinda encouraged me to like, stay in school and she would... with her problems and some of her classes, you know, she would call me and either complain or whatever. And I would talk with her and then vice-versa when I had a problem, I'd call her.

Friends were important to the persisters. Tridi observed,

All my close friends are all in college, they're all working. We're all active in school.We have a lot of things in common. Some of them I met through classes. Some of them I met in clubs I participate in and we end up finding a common bond. We go out sometimes in and out of school...we participate in the same activities, take the some of same classes. Mostly, we're friends because we have a lot of common bonds and interests. Sometimes I might be lazy and not want to do homework or postpone other projects, and they're like, "Hah, we gotta get this out of the way." Sometimes they encourage me to do what I'm supposed to do. They're like, “Don’t!” Stop slipping!” "You need to go to class!”

Describing his friend who now attends a state university, Joseph emphasized, “We’ve been close friends ever since the ninth grade and he's up at [state university] right now and that's where I plan to go. He promotes me to do well and I promote him to do well.”

When talking about her friend "P”, Juanita remarked, “Now that we're in school together, we help each other out a lot. I think it's better. 'Cause now we talk about school, same class, same everything.” Kyla-Renee said, “The ones that are in college, it’s nice to talk to them to see what it's like, what they're doing. It's a support.” Similarly, Star expressed,

I have two best friends in the Bahamas. I would definitely say they affected me in a positive way because I always have friends who would never steer me in the wrong direction, although they didn't have the opportunity to study, go to college... if I tell them, I'm talking on the phone and I have a test tomorrow, we can't go out, they'd be like fine, that's more important. 
The non-persisters mentioned friends as a support as well. They referred to many friends who were enrolled in college and who served as role-models. For example, Anna, who was considering returning to school, explained,

I have one close friend. She's at ABC. Basically, she's the one who keeps telling me to come back. She's like, what are you doing? You're 23! You need to get back. She'll tell me, like, make sure that I sit down and look over my credits and how much credits I need to be full-time. She'll assist me with filling out my financial aid.

Sacha noted,

I have two friends, C and A. They're someone I like to hang out with. C, she goes to ABC. She's always pushing me to come back. She tells me not to give up. When I come back to school, she'll help me. She'll give me her old notes for me, her books. Because she's always helping me to be, like, strong. She's a really, really good friend.

\section{High School Teachers}

The fourth sub-theme in the community influences theme found particularly among the persisters is high school teachers. Since the majority of the participants had recently graduated from high school and were first generation in college students who did not possess the cultural capital from family or friends who could suggest which post secondary institution to attend or help them navigate the college application process, participants often indicated high school faculty or guidance counselors who had had an influence. For example, Tridi elaborated,

I was in the academy of finance and DECA [Delta Epsilon Chi Marketing Club] in high school and I remember talking to one of my teachers and he was like, it's better if you go to ABC cause the classes are small and it's not really expensive - better than going to a university where the classes are large and you don't get that much interaction with the teachers and all of these other positive things he was telling me, so I said, "Let me go for it because the university will always be there." It's better that I go here. It will be a better transition from high school to college. 


\section{Robert concurred,}

When I was in high school, from what I heard from my teachers, my counselors, ABC would be, like, a good place to start. One of my counselors transferred to [local university] when she was attending ABC and I wanted to follow in her footsteps.

One of the non-persisters mentioned a high school teacher who influenced him.

J.R. explained,

I had a free ride at the [private art school]. I was a very promising student. I got a recommendation from my high school art teacher....my best experience was getting an award in art. One of the teachers in high school entered one of my artwork in a contest and I got first place...I didn't know...she did it behind my back. When I won, I was pretty happy.

Theme 3: Social Involvement

Social involvement is related to students who are involved on campus in different clubs and organizations and their interaction with other students. Much of the literature indicated that involvement outside the classroom contributes positively to student success. In regarding to his findings from a study of more than 20,000 students, 25,000 faculty members and 200 institutions, Astin (1993) underscored

...the tremendous potential that student involvement has for enhancing most aspects of the undergraduate student's cognitive and affective development. Learning, academic performance, and retention are positively associated with academic involvement, involvement with faculty, and involvement with student peer groups. (p. 394)

It was then expected that participants expressed many of these benefits when sharing their own experiences; yet this is untested among underprepared ethnically diverse college populations. 


\section{Student Life Activities and Peer Interaction}

Graduates discussed student activities, clubs and organizations which seem to give their college experience purpose and to develop a peer network. In talking about student clubs, Nekee pointed out, "Yeah, the dance team, student ambassadors, part of everything. I joined like every club. Student Life made, umm, me very comfortable because before when I first started here, I wasn't comfortable at all.” Janice echoed the same sentiment saying,

What made me feel comfortable was the friendships that I made, with not only with the students in my class, but with other people, like in Student Life. Like, they were also a big support, like, you know, I just felt like they were a second family. And I felt really good, you know, coming. I felt comfortable.

Campus involvement was mentioned by the persisters. Having participated in several student organizations, Melissa claimed,

Definitely being involved on campus made a difference. I think that's one of the main reasons that I'm finishing up now...that probably had the biggest role to do with anything - being active and constantly being here...the out-of-classroom stuff, I think helps the most with the inside-the-classroom.

Similar to Melissa's experiences, Andye was highly involved with the campus ambassadors program. She noted,

Thank goodness for the [campus ambassadors]. It's an experience. I'm happy that I did not go through school without them. Being with them was the first time that I didn't think about home, work, or school. The focus was on me and I think I needed that.

Some of the persisters spoke about their interactions with peers. Tridi

remembered students from the FYE program: "Whenever I needed someone to talk to or needed help or any questions, I always found someone to talk to.” Furthermore, she described relationships she made with older students in class: 
When I started attending ABC, I met a lot of older adults who were probably in their 30's and 40's who I met through classes. If we do study together or meet up for a project, they end up telling us about their experiences about how they left college and had to struggle for them to come back to college, especially if they have a family, and how they have to work hard for their family and go to school. It was kinda good to hear from an older generation who's been through it and try to help the younger generation out by warning us in advance so we don't fall in the same cracks they did.

In referring to the FYE program and her peers, Andye explained,

I like the fact that they monitored you throughout in case you're failing or having problems, you had someone to go to. You didn't feel like a stranger. Like so many students, I see them (pause) classes are over, they just head straight to their car and that's it. FYE tries to get you involved in a lot of stuff and bring it together. Plus, you have classes with students you see all the time. You create a bond or exchange numbers and call them and get... well, I never miss (light chuckle) I try not to miss a day, but if someone is missing, I'll call them and say, "What happened? You missed so and so.”

Juanita agreed, “I know if I was taking speech without those people, I wouldn’t do it. I couldn't. But since I knew them for that whole year, I was the first one up there. Can I go? I want to present first.”

Only one of the four non-persisters reported involvement with campus activities (J.R.). The other non-persisters were not involved or were likely to attribute their lack of involvement to lack of time. Anna said, “No, I really didn’t have a lot of time. I had to work.” Aleida and Sacha agreed.

On the other hand, the non-persisters mentioned the value of the FYE program, even if it did not keep them in college. Anna noted, "When I was in FYE, my grades were a lot better then. I'm guessing because you had that community. You knew everyone in your class, so, it was easy to find someone to study with.” Aleida explained, "I got lots of help. Having small classes, we knew each other in the group. We were able 
to bond with each other. If I missed a day of school, I could call a classmate for the work.”

Theme 4: Academic Integration

Academic integration refers to the students' inclusion in the campus academic culture and their interface with academia. Underprepared students who may have had limited academic success in the past gained an understanding and developed skills essential for success. This often included the development of positive interactions with faculty, recognition of college expectations, and effective study habits. There were four sub-themes (a) faculty, (b) campus resources, (c) time management, and (d) self-reliance/ independence.

Faculty

The first sub-theme in the academic integration theme is faculty. Each graduate and persister identified at least one faculty member who had a great impact. Further, participants discussed beneficial characteristics of faculty such as engaging, being passionate about their discipline, being helpful, and caring. This theme was consistent with the findings of Strong (2008), who noted that students who had access to and frequent interactions with their professors, had more positive experiences and higher motivation to stay in college. Ashar and Skenes (1993) found that classes that are smaller, more homogeneous, and thus socially integrated, with supportive faculty who have a positive attitude, lost fewer students. In comparing faculty at the university to faculty at the community college, Absum said, “ABC classes are smaller than those at [state university], they're large. ABC teachers do care about students. They know you personally.” Nekee also compared the university faculty to the community college 
faculty: "The [university] professors, they are always trying to remind you - oh, this is not $\mathrm{ABC}$. This is, you know, the university. Teachers at $\mathrm{ABC}$ - they kinda care about you more"

The persisters reported they had positive faculty experiences. Robert explained that his favorite class was Student Life Skills (SLS) because "we got to interact with each other a lot.” He elaborated,

The $[\mathrm{ABC}]$ teachers are very understandable and patient. Basically, they just, when you go to class, the teachers normally take their time and if you have questions, they would try and answer. If they can't answer the question at the time, they will go to their office and for the next class, they will give you the answer...the teacher made you feel like you were at home.

Nettie agreed, “The professors helped me. If I'm failing a class, they would call me and ask, 'What's going on?' Everybody on the staff was pushing me, to tell you the truth.” She added,

I didn't like math at all, and once I was taking algebra, they have an after-class program where you go to a student that helps you with math to answer any questions and stuff. That actually motivated me. She can do it, why not me?

In reference to the faculty and staff, Kyla-Renee emphasized, "I like that they were really into our stuff. It was nice. It was like everybody was interested and I felt like everyone cared.”

The non-persisters reported varying experiences with their faculty. J.R. noted, "The teachers that we had were pretty good. They cared about the students. It's not a great, great big school, so you get to know your teachers.” However, Anna shared,

I've had teachers that are - let's say too strict, like the math teacher I had. For instance, if you had a question, she would ask you, "Sure, what's your question?" You'd raise your hand and [she would say], "I won't answer that because that's something you should have learned in 0012, and I'm 
like, some of us did not take that class, or we're not in here for a while. So, that's kinda discouraging for me, asking questions.

\section{Campus Resources}

The second sub-theme in the academic integration theme is campus resources. Graduates and persisters identified several campus resources or departments that contributed toward their success to include math lab, tutors and advisors, the FYE program, and Student Life Skills class. These participants agreed that the FYE program provided consistency, peer support, and structure. Furthermore, particularly for the introverted participants, it seemed that the FYE facilitated their integration into the academic community and helped to foster social involvement as well. For example, Nekee (a graduate) discussed the FYE program and how it helped her. She said,

Because we had the same people in the class, so it's like, you worked together more and you helped each out, 'cause now I'm still friends with people in FYE. So, it helps you because you actually work together. You don't go to the next class and see other, different people and, you know, when you're in college, if you see different people, they're not going to really talk to you and help you out. If you go to class and see the same people, you gonna bond and build, you know, friendships and relationships, or whatever, and then you'll work together.

Another graduate, LeLe, echoed these sentiments: "FYE helped me in becoming more driven, more outspoken. It was - it became more comfortable. I was able to meet new people who I wouldn't have met otherwise. I was able to make more friends. I was able to do more things in the college.” Sara, a graduate, added, “I went to the math lab and I spoke to some of the tutors in there that would help with a problem. They really helped me.”

Persisters expressed appreciation for the FYE experience and explained how they used many of the campus resources because of exposure during FYE. Tridi remembered, 
[FYE] helped me to understand why I'm in school. They informed me about all the activities and programs that are taking place, because honestly, if I wasn't in FYE, I wouldn't even know they existed. And they told me about all the career paths and educational scholarships, volunteering - things that I didn't know ABC was involved with.

Nettie concurred. Despite limited external support, she said, “If it wasn’t for FYE, I wouldn't know what classes to take or about college. I found out everything that's here for me. It was especially helpful.”

Dora noted, “I go to the math lab. If it wasn’t for [a math lab tutor] I would never [have] got an "A” in College Algebra. The guy's amazing.” Juanita agreed. She said, "I go to the tutor here in the library, with "Bianca." I studied chemistry with her and anatomy a little bit. I would go there everyday, even if I didn’t have an appointment. She was really good. I liked her.”

Andye’s experiences were very similar. She shared,

I go to the Resource Center and the math lab. I jot my name down for a tutor when I can get it or I leave home early for the open sessions that the tutors have. If I can get in, if I have a problem, I work with them to have a better understanding.

The non-persisters did not report that they used the campus resources as consistently as the persisters and graduates. Unless attendance was mandatory, services were not utilized. Only one of the four mentioned accessing specific departments on campus. When asked about resources she had used, Anna replied, "It's just me. I didn't go to any people." When asked if she ever used tutoring or went to the support labs, Aleida answered, "No, not really. We had a tutor in the algebra class that met with us, but she came to class." 


\section{Time Management}

The third sub-theme in the academic integration theme is time management.

Participants discussed essential time management skills. Graduates reported they spent more time studying compared to persisters and non-persisters. Most graduates reported their study time averaged 5-10 hours per week although Absum said, "While at ABC, I studied 12 -15 hours per week. Now at [state university], I’m studying 20 -24 hours.” LeLe explained,

Time management was something that I learned in college. SLS was a good class in the fact that it taught me time management and it taught me planning out...I study 20 hours a week...I would try to study before everyone started coming because then it would get noisy and hectic.

Many of the persisters emphasized the use of a daily planner. Melissa stated,

Struggling through some of the classes, it takes a lot sometimes, but you have to manage your time. My planner goes with me and just writing everything down, like, no matter what I'm going to do. If I was going to meet someone for lunch, like writing everything down. I started keeping a planner when I got to ABC. During my first semester, it's a lot. It's a big change coming from high school and then having so much work all the time. There's so much going on, so, keeping it all written down and when you look at it and see - this is at this time and - every week lets you know what you have to do. Sometimes you just need to see where you can be like, okay, I don't have anything going on here. That's when I need to do my homework, and that's when I need to study.

Juanita agreed, “My planner represents me because as you can see, look, everyday, everything that I'm going to do - from what time I work, my hours, my appointments, everything.” Robert said,

ABC has taught me a lot especially in the FYE program. The FYE program taught me a lot of stuff such as how to stop procrastination - how to be a better student. Before I came to ABC, I used to procrastinate more. $\mathrm{ABC}$ has helped me a lot with that. Honestly, I see a big change in my life. 
The non-persisters did not appear to be able to balance the demands of a college regimen as part of their lives. Anna and Sacha both pointed out the demands of multitasking. Anna said, "I stopped because of work and school...being too much.” Aleida disclosed, “I guess, I’m not always patient. I want things to happen right away.” Self Reliance and Independence

Related to time management, the fourth sub-theme is self-reliance and independence, particularly among the graduates and persisters. Despite external influences, as college students, participants expressed a need to be independent and much of this sense of independence was cultivated in college. In other words, students did not necessarily enroll in college possessing self reliance and independence.

Independence and self-reliance are defined on the basis of the following representative verbatim remarks from the participants. Many students conveyed the desire to prove their maturity and to accomplish things on their own. Tridi exclaimed, "I want to be independent and be on my own two feet!” Addison emphasized,

[Going to college] was something I really wanted to do. I wanted to see if I could do what my father did and go farther. So, what I wanted to do was pass every class on the first tray, and then continue on and branch out from there. It's like a personal challenge. I want to be in control. I want to see what I can do. The math lab is nice. I ended up not going there that much just because I figured that I could do it by myself, or to see if I could do it by myself.

Highly independent and returning to school as an adult, Andye cited, "Hard work and challenges motivate me. I like challenges. I always try to do things that people especially tell me you can’t do that. I prove them wrong." Kyla-Renee emphasized, "I want to go to college 'cause I'm the type of person. I like my own stuff. I just want to get older and have my career, you know, make my money, have my education. I don't want to 
struggle.” Similarly, the non-persisters seemed to be independent and self-reliant. Many broke from family expectations to drop out. For some non-persisters, however, their priority was not to attend school. Anna explained, "I chose to leave. I did that all by myself.”

\section{Other Observations}

The researcher made other observations during this study. Most interesting is that the majority of the students who participated in the study were ethnically and linguistically diverse. Furthermore, although all students graduated from an American high school, $82 \%$ of the participants were either first generation in college and/or first generation in the United States.

Moreover, the majority of the students, including the non-persisters, did not blame family, school or another external influence for failed classes, extended time to graduate or stopping out. They accepted the decisions as their own, also with few to no regrets. As Juanita said, “Don’t regret what you do. Regret what you don’t do. I don’t regret anything I do, but I regret what I haven’t done.”

Overall, the men were quieter and more reserved; women were more open and outgoing. During the interview process, women seemed to be more open to share their experiences, whereas the men needed more prompts and follow-up questions. In reviewing the transcripts, their responses were shorter and briefer. In addition, more attempts and reminders were needed to schedule interviews with the men as compared to the women. Two of the five men had to be rescheduled twice.

Furthermore, it should be noted that there were differences amongst the graduates, persisters, and non-persisters. Whether graduates, persisters, or non-persisters, students 
with lower grade point averages did not express the same sense of purpose and direction as those with higher grade point averages. For example, when asked about her goals one year from now, Nettie indicated, “I don’t know.” Declared as a pre-med major, she had attempted to pass chemistry and biology twice. According to her, biology is her least favorite class. She also had no friends and family seemed uninvolved. She indicated that although she was scheduled to graduate at the end of Summer 2008, her parents "do not know.” On the other hand, Aleida, a non-persister who unexpectedly became pregnant, would have likely stayed in school had she not started a family. Aleida had earned a higher grade point average (2.92) than all of the graduates and half of the persisters. In addition, many students indicated that, when they began their studies at ABC, they did not know they needed to take remedial courses. For example, those students who expressed disappointment with the FYE program indicated that the remedial reading classes were a "waste of time." Caridad said, "I can say that I wasted a little bit of time in the beginning with reading - the mandatory hours you had to do in lab. I kinda didn't think it was necessary.” Addison said, “I felt I didn’t need to take some of the classes. I kinda wish you had more options. After taking the reading class, it wasn't necessarily that it bothered me, but I could have taken something else.” Despite having enrolled and passed the developmental classes, some students did not realize that these courses, based on test scores, were mandatory and prerequisites to the advanced courses in their curricula.

Students who participated in the FYE program reported they were involved in campus activities. The study participants, underprepared ethnically diverse college students who had completed the FYE program, indicated a higher percentage of campus 
involvement in contrast to the 3 - 5\% of the general student population who are typically involved in campus activities (Achieving the Dream, 2006). Out of the 22 study participants, 13 (52\%) were involved. The majority of those who were involved were men (3 of the 5). Of the women, 10 of the 17 were involved. In contrast, fewer nonpersisters reported they were involved: in fact, only one reported being involved in campus activities.

\section{Limitations}

There were three limitations of the study. First, a limited number of non-persisters were interviewed. Fifty-one students dropped out of the college, but only four participated in the study. Despite multiple efforts to contact them (i.e. mailing, phone calls, internet, place of employment, peers), it is possible that many of the former students (who may have owed money to the institution) regarded the researcher as a collections agent and disregarded the mailings or phone contacts. Additionally, because

of their limited success, some of the non-persisters may have been reluctant to talk about their college experiences. Furthermore, it became apparent that the non-persisters were members of a transient population as many of the addresses and phone numbers on file at ABC Community College were no longer valid. In contrast, 6 of the 7 graduates and 12 of the 13 persisters were interviewed. Thus the findings, although not representative of the non-persisters, can be considered representative of the persisters and the graduates.

Another limitation was not including students who did not join the FYE learning community and who graduated or persisted. Although to date there were only seven students (two Non-FYE graduates and five Non-FYE persisters) out of 102 who fit this 
category, it may be interesting to see if their experiences yield themes that are similar to FYE participants.

Finally, the nature of the questions that were posed during the interviews may have been a limitation. Although the questions were informed by the literature review, the researcher realized that the themes were identified by the questions asked. For example, had the researcher asked questions about their middle and high school experiences, other themes could have been identified that could inform the K - 12 system. Nonetheless, the data collected and subsequently analyzed, and the themes/subthemes identified and discussed have the potential to inform the field and practitioners working with underprepared college students.

Summary

This chapter contained a description of the participants and a presentation of the findings. The participants included six graduates, 12 persisters, and four non-persisters who had participated in the FYE learning community. The themes of (a) pre-college characteristics and traits, (b) community, (c) social involvement, and (d) academic integration emerged from the interviews. To capture the perspectives of the participants, verbatim quotations from the participants were included to illustrate the themes. The precollege characteristics and traits theme was used to describe the students' internal values and attributes which they possessed before attending postsecondary education. The external college support/community influence theme described families', friends' and high school teachers' support and persuasion to attend college. The social involvement theme was used to describe participation in campus activities and their interaction with 
other members of the college community. The academic integration theme described how students use campus resources and their interaction with the teaching faculty.

Although the disparity between the number of graduates (6 of the 7 graduates were interviewed), persisters (12 of the 13 eligible students participated in the study), and nonpersisters (4 of the 51 non-persisters were found) makes it difficult to draw generalizations, the common themes amongst all participants included parents, faculty, faith, and personal characteristics such as independence. However, the perceptions of the graduates and persisters seemed to be qualitatively different from the non-persisters. Persisters more frequently mentioned a sense of responsibility, goal orientation, resourcefulness, and determination. They were more likely to explain how their culture, race, or ethnicity influenced their success. Furthermore, they reported they were more involved in campus life. In addition, they shared a belief that an education was a liberatory means to achieving their goals. Instead, the non-persisters appeared to have been more likely to be deterred by life circumstances. The findings provided the basis for policy, practice, and research recommendations that are presented in chapter 6 . 


\section{CHAPTER VI}

\section{DISCUSSION}

This chapter summarizes the major findings from the study and provides recommendations for policy, practice, and research. The first section focuses on the purpose, methods, and findings of the study. Next, the research question is addressed. The findings led the researcher to conceptualize an emerging model to explain the persistence of underprepared ethnically and linguistically diverse college students. Finally, the researcher offers recommendations and implications for theory, policy, and practice by community college administrators, faculty and staff working with underprepared students, as well as recommendations for further research.

\section{Summary of the Study}

Increasingly, more students enter post-secondary education underprepared. There is an emphasis on meeting the needs of first year students to increase their success, retention and ultimately, graduation. The purpose of this study was to gain an understanding of the perceptions of underprepared college students who have participated in learning communities and who persisted to complete developmental classes and earn at least 30 college-level credit hours or graduate as compared to their peers who have dropped out of college. Various theories including Tinto, Astin, and Freire were used as a framework for this case study. A qualitative case study design was used to address the research question. Six graduates, 12 persisters and four non-persisters participated in the individual interviews and seven participants contributed to the group interview. Each 
student had participated in the First Year Experience Learning Community at a large, urban community college.

The narrative data produced from the interviews were transcribed, coded, and analyzed to gain insights into the experiences and perspectives of the participants. Member checking was used after the interview process to ensure accuracy of the profiles constructed by the researcher. A peer reviewer provided feedback during the data analysis phase. Four major themes emerged: (a) pre-college characteristics and traits, (b) external college support/community influence, (c) social involvement, and (d) academic integration. Sub-themes were also developed for each theme. The pre-college characteristics and traits theme was used to describe the students' internal values and attributes which they possessed before attending postsecondary education. The external college support and community influence theme described the support from families, friends, and high school teachers and their persuasion to attend and complete college. The social involvement theme was used to describe their participation in campus activities and their social interaction with other members of the college community. The academic integration theme described how students used campus resources and their interaction with the teaching faculty.

\section{Research Question}

The following question framed the study. How do underprepared community college students who participated in a learning community and completed their developmental classes, explain their experiences in having graduated (graduates) or earned at least 30 credit-bearing college credits (the persisters) as compared to those who participated in a learning community, but have dropped out of college (the non- 
persisters)? Findings from the data presented in chapter 4 and the themes that emerged (chapter 5) addressed this question. In addition, the researcher asked the graduates and persisters directly, “What made the difference for you?” Based on the interview data, it can be reported that they indicated a sense of purpose, priority, motivation, and family expectation.

As an example from one the graduates, Janice replied, "I have the motivation and I have the strong will. I have my goals that I'm striving for," Frieda, a graduate, said, "I don't let obstacles discourage me. I knew where I wanted to go. It just pushed me to keep working hard.” Sara, another graduate, said, "I know what I want and I strive for that. I just knew I wanted to graduate.” Speaking of family, Absum, a graduate, explained, “I think my family had a great impact on me. They never let me quit. They kept pushing me." Nekee, a graduate, echoed the same sentiment saying, "Mainly my parents and my family because I didn’t want to disappoint them. I didn’t want to be a disappointment.”

The persisters pointed out similar reasons. Melissa said, "Definitely being involved on campus - being out of the classroom you meet so many people that it makes you want to be here. It brings you back.” Juanita answered, "For me, I want to go to school. I like school. I guess it’s just me. I like all the learning.” Other persisters indicated that the satisfaction of "accomplishing something" was a source of motivation. Addison mentioned, “Motivation. That pretty much tells it all.” Kyla-Renee stated, “I want to take it all the way to the end. I want to finish. I don’t want to start, go through all this and all I have to show in life is my high school diploma. Like, I want to show I can do more. Make my money and stuff like that.” Star claimed, “Motivation. If I did not have the power to look at my life and say I want more and I know how important a 
college education is. I've come too far to turn back around and give up. I have to make it.” Andye suggested, “I was more serious.” Joseph indicated, "I think I can push myself to the limit. I really think I can succeed and finish my school. I have a plan and know where I want to go.” Nettie noted, “Quitting is never an option for me, so I don’t see myself as a quitter or dropping out of school. This is something I want to do. No matter what, I will stick with it.” Dora explained, “I think I knew what I wanted. I knew I wanted to go to school and become something. I want to have a career and help people.” Tridi said,

Wanting to graduate. Because I have such a good experience graduating from high school, I want the same thing for college. I don't want to just drop out, because what I am going to gain from it? I just love the experience of graduating and going to another level of succeeding. That's why I stay in school.

Other persisters referred to family expectations. Caridad asserted,

Some people just don't have family who support them in the same way. I really had something to go on - my mom. Giving up is not an option. It's in me. It's a choice to make a difference in my life.

Robert shared, "I come from family that schooling is important. It’s everything I have.

Everything I need to succeed in life. I don’t have anything else.”

The researcher asked non-persisters, "What would have kept you in school?” Most claimed they needed an external motivator or they identified competing commitments outside of college. For example, Anna answered, "Structure. If I was still in the FYE program, if someone said, 'Here, go do these classes.' Yeah, that would be good.” J.R. replied, “I didn’t realize what I wanted. If I had a counselor to speak to and give me a slap in the face and reiterate everything - accept responsibility.” Aleida 
emphasized, “The time was not right. I would have stayed in school if I didn’t get pregnant. It’s hard to go to school and have a baby.” Sacha observed,

I left school because I couldn't pass my ACT and FCAT. I had to go to another school to take English, reading, and math. It was a little bit too much for me. It was better. Instead of coming and doing classes and end up failing more classes, I needed to finish that first.

Emerging Model to Explain Persistence of Underprepared College Students

Based on the findings from the present study, the researcher developed an emerging model to explain the persistence of participating underprepared college students who persisted. A visual representation of the model is shown in Figure 3. The varying sizes of the circles represent the relative strength of the themes. Larger circles indicate themes that seemed to have a stronger impact on the participants (i.e., external college support/community influence). Because the previous models developed by Tinto and Astin were based on the traditional Anglo population, a new model was needed to take into consideration the needs of the underprepared college student from linguistically and ethnically diverse heritages. In contrast to students who are represented in the models proposed by Tinto and Astin, the underprepared college students in this study were (a) first generation college students, (b) first generation in the United States, (c) non-native English speakers, (d) women, and (e) from under-represented minority populations. Many participants provided examples of various internal and external influences that helped them negotiate college and use or learn skills/behaviors to persist.

Although Tinto and Astin suggested successful students change and assimilate to the institution's culture or become involved on campus, ethnically diverse, underprepared student populations bring their cultural heritage and family backgrounds which influence 


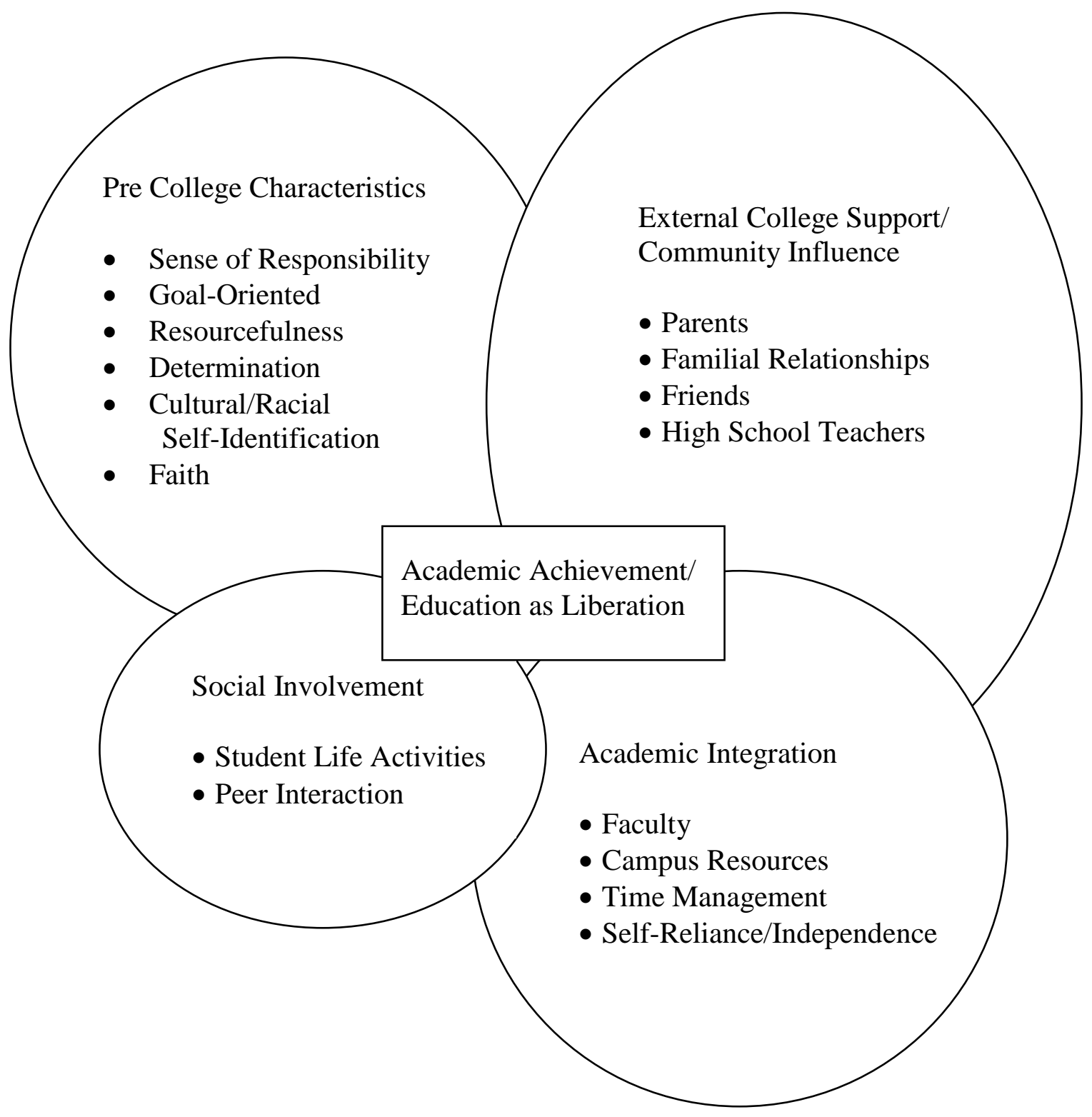

Figure 3. An emerging model of the factors that influence underprepared college students' persistence to academic achievement and education as liberation. 
their achievement in college. For example, Absum, Andye, Anna, Janice, J.R., KylaRenee, Nekee, Nettie, Robert, Star, and Tridi immigrated to the United States with their families for better opportunities. Each mentioned that their heritage cultures valued education. As Janice said, "Your family don’t come to America to do nothing... you come for a better life...to get an education.”

Graduates and persisters consistently regarded education as a means to liberation to achieve financial independence and fulfilled lives. The participants provided the following reasons for needing a postsecondary education. Sara indicated, "I just want to be successful. I want to be able to afford things.” Janice stated, “It's needed after $12^{\text {th }}$ grade. You need to go to college, get a college education, get a degree, and get a job.” Absum claimed, "I want to be something on my own.” Freida observed, "I knew that stopping with high school wouldn't really help me in the long run 'cause I do wanna have a family and be able to provide for my kids.” Nekee said, “To get better job, to make more money, because right now, I'm not making any money.” As a persister, Melissa explained, "Pretty much nowadays you hafta have an education no matter what you're doing. Tridi shared, “It’s important to have a good education. You're better prepared for life.” Caridad noted, “I want something better for me. I want a house, car.” Kyla-Renee remarked, "I want to make my money and own stuff.” Andye said, "Mainly to take care of my boys financially and myself." Robert stated, "College is important cause out there is not easy."

The non-persisters agreed. Aleida found, "I felt like I was supposed to go to college... a high school degree doesn’t help you get a good job. J.R. explained, “I wanted to go to college to make some money.” 


\section{Connection to the Literature Review}

In linking the study findings to previous research, it appears that there are some similarities. For example, Hodges (2008) studied participants from a selective admission institution and all students were members of a natural science learning community, they expressed "learning to be an adult/growing up”, “gaining the credentials necessary for their chosen career" and the "influence from parents, other family members, high school teachers, and peers” as themes for persistence. There were however, some differences between that and the present study. The focus of the current study was on underprepared college students. The students in the current study (particularly the graduates and persisters) were active on campus, whereas students in the Hodges' study were concerned about resume-building in preparation for medical and/or graduate school.

Poindexter (2007) reported participants’ positive influences on their college experiences: (a) immediate family members' support of their educational goals, (b) the collaborative environment of the learning community, and (c) enthusiastic faculty. Yet, unlike the students at the University of San Francisco (USF) in that study, the FYE students at ABC also used college support services and participated in campus activities. Like the USF students, ABC participants reported family support, benefits of their learning community, and enthusiastic faculty. The differences may be related to the culture of ABC Community College as compared to the university campus in the Poindexter study. Two other factors may have influenced the differences: (a) the majority of the FYE students at ABC were recent high school graduates, and (b) the majority of FYE students were first generation college students. 
Consistent with findings from Byrd and MacDonald (2005), the FYE participants in this study (particularly graduates and persisters) emphasized time management skills, goal-setting, and family as contributing to their success. The FYE graduates and persisters had clear goals, such as transferring to a university and specific career aspirations. Valadez (1993) found that the majority of the students in that study pursued a college education to improve their economic status. This finding was consistent with the FYE students at ABC Community College, particularly the first generation college students. Many of the participants in the current study regarded their education as liberating, as a way to increase their opportunities to gain a better life. In contrast to Valadez (1993) who found that underprepared students do not have the cultural capital in regards to family or friends who can help negotiate college bureaucracies, the participants in this study were able to draw on family, friends, and contacts with faculty and staff which they had made during FYE.

Smith and Commander (1999) found that underprepared students failed to exhibit practical behavior such as attend class or use campus resources. In contrast, the participants in the current study (particularly the graduates and persisters) were keenly aware of the resources they could utilize, possibly because of their participation in FYE.

For the non-persisters (albeit only four were interviewed), factors typically associated with the persistence of community college students were not evident. Bers and Smith (1991) found that educational objectives, such as strong goals, and working fewer hours, contributed to persistence. Some of the non-persisters did not seem to have clear goals or were pursuing a program of study in which they were not necessarily interested. In addition, they were working full-time. Maxwell (2000) found that student engagement 
in the classroom was important. It appears that for the majority of non-persisters, once they completed the FYE program, they did not have the same interactions with peers and faculty as the graduates and persisters. Several non-persisters suggested that the program should be continued for the second year.

In summary, the findings of the current study were consistent with many previous studies. Internal variables such as goals, time management and external variables such as family, social interaction with peers and faculty, student engagement both in and outside the classroom, contributed to success of underprepared college students in this study.

Factors that Influence Underprepared College Students’ Persistence

The findings from the data were examined and several factors were identified that contribute to the emerging model shown in Figure 3. The researcher based these factors on his interpretation of the findings. The major factors that influence underprepared college students’ persistence were: (a) External College Support/Community Influences, (b) Pre-College Characteristics, (c) Social Involvement, (d) Academic Integration, and (e) Education as Liberation. As illustrated by the larger circle in the figure, external college support and community influence such as parents, familial relationships and friends represent the strongest factor that influenced the participants in this study.

\section{External College Support/Community Influence}

Family and peers have an influence on students. Students who attend a community college are more apt to live at home with parents. In addition, peers influenced their behavior. Of the 22 participants interviewed, 19 described friends who were attending other universities in the state. This finding is similar to that of Pascarella et al. (2002). In addition to the circle of university friends, which Sara defined as "the 
right crowd", most of the participants referred to other peers or family members who held them accountable and encouraged them to complete their college goals. Pre-College Characteristics

Characteristics such as positive self-image, self-esteem, and internal locus of control have been found to correlate with successful academic achievement (HarveySmith, 2002). In this study, graduates and persisters who had a strong sense of determination, responsibility, and had concrete goals, tended to persevere and complete their program of study. For example, Frieda delayed marriage to her fiancée until graduation. Star persevered despite several obstacles with U.S. immigration concerning her student visa and health insurance. Andye overcame negative family expectations about her decision to return to school at a more mature age. In spite of life crises or failed classes, which may lengthen the time to degree completion, the graduates and persisters returned to college to graduate. Overwhelmingly, the successful participants (those who persisted) mentioned math classes as a barrier, but several echoed the sentiments of Nettie who said, "I never think about quitting, never. It’s not an option.”

\section{Social Involvement}

Students need to interact with peers to enhance their academic experience. Underprepared college students use the classroom as their stage to meet other students and find peer support. Many of the graduates and persisters were involved in extracurricular activities. Although many of the students participated in long-standing groups such as campus ambassadors or student government, some of the students created a new organization, such as the dance team in which to be involved. As shared by 
Melissa, "Being active on campus motivates me the most. It helps me get through school and keep my GPA up and all that stuff.”

Academic Integration

Although many faculty believe the curriculum and basic skills should have been taught and learned in secondary education, students in this study were critical of the pedagogy and the format in which the courses were taught at ABC, particularly in the discipline of mathematics. Faculty who incorporated group learning and encouraged students to support each other created a positive experience for the students. For example, LeLe illustrated how her sociology professor encouraged students to talk about current events and subsequently relate them to the discipline and Caridad talked about her English professor who encouraged students to write about experiences they lived and understood. In mathematics, it appears that the faculty kept the topics abstract and there was little opportunity to work collaboratively.

Current college teaching techniques are beginning to focus more on the peer group. Growing literature on cooperative learning (e.g., Wild \& Ebbers, 2002) shows that it is often much more effective than traditional classroom instructional technique. When college faculty assign students to work together to learn classroom material in small groups, they serve as teachers to each other. For example, with the support of the National Science Foundation (NSF), the Mathematical Association of America (MAA), and the American Mathematical Association of Two Year Colleges (AMATYC), several institutions have begun to reform college algebra courses so as to increase retention and higher pass rates. Currently, the learning outcomes of the course emphasize algebraic techniques needed for calculus. However, since only $10 \%$ of students who enroll in 
college algebra intend to prepare for technical careers (Dunbar, 2006), the refocused courses emphasize conceptual understanding, communication skills, realistic problemsolving conducted in small groups, in-class activities, and out-of-class projects (Gordon, 2006). However, no participant in the current study mentioned positive aspects about the pedagogy in their math classes or developmental classes; instead they often reported experiences which humiliated or demeaned them.

Related to pedagogy and classroom instruction, the interaction between students and faculty emerged from several studies as having a tremendous impact on retention. Beginning with high school, many of the participants had established strong relationships with their high school teachers and indicated that they had influenced their decisions to continue their education and attend college. This important factor continues in college. Students who are provided opportunities to interact with faculty at greater levels also tend to perform better academically (Harvey-Smith, 2002). Modeling is important and cited as essential for student success. Both the availability of quality role models and the opportunity for high quality faculty interactions have been found to be prime factors in retaining students (Harvey-Smith, 2002). Although the graduates and persisters remember more positive faculty encounters, all students described both positive and negative faculty experiences. Professors who were engaging, passionate about their discipline, encouraging and open tend to have the greatest positive influence.

\section{Education as Liberation}

As indicated by Freire (1970), education can serve as a liberatory experience from the present situation. Educators must understand the social, cultural, political, ideological, and economic forces that affect cognitive development (Kincheloe, 2008). Although all 
the participants mentioned finances, only Robert represented himself as a member of an oppressed lower socioeconomic class. Yet, all participants wanted something better and saw education as a means to achieve an improved life. As for race and ethnicity being an influence, a few students (LeLe, Star, and Caridad) mentioned their race and ethnicity; however, the others did not refer to race or ethnicity. The majority of participants referred to the influence of coming from heritages where education was valued. Rather than point to being Black or Hispanic, the participants more frequently spoke about their Haitian, Jamaican, Cuban, or Guatemalan cultures as sources of influence to attend and stay in college.

A critical perspective is currently not part of the ABC curriculum. Not all classes induce students to challenge the dominant power structure and social stratification or develop a critical consciousness which Kincheloe (2008) defines as “developing new forms of understanding that connect the faculty member to understanding, empathizing and acting to alleviate suffering” (p. 13). Institutions need to be cognizant that education is always political as it supports the needs of the dominant culture while subverting the interests of marginalized cultures. Critical consciousness can be elusive since the oppressed are blinded to the myths of dominant power that keep them "in their place” (Kincheloe, 2008). Yet many of the study participants do not accept such a view and instead see education as an opportunity for hope. Freire (1998) wrote, "Hope is a natural, possible, and necessary impetus in the context of unfinishedness. Hope is an indispensable seasoning in our human, historical experience” (p. 69).

Although the students in this study did not report having professors who encouraged a critical perspective, when faculty choose to teach with a critical 
perspective, they can encourage students to see themselves and how they became themselves from the perspective of other people. From this context, all parties can gain the benefit of self-knowledge and the ability to change oneself as an emancipatory means to revolutionize the oppressive effects of the dominant power (Kincheloe, 2008). Some of the students in the current study seemed to show an awareness of the influences of the dominant culture. For example, Andye noted,

Coming from the Caribbean, I don't like the idea that whatever you learned, doesn't count. You have to be qualified by the U.S. standard, so, it holds us back. It puts us in a position where you have to adjust our lives, go through the GED, even if we have a high school diploma from back home, and you have to go through everything, learn all over again and it's depressing. I think that's why the men who come over here, they don't want to go to school. 'Cause they've gone to school already. So, they take menial jobs and just get by.

Moreover, rather than reject their ethnic or cultural backgrounds, the participants in this study embraced their respective cultures which seemed to help them be successful graduates. For example, Janice emphasized the fact that her family came to America from Jamaica so she could look "for a better life...to get an education.” Nekee, also of Jamaican descent, wanted to gain an education because she perceived it as "the opportunity" her parents did not have and felt compelled "to take advantage of it." Sara spoke about her parents emigrating from Haiti and how they "wanted my brothers and I [sic] to get an education.” LeLe, as an African American born in the United States, stated, "After high school, there was no, what do I do now? There was always college. You had to go somewhere.”

Among the persisters, Dora suggested,

Some people don't expect much. I don't know why. Maybe they look at you and see a Spanish girl or something. I sometimes see that with my 
parents when other people think they're stupid because my father's a security guard or they speak with accents. You need to get to know them and see how far they've come before you judge them.

Tridi indicated,

My family comes from Haiti and it's a struggle for them. I don't want to end up struggling. When I look at them and other people who are struggling to make a living, I always go towards my education cause I know once I have it, I won't have to struggle as much as they did.

Similarly, Robert expressed his views regarding class differences between Haiti and the United States,

I'm proud to be Haitian $100 \%$. 'Cause it's not about where you come from, it's about what you try to do in your life. Being a Haitian is not something I can change. I [will] always be a Haitian. I will always be Black. In the American culture, you have so many opportunities to go to school. You really don't have that in Haiti. A lower economic class helps me see what I have and where I want to be 'cause if you want to work in the next level, you're the one that has to get it. They're not going to just give it to you and this is the same thing that I'm trying to do with school cause I'm the one that has to work hard...study hard in order to get it.

\section{Implications for Theory}

The emerging model provides an insight to the retention of underprepared college students. This study supports Tinto and Astin who discussed certain pre-college charactersistics, social involvement and academic integration which contribute to persistence. Tinto’s Academic Integration theory emphasizes pre-matriculation characteristics; in other words, those pre-college traits that students possess which influence their initial level of commitment to the institution. Tinto identified ethnicity, level of family support, socioeconomic status, and secondary school achievement as primary characteristics. After the student has enrolled, Tinto uses the rites of passage three-phase process of separation, transition, and incorporation which contributes to 
retention. Tinto argues that the more students assimilate to the institution's culture and the more they feel themselves to be valued members of the campus, the more likely they are to persist to graduation.

The characteristics of the students that Tinto studied included mostly White-NonHispanic students, who came from middle-class and higher socioeconomic status and had higher secondary school achievement records. In contrast, the participants in the current study included seven Black Haitians, five Black Jamaicans, two Black Americans, two White Americans, one Black Bahamian, one Hispanic Guatemalan, one Hispanic Costa Rican/Italian, one Hispanic Puerto Rican/Dominican, one Hispanic Cuban and one Asian Indian. They all expressed high levels of family support. Economically, the majority did not talk about socio-economic class (interestingly, few of the study participants qualified for financial aid.) The graduates and persisters more frequently than non-persisters spoke about other personal characteristics not mentioned by Tinto, such as sense of responsibility, goal orientation, resourcefulness, determination, and faith. Perhaps the most important finding of the current study that differs from Tinto's theory is the influence of the study participants' cultural self-identification, particularly the emphasis their families placed on the importance of an education. As mentioned previously, this finding was supported by Tierney (1992) and his study of Native American students. Although Tinto mentioned the level of family support as an initial influence, he emphasized the need for disengagement from past relationships and familial cultures so that students could assimilate to the college culture, and disengagement of past relationships to create new ones. In contrast, the participants in the current study (particularly the graduates and persisters) kept their relationships with family members 
and high school friends. They also reported that their high school teachers made a difference in their decision to stay in college. The graduates and persisters did make new friends, but the more important influences were external to the college/campus community. In contrast to the graduates and the persisters, the non-persisters had strong family support to attend college and continue their education. Yet many of their friends did not attend college or share in the same academic experiences.

Consistent with Tinto, the persisters and graduates appeared to have had good experiences and positive interactions with college faculty and accessed campus resources. In addition, they learned good time management skills. To a lesser extent, they were selfreliant/independent. Some participants described breaking from their family financial dependence.

In contrast to Tinto, Astin's theory emphasizes that, rather than change and assimilate to the institution's culture, college students should maintain their individuality yet become socially engaged in programs and initiatives (i.e., college activities, involvement in the classroom, such as when working on class projects, interaction with the faculty). In this study, it was found that many of the graduates and the persisters expressed many of the benefits of social involvement when sharing their own experiences; yet until this study, it remained untested among underprepared ethnically diverse college populations.

As admitted by Astin and Tinto, social involvement and academic integration do not entirely address the needs of ethnically, diverse underprepared college students. The need for a new theoretical perspective is even more evident as a result of this study. All of the participants met one or more of the following characteristics: first generation in 
college, immigrants or children of immigrants, English as a second language, racial or ethnic minority status, or women. Current retention models address the needs of White, middle-class, college-prepared university students; the needs of underprepared students are not addressed. Perhaps, as some critics argue, those who are not prepared for college should not attend college. Yet the community college system was created for this population and as seen through this study, some underprepared students do succeed. Although perhaps the educational system had failed them somewhere along the way, all of the graduates and persisters considered a college education as a means to emancipation from their current life and as an opportunity for greater success. The critical theory approach adds a promising dimension to understanding the needs of a more diverse student population.

\section{Implications for Community College Practice}

Based on the findings of this study, factors identified, and the emerging model of the factors that influence underprepared college students' persistence illustrated in Figure 3 , the researcher poses implications for practice at the 2-year institution. While those intended for practice are offered as a result of this specific study, it is anticipated that some recommendations may be appropriate to higher education administrators, faculty, and staff working with other underprepared students at other institutions.

First, parents and extended family are so instrumental in the lives of underprepared ethnically diverse students in this study (especially the graduates and persisters). Although only a few non-persisters contributed to the study, their experiences reflected an absence of familial supports. Therefore, college personnel should consider developing programs and strategies to involve parents and family members. Rather than 
expecting all college students to detach or separate from their families to create new social support systems, college personnel can engage the parents and family members. As reported by several participants in this study, parents participated in pre-enrollment activities, such as new student orientation. Many mothers encouraged, if not insisted, their students to join the FYE program. Although some institutions have offered a "Parents Going to College" session during the freshman orientation program to include information on degree requirements, campus resources, financial aid, and contact information, post-secondary institutions, particularly community colleges, could do more. Rather than provide only one initial experience, programs should be continuous and sustained throughout their family member's enrollment. For example, a family guidebook of campus resources and important contact information should be provided to each household. In addition, a family advisory council could be created where at least once a semester, members review and provide feedback to campus initiatives and programs. Finally, colleges could co-enroll parents and their son or daughter in a student life skills course or seminar to reinforce habits and behaviors that promote success at home. The majority of students reside with their families and it appears parents and family members want to and need to be involved. As indicated by Dora who noted,

My parents don't speak English extremely well. When I was in high school, my mom used to help me study for advanced vocabulary and my science classes. She would sit with me at the dining room table and quiz me at night. She had no idea about what I was studying and couldn't pronounce the words, but she helped me.

In other words, when a son or daughter attends college, it is often the entire family, not just the enrollee. The home culture should not be considered a distraction. 
Second, faculty and administrators might develop new programs based on the types of student learning experiences known to support student success and persistence to graduation. Failure to connect with others on campus to include peers, student organizations, faculty and or staff, contributes more to voluntary withdrawal than almost any other factor (Brittenham, et al., 2003). This finding is consistent with this study. Students spoke highly of the co-curricular activities (leadership retreats, field experiences) where the classroom lesson was supported by Student Life. As Juanita indicated,

The whole FYE thing was good because we had trips and activities. It was actually doing it and going. I've heard about professors that don't care, but the professors I've taken have been great. They don't make me feel like I don't want to come, they make me feel like I want to be in class.

In summary, many underprepared community college students could benefit from such clubs and organizations that are tied to their major if incorporated more in the classroom. Postsecondary institutions need to expand the concept of learning to include affective outcomes such as leadership, self-understanding, and citizenship, as well as cognitive outcomes. It is a serious mistake to limit learning outcomes to only cognitive values (Astin, 1996).

Third, the instructional delivery system, particularly in developmental classes, should change. Some of the participants in this study regarded the preparatory classes as punitive since they did not generate college credit. Also, they emphasized that the courses, especially the developmental courses, were taught in ways that were too similar to what they experienced in high schools. Furthermore, they were required to pay for the remedial instruction which should have been learned in high school. Melissa explained, 
When I found out I had to take the prep classes, I was a little bit - I don't know - discouraged, maybe intimidated because you go through high school and then a lot of like, that first English class, 0021 is straight from high school. So, you feel like you're back in high school. So I think it kinda pushes you away because you are like, I already did this. It doesn't make sense. So, I think that's what a lot of it is - I guess having to pay for the class. They don't like that. Then you don't really get the credit for it. I think it pushes people away.

Perhaps developmental classes should be taught in a different format where students could focus on specific competencies. Students could achieve incremental success and feel as if they are making timely progress. Janice noted, after transferring to another local college where she experienced success due to a more creative format, "It's one class a month. So, you're just concentrating on that one class which I like.”

Fourth, underprepared college students should be allowed to earn transferable credits while enrolled in remediation (Killacky et al 2002). Many of the participants in this study felt developmental courses were a discouraging barrier that extended the time to completion of their programs of study. Frieda explained,

After I graduated I talked to one of my friends that I went to high school with and I told her that I graduated and everything and she asked me if I took any prep classes and I said, "Yeah, I took a couple of prep classes", and she said that she kinda felt like she wanted to go to school but she feels that people that take prep classes, it's like they're never going to graduate. I said, “No, I mean, I probably would have graduated earlier if I would have taken classes the first summer when I started here.” But I think maybe prep classes make the students feel like they're not gonna get out.

If skills learned in the developmental courses (i.e., reading) can be applied in related college-level courses (i.e., computer concepts, sociology) and students earn college-level credits simultaneously, they are more apt to discover interdisciplinary application and make progress in earning credits toward their degree. Developmental 
courses should not be taught in insolated silos but rather in ways that allow students to see the connected relationships among disciplines. Learning communities may facilitate that process.

Fifth, the results of the study indicate that college administrators and staff could support the transition of students as they enter the mainstream. Some students missed the peer support they had while in FYE and recommended that the program be extended. The voices of persisters (Dora, Nettie, and Juanita) and non-persisters (Anna) emphasize the importance of peer support. Dora noted, “The semester after FYE, I felt confused and a little alone. The students I knew were no longer around or in the same class. I had phone numbers and we would sometimes chat on-line, but it wasn't the same.” Nettie commented,

I wish that FYE could be longer - for 2 years. You could have someone push you. I wish it could be longer. After the first year, students ask, "What do I do next?" I believe that a lot of kids drop out because it's just like, well, for the first year you have somebody pushing you, but now you're by yourself.

Juanita affirmed,

When I was in FYE, I was [on campus] everyday after class and then I would go home. 'Cause I was with all the same people and we would all get of class together. It's not like now where I don't know a lot of people and I don't have anything to do. So, I just go home and straight to work.

These sentiments were also expressed by a non-persister, Anna, who noted, "If I was still in the FYE program, it could have kept me in school. It was more structured.” Perhaps colleges should consider the implementation of a Second Year Experience.

Sixth, to increase the sense of academic integration, administrators could group students based on major to increase the identification with academic discipline. Absum 
reported, "If I had the same major of students with me who were focusing on...in the same direction, I think, it would have helped a lot.” Perhaps more of these peer support relationships would continue beyond the first year if they were in the same program of study.

\section{Implications for Community College Policy}

Realizing that FYE had an impact on students, there are some policy implications that institutions such as $\mathrm{ABC}$ might implement. For example, the number of FYE learning communities may be expanded to involve more students. Furthermore, to attract more students, additional cohorts could be added to include evening or part-time groups.

In addition, the development of a 3-credit student success course (Student Life Skills) may be beneficial. The literature supports the implementation of a freshmen seminar class that teaches time management, goal-setting, and educational planning and complements the academic disciplines (Fidler \& Godwin, 1994; Folger, Carter, \& Chase, 2004; Ishler, 2003). As found in this study, many of these behaviors may be learned in college to enhance student success and retention.

Finally, the sequence of courses has been shown to have an impact. In this developmental advising model adopted by ABC, full-time students who test into all developmental areas are mandated to take their developmental reading, developmental English, college success course paired with introduction to computers or wellness in their

first semester Students are advised to take developmental mathematics in their second or third term of enrollment. Students who experience greater success in their first semester are less likely to withdraw (Pascarella \& Terenzini, 1991; Roueche \& Roueche, 1999). 


\section{Recommendations for Future Research}

Developmental education can greatly benefit from continued studies that listen directly to students’ voices, perceptions of their own college experiences. Longitudinal research that includes case studies, interviews, surveys, and focus groups and tracks students through their college transitions, explores changes in attitudes, beliefs, achievements, identities, and self-perceptions are most critical. By focusing on issues of access and preparation, researchers can provide additional information about possible barriers, motivational issues, diversity, cultural factors and students’ learning orientations.

To develop the knowledge base related to underprepared college students and their success, a study of the experiences and perceptions of men would be helpful. Approximately one-third of the students who entered the FYE program at ABC College were men. In addition, there is a disproportionately small number of men (29) who started in the FYE program compared to those who graduated or have earned 30 or more credits (4). In other words, approximately, 14\% have been retained. In comparison, 16 women graduated or earned 30 or more credits out of 69 women who initially joined FYE. In other words, 23\% of the women persisted. Understanding the needs of men who persist may help administrators and faculty introduce more effective support services to retain them.

In addition, a further study of students enrolled in developmental mathematics is warranted. Both the archival data and interview transcripts showed that the majority of students encountered difficulty with mathematics. In the current study, the participants withdrew or failed their math courses, requiring that the courses be repeated. 
A study of underprepared students who did not participate in a learning community might reveal that their experiences are qualitatively different from those who did participate. In this study, it was found that half of qualifying underprepared students joined the program. Perhaps there are characteristics that distinguish the learning community participants from those students who choose not to join. Outside of basic demographical information and entry test scores, little is known about those who do not participate in FYE. The nature of the differences could inform college administrators and faculty about how to better engage these students so as to increase their retention through graduation. Clearly, more research is needed to further validate the value and success of the FYE program.

Tinto (1975) studied the pre-college factors that predict success of college students. However, his model did not explain the successes of ethnically diverse, underprepared college students. A study of the internal characteristics using different instruments to revise Tinto’s pre-college factors of ethnically diverse, underprepared students could lead to important considerations.

Although Tinto refers to family support as an initial influence for college students, the findings from the current study differs from Tinto's theory with respect to the influence of the study participants' cultural self-identification and the emphasis their families placed on the importance of education. Based on the findings, the researcher posed an emerging model to explain the success of underprepared college students. A study designed to determine the impact of family as a variable that influences persistence is warranted. 


\section{Reflections}

Many of the students who participated in the study hoped to make a difference by sharing their experiences. The participants received no compensation for their time and effort and graciously agreed to join the study. One student, Andye, consented to be interviewed for a second time when it was discovered that the first recording was inaudible. Tridi indicated, "It’s kinda good to hear from somebody who's been through it and try to help the younger generation out so they don’t fall in the same cracks.” Melissa noted, “I’m always ready to give a hand to whoever needs it. It's important to network with people and help them through classes and stuff.” Star explained, "I'm willing to take in and give my opinions and learn.”

Many participants described themselves as helpers. LeLe emphasized, "I think I've always had this helping nature in me - to help teach people and show them something.” Juanita noted, “I want to help people.” Even Sacha, a non-persister, said, “I love helping people.” When asked why they participated in the study during the group interview, Joseph remarked, "I want people to accomplish their goals and be successful in life. Andye added, “I like to share my story, because it’s important to show that age or responsibility does not stop you from pursuing your goals.”

In addition, this study has had an impact on the researcher, an administrator at a community college. First, his assumptions were supported by the findings. In learning about the participants' lived experiences, he has a deeper and more comprehensive appreciation of the participants’ cultures and backgrounds. He found that persistent individuals will eventually achieve their intended outcomes. Further, he has a greater respect for the fact that all the students who participated in the study took responsibility 
for their actions and exercised an internal locus of control. In his researcher's log, he wrote, "What I learned today is that despite the good intentions from parents, ultimately kids make their own decisions. Although we as parents fear for our children and wish to protect them, the students are happy with their decisions and don't regret anything. Maybe it’s youth, but they celebrate life.”

Second, as a result of the study, he now examines many of the programs and services offered at the college through more critical lenses so as to better support students. Realizing that today's student population tends to experience more external distractions (e.g., concurrent employment, family obligations), students may not regard many programs as important or necessary. In the researcher's log, he wrote, "I wonder why we continue to require certain classes, like algebra, when most students will never use the concepts. Plus, we think that the only way students will come to certain programs or use resources is to make it mandatory which seems to be punitive. As college personnel, we should seek input from students to determine priorities and how to advertise initiatives to increase participation.” For example, the students in this study consistently failed algebra classes. As the dean of students, he realizes one role he could assume is to help academic affairs improve the instruction of high-risk courses, such as algebra, and perhaps change the curriculum to address problems presented as real world situations. With the support of the National Science Foundation (NSF), many institutions have begun to refocus the college algebra course from exclusive algebraic manipulation to transferable problem skills such as exploration, modeling, inductive and deductive reasoning, communication, and use of technology (Gordon, 2006). The researcher intends to bring the findings of the study to the attention of the academic dean and the faculty and 
work with interested colleagues to apply for an NSF grant to reform college algebra. $\mathrm{ABC}$ faculty and administration need to seek ways to improve pedagogy used in algebra courses so that students may experience better connections between the logical processes algebra entails and their fields of interest.

Third, by understanding the internal and external influences of underprepared college students who enrolled in developmental coursework, he is better informed to share possible barriers and challenges and how students were able to overcome them. Few administrators create the unique opportunity to hear the students’ stories and learn about their family histories, circumstances, and dreams. In his researcher's log, he wrote, "I am encouraged getting to know about their lives. I'm reminded why I entered this field. It's for the opportunity to make a difference.”

The results of this study may be important because the ideals of learning communities are consistent with the values of community colleges, that is, to promote the education of all who wish to pursue educational goals. The underprepared, ethnically diverse participants in this study, especially the graduates and the persisters, emphasized that their experiences with a structured learning community in their freshman year appeared to promote high level of faculty-student interaction, integration of academic and social activities, opportunity for involvement, leadership experiences, cultural and social support, and use of campus resources. Listen to the voices of Dora, Andye, and Robert! Dora appreciated the friendship factor: "Definitely join FYE. It helps you get started to be with the same group of students - to make friends. It's a good change from high school to college.” Andye noted the importance of monitoring: "I like the fact that they monitored you throughout. In case you're failing or having problems, you had someone 
to go to; you didn’t feel like a stranger. FYE tries to get you involved.” Robert emphasized the focus on success: "FYE has been like, a great success. It teaches you a lot of things and I believe that every new student needs to be part [of it], 'cause it's one of the best experiences I've had.” 


\section{REFERENCES}

Achieving the Dream. (2006). Office of Institutional Research, ABC Community College.

Adamson, N., Briskin, L., \& McPhail, M. (1988). Feminists organizing for change: The contemporary women's movement in Canada. Toronto, ON: Oxford University Press.

Adelman, C. (1996, October 4). The truth about remedial work: It's more complex than windy rhetoric and simple solutions suggest. Chronicle of Higher Education, p. A35.

Amey, M. J., \& Long, P. N. (1998). Developmental course work and early placement: Success strategies for underprepared community college students. Community College Journal of Research \& Practice, 22(1), 3-10.

Anderson, G. M., Alfonso, M., \& Sun, J. C. (2006). Rethinking cooling out at public community colleges: An examination of fiscal and demographic trends in higher education and the rise of statewide articulation agreements. Teachers College Record, 108(3), 422-451.

Ashar, H., \& Skenes, R. (1993). Can Tinto’s student departure model be applied to nontraditional students? Adult Education Quarterly, 43(2), 90-100.

Astin, A. W. (1984). Student involvement: A developmental theory for higher education. Journal of College Student Personnel, 25(3), 297-308.

Astin, A. W. (1985). Achieving educational excellence, San Francisco: Jossey-Bass.

Astin, A. W. (1993). What matters in college? San Francisco: Jossey-Bass.

Astin, A. W. (1996). Involvement in learning revisited: lessons we have learned. Journal of College Student Development, 37(2), 123-134.

Bean, J. P. (1980). Dropouts and turnover: the synthesis and test of a causal model of student attrition. Research in Higher Education, 12(2), 155-187.

Bers, T. H., \& Smith, K. E. (1991). Persistence of community college students: the influence of student intent and academic and social integration. Research in Higher Education, 32(5), 539-556.

Bogdan, R. C., \& Biklen, S. K. (2003). Qualitative research for education. Boston: Allyn and Bacon. 
Bourdieu, P. (1977). Cultural reproduction and social reproduction. In Jerome Karabel and A.H. Halsey (Eds.), Power and ideology in education (pp. 487-510). New York: Oxford University Press.

Bourdieu, P. (1984). Distinction: A social critique of the judgment of taste. Cambridge, MA: Harvard University Press.

Boylan, H. R. (1999). Developmental education: Demographics, outcomes, and activities. Journal of Developmental Education, 23(2), 2-9.

Boylan, H. R., Bonham, B. S., \& Bliss, L. B. (1994). Who are the developmental students? Research in Developmental Education, 11(2), 1-4.

Bragg, D. D. (2001). Community college access, mission, and outcomes: Considering intriguing intersections and challenges. Peabody Journal of Education, 76(1), 93-116.

Brint, S., \& Karabel, J. (1989). The diverted dream: Community colleges and the promise of educational opportunity in America, 1900-1985. New York: Oxford University Press.

Brittenham, R., Cook, R., Hall, J. B., Moore-Whitesell, P., Ruhl-Smith, C., et al. (2003). Connections: An integrated community of learners. Journal of Developmental Education, 27(1), 18-25.

Bryant, A. (2001). Community college students: Recent findings and trends. Community College Review, 29(3), 77-93.

Burley, H., Butner, B., \& Cejda, B. (2001). Dropout and stopout patterns among developmental education students in Texas community colleges. Community College Journal of Research and Practice, 25(10), 767-782.

Byrd, K. L., \& MacDonald, G. (2005). Defining college readiness from the inside out: First-generation student perspectives. Community College Review, 33(1), 22-37.

Clark, B. (1961). The cooling-out function in higher education. In A.H. Halsey et al. (Eds.), Education, economy, and society (pp. 513-521). New York: Free Press.

Cohen, A. M., \& Brawer, F. (1982). The American community college. San Francisco: Jossey-Bass.

Creswell, J. W. (1998). Qualitative inquiry and research design. Thousand Oaks, CA: Sage. 
Creswell, J. W. (2001). Qualitative inquiry and research design: Choosing among five traditions. Thousand Oaks, CA: Sage.

Denzin, N. K., \& Lincoln, Y. S. (1989). The landscape of qualitative research. Thousand Oaks, CA: Sage.

Dunbar, S. (2006). Enrollment flow to and from courses below calculus. In N. Hastings (Ed.), A freshstart for collegiate mathematics: Rethinking the courses below calculus (pp. 28-42). Washington: Mathematical Association of America.

Durkheim, E. (1961). Suicide. Trans. J. Spaulding and G. Simpson. Glencoe, IL: The Free Press.

Fidler, P. P., \& Godwin, M. A. (1994). Retaining African-American students through the freshman seminar. Journal of Developmental Education, 17(3), 34-41.

Firmin, M. W. (2006). External validity in qualitative research. In M. W. Firmin \& P. Brewer (Eds.), Ethnographic and qualitative research in education: Vol. II (pp. 17-30). Newcastle, UK: Cambridge Scholars Press.

Flowers, L. A. (2003). Test-retest reliability of the learning and study strategies inventory (LASSI): New evidence. Reading Research and Instruction, 43(1), 31-46.

Folger, W. A., Carter, J. A., \& Chase, P. B. (2004). Supporting first generation college freshmen with small good intervention. College Student Journal, 38(3), 472-476.

Freire, P. (1970). Pedagogy of the oppressed. New York: Continuum.

Freire, P. (1992). Pedagogy of hope: Reliving pedagogy of the oppressed. New York: Continuum.

Freire, P. (1998). Pedagogy of the heart. New York: Continuum.

Gall, M. D., Gall, J. P., \& Borg, W. R. (2003). Educational research: An introduction ( $7^{\text {th }}$ ed.). Boston: Allyn and Bacon.

Glesne, C. (1999). Becoming qualitative researchers. New York: Longman.

Gordon, S. (2006). Where do we go from here? Creating a national initiative to refocus courses below calculus. In N. Hastings (Ed.), A freshstart for collegiate mathematics: Rethinking the courses below calculus (pp. 274-282). Washington: Mathematical Association of America. 
Grubb, W. N., \& Cox, R. D. (2005). Pedagogical alignment and curricular consistency: The challenges for developmental education. In C. Kozeracki (Ed.), New Directions for Community Colleges, 129 (pp. 93-103). San Francisco: JosseyBass.

Guest, G., Bunce, A., \& Johnson, L. (2006). How many interviews are enough? An experiment with data saturation and variability. Field Methods, 18(1), 59-82.

Hagedorn, L. S., Maxwell, W., Rodriguez, P., Hocevar, D., \& Fillpot, J. (2000). Peer and student-faculty relations in community colleges. Community College Journal of Research and Practice, 24(7), 587-598.

Harvey-Smith, A. B. (2002, November). An examination of the retention literature and application in student success. Promoting Inclusion, 5, 14-26.

Higbee, J. L., Arendale, D. R., \& Lundell, D. B. (2005). Using theory and research to improve access and retention in developmental education. In C. Kozeracki (Ed.), New Directions for Community Colleges, 129 (pp. 5-15). San Francisco: JosseyBass.

Hilmer, M. (1997). Does community college attendance provide a strategic path to a higher quality education? Economics of Education Review, 16(1), 59-68.

Hodges, J. P. (2008). College students' reasons to attend college and learning community Participation (Doctoral dissertation, Michigan State University). Dissertation Abstract International, 68(09), 0128A.

Horkheimer, M. (1982). Critical theory. New York: Seabury.

Hoyt, J. E. (1999). Remedial education and student attrition. Community College Review, 27(2), 51-72.

Ishler, J. L. (2003). Laying the foundation for general education: The role of first-year and short seminars. Journal of General Education, 52(2), 71-83.

Jacobson, S. P. (2008). Initiating residential learning communities: Critical elements and Practice (Doctoral dissertation, University of the Pacific, 2007). Dissertation Abstract International, 68(08), 0173A.

Killacky, J., Thomas, C., \& Accomando, A. (2002). Learning communities and community colleges: A case study. Community College Journal of Research and Practice, 26(10), 763-775.

Kincheloe, J. L. (2008). Critical pedagogy. New York: Peter Lang. 
Kincheloe, J. L., \& McLaren, P. (2000). Rethinking critical theory and qualitative research. In N. Denzin \& Y. Lincoln (Eds.), Handbook of qualitative research (pp. 279-314). Thousand Oaks, CA: Sage.

Knight, W. (2003). Learning communities and first-year programs: lessons for planners. Planning for Higher Education, 31(4), 5-12.

Kraemer, B. A. (1997). The academic and social integration of Hispanic students into college. Review of Higher Education, 20(2), 163-179.

Kraska, M. F., Nadelman, M. H., Maner, A. H., \& McCormick, R. (1990). A comparative analysis of developmental and nondevelopmental community college students. Community College Journal of Research and Practice, 14(1), 13-20.

Lareau, A. (1987). Social class differences in family-school relationships: The importance of cultural capital. Sociology of Education, 60(2), 73-85.

Lau, L. (2003). Institutional factors affecting student retention, Education, 124(1), 126-136.

Lemeke, J. (1993). Discourse, dynamics, and social change. Cultural Dynamics, 6, 243-275.

Ley, K., \& Young, D. B. (1998). Self-regulation behaviors in underprepared (developmental) and regular admission college students. Contemporary Educational Psychology, 23(1), 42-62.

Malnarich, G. (2005). Learning communities and curricular reform: Academic apprenticeships for developmental students. In C. Kozeracki (Ed.), New Directions for Community Colleges, 129 (pp. 51-62). San Francisco: Jossey-Bass.

Marshall, C., \& Rossman, G. B. (2006). Designing qualitative research. Thousand Oaks, CA: Sage.

Maxwell, W. E. (2000). Student peer relations at a community college. Community College Journal of Research and Practice, 24(3), 207-217.

McCabe, R. (2003). Yes, we can! A community college guide for developing America's underprepared. Phoenix, AZ: League for Innovation in the Community College.

McLaren, P., \& Hammer, R. (1989). Critical pedagogy and the postmodern challenge. Educational Foundations, 13(3), 29-69.

Meehl, P. E. (1996). Clinical versus statistical prediction. Northvale, NJ: Jason Aronson. 
Merriam-Webster's collegiate dictionary (10th ed.). (1993). Springfield, MA: MerriamWebster.

National Learning Communities. (n.d.) National resource directory. Olympia, WA: Evergreen State College Washington Center for Improving the Quality of Undergraduate Education. Retrieved July 25, 2007, from http://www.evergreen.edu/washcenter/directory_entry.asp

Pace, C. R. (1984). Measuring the quality of college student experiences. Los Angeles: University of California Higher Education Research Institute.

Pascarella, E. T., \& Terenzini, P. T. (1980). Predicting freshman persistence and voluntary dropout decisions from a theoretical model. Journal of Higher Education, 51(1), 60-75.

Pascarella, E. T., \& Terenzini, P. T. (1991). How college affects students. San Francisco: Jossey-Bass.

Pascarella, E. T., Whitt, E., Nora, A., Edison, M., Hagedorn, L. S., \& Terenzini, P. T. (1996). What have we learned from the first year of the national study of student learning? Journal of College Student Development, 37(2), 182-192.

Pascarella, E. T., Wolniak, G. C., Pierson, C. T., \& Terenzini, P. T. (2003, May/June). Experiences and outcomes of first-generation students in community colleges. Journal of College Student Development, 44(3), 420-429.

Patton, M. Q. (2002). Qualitative research and evaluation methods ( $3^{\text {rd }}$ ed.). Thousand Oaks, CA: Sage.

Peshkin, A. (1988). In search of subjectivity - one's own. Educational Researcher, 17(7), 17-21.

Pintrich, P. R., Smith, D., Garcia, T., \& McKeachie, W. J. (1991). A manual for the use of the Motivated Strategies for Learning Questionnaire (MSLQ). Ann Arbor, MI: National Center for Research to Improve Post-Secondary Teaching.

Poindexter, L. D. (2007). Exploring collaboration and persistence among college women enrolled in a learning community (Doctoral dissertation, University of San Francisco, 2007). Dissertation Abstract International, 68(02), 6019A.

Raftery, S. (2005). Developmental learning communities at metropolitan community college. In C. Kozeracki (Ed.), New Directions for Community Colleges, 129 (pp. 63-71). San Francisco: Jossey-Bass. 
Reid, C. J. (2004). Advancing women's social justice agendas: A feminist action research framework. International Journal of Qualitative Methods, 3(3). Retrieved August 24, 2007, from http://www.ualberta.ca/ iiqm/backissues/3_3/html/reid.html

Roueche, J. E., \& Roueche, S. D. (1999). High stakes, high performance: Making remedial education work. Washington: Community College Press.

Schwandt, T. A. (2007). The SAGE dictionary of qualitative inquiry. Thousand Oaks, CA: Sage.

Seidman, I. (2006). Interviewing as qualitative research. New York: Teachers College Press.

Singleton, R. A., Garvey, R. H., \& Phillips, G. A. (1998, May/June). Connecting the academic and social lives of students. Change, 30(3), 18-25.

Slaughter, R. A. (1989). Cultural reconstruction in the post-modern world. Journal of Curriculum Studies, 21(3), 255-270.

Smilkstein, R. (2003). We're born to learn: Using the brain's natural learning process to create today's curriculum. Thousand Oaks, CA: Corwin Press.

Smith, B. L. (2001, Summer/Fall). The challenge of learning communities as a growing national movement. Association of American Colleges \& Universities Peer Review, 4(1), 4-8.

Smith, B. D., \& Commander, N. E. (1997). Ideas in practice: Observing academic behaviors for tacit intelligence. Journal of Developmental Education, 21(1), 3035.

Spady, W. (1970). Drop-outs from higher education: An interdisciplinary review and synthesis. Interchange, 1, 64-85.

Stefanou, C. R., \& Salisbury-Glennon, J. D. (2002). Developing motivation and cognitive learning strategies through an undergraduate learning community. Learning Environments Research, 5(1), 77-97.

Strong, P. E. (2008). A qualitative investigation of out-of-class student-faculty interaction in an undergraduate residential learning community (Doctoral dissertation, Michigan State University, 2007). Dissertation Abstract International, 68(09), 0128A.

Thombs, D. L. (1995). Problem behavior and academic achievement among firstsemester college freshmen. Journal of College Student Development, 36(3), $280-288$ 
Tierney, W. G. (1992). An anthropological analysis of student participation in college. Journal of Higher Education, 63(6), 603-618.

Tinto, V. (1975). Dropouts for higher education: A theoretical synthesis of recent research. Review of Educational Research, 45(1), 89-125.

Tinto, V. (1997, November/December). Classrooms as communities: Exploring the educational character of student persistence. Journal of Higher Education, 68, $599-624$.

Tinto, V. (1998). Colleges as communities: taking research on student persistence seriously. Review of Higher Education, 21(2), 167-177.

Tinto, V., \& Goodsell, A. (1993). Freshman interest groups and the first-year experience: constructing student communities in a large university. Journal of the Freshman Year Experience, 6(1), 7-28.

Tokuno, K. A. (1993). Long term and recent student outcomes of the freshman interest groups. Journal of the Freshman Year Experience, 5(2), 7-28.

Valadez, J. (1993). Cultural capital and its impact on the aspirations of nontraditional community college students. Community College Review, 21(3), 30-43.

Van Gennep, A. (1960). Rites of passage. London: Routledge and Kegan Paul Ltd.

Wild, L., \& Ebbers, L. (2002). Rethinking student retention in community colleges. Community College Journal of Research and Practice, 26(6), 503-519.

Wilmer, E. C. (2008). The influences of interaction on the satisfaction, achievement, and retention of developmental community college students (Doctoral dissertation, Old Dominion University, 2007). Dissertation Abstract International, 68(09), 0418A.

Zhao, C., \& Kuh, G. (2004). Adding value: Learning communities and student engagement. Research in Higher Education, 45(2), 115-138. 
APPENDICES 
Appendix A - Cover letter for Exempt Status for Interviewees 


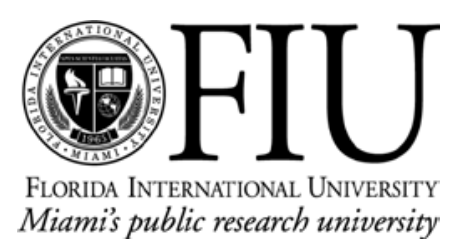

FIU IRB Approval \#121407-00

\section{Dear Student:}

As a former First Year Experience (FYE) student, the college faculty, administrators, and students can to learn from your experience. You are invited to participate in a research study to learn about FYE students and their perceptions and attitudes about college. This research is being done as part of my program as a doctoral student at Florida International University.

I am asking you to participate because I believe that your ideas and feelings about college would help me better understand students who test into all three prep areas. The personal benefits of doing this study are that you might learn some new things about yourself, and you might enjoy sharing your ideas and perceptions about college. In addition, your participation in this study may help me and others better understand what colleges can do to help students be successful. There should be no risks in talking about your perceptions of college.

I will be the only person who knows you are participating in this study. Anytime I use the information you give me or quote you, I will always identify you with a pseudonym. When I interview you, I would like your permission to tape-record our interviews. I will also take notes to remind me about what we talked about. I will be the only person who listens to the tapes and reads the notes. When I am not using them, they will be kept in a locked cabinet at home to which I only have the key.

As part of your participation in this study, I will spend time with you and talk with you over the course of several months. Initially, I will talk with you for an hour or two and ask questions about your experiences. Also, I will ask that you participate in a focus group to clarify ideas and ask if my interpretations capture your thoughts, perceptions, and experiences.

The most important thing for you to remember while you are participating in this study with me is that there is no right or wrong answers to the questions I ask you. All I am looking for is your opinion or ideas. If I ask you to tell me more or explain your answer, it is because I want to be really sure I understand what you are telling me. Always remember that in this situation, you are the expert and are explaining to me your experiences as a student. 
You may also ask questions concerning the study at any time. You may contact the major advisor and supervisor for this study: Dr. Nevin at 954-483-3175 or Dr. Patricia Price, the Chairperson of the FIU Institutional Review Board at 305-348-2618 or 305-348-2494.

You should also know that you can decide to not participate in this study or stop doing it at any time after you have started. This is your decision. If you decide to stop doing this study, your decision will not affect any contact you have with me, your professors, ABC Community College, or Florida International University. Just like FYE, this is completely voluntary.

I am grateful for your participation. Thank you.

Sincerely,

Peter Barbatis

Principal Investigator 
Appendix B - Letter of Informed Consent for Interviewees 


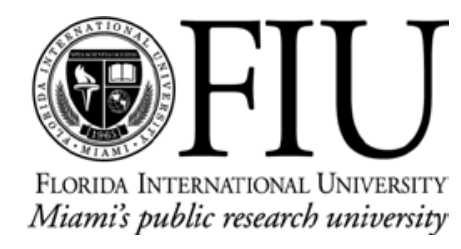

FIU IRB Approval \#121407-00

December 14, 2007

\section{Dear Former FYE Student,}

You are being asked to participate in a research study. The principal investigator of this study is Peter Barbatis, a doctoral candidate in the Higher Education Program, Department of Educational and Leadership Policy Studies in the College of Education at FIU. Your participation as an interviewee will require a total of about 2 hours of your time. We want to learn more about your experiences as a college student.

If you decide to participate in the study, you will be interviewed at a place and time convenient to you. The interview will be audio-taped, transcribed, and returned to you for editing and approval.

We do not expect any harm to you as a result of participating in this study. You may change your mind and stop your participation at any point should you feel uncomfortable or feel upset in any way without consequence. The audio-tape and transcript of your interview will be identified by a special number (not your name or student number). All information will be kept strictly confidential and will be destroyed at the end of the study.

If you would like more information about this research, please feel free to contact Dr. Ann Nevin, Major Professor, at (954) 483-3175. If you would like to talk to someone about your rights of being a subject in this study, you may contact Dr. Patricia Price, Chairperson of the FIU Institutional Review Board at (305) 348-2618 or (305) 348-2494.

Your signature below indicates that all questions have been answered to your satisfaction. You are aware of your rights and agree to be interviewed for the study.

Signature of Participant

Printed Name

Date

I have explained the research procedure subject rights, and answered questions asked by the participant. I have offered him/her a copy of this informed consent form.

Signature of Witness

Date 
Appendix C - Individual Interview and Focus Group Protocols 


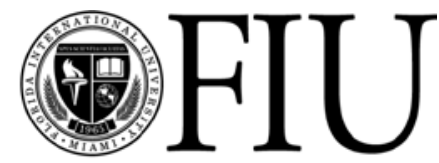

FLORIDA INTERNATIONAL UNIVERSITY

Miami's public research university

FIU IRB Approval \#121407-00

Tell me about your life as a student at this college?

Tell me about your family. How does your family influence your college experiences? Have you encountered any barriers or obstacles? How have you been encouraged to go and stay in college?

Who are your closest friends? Where did you meet them? What are they like? Why are they your friends? In what ways do they affect your education at this college?

Tell me some of the reasons for deciding to continue your education and go to college?

What factors lead you to choose this community college?

What is/was your major? Why did you choose this major?

Why did you choose to participate in FYE?

In what ways did FYE fail you or disappoint you? How did FYE help you?

What did you expect to encounter in college? How or how not were those expectations met?

Tell me about a typical professor you've had for class. What classes have been your favorites? What professors have made the most impact on you? How about your least favorites?

What are your goals? Where do you see yourself one year from now?

Who helps you succeed in college classes? Who have you asked for help while in college? Tell me about any employees of ABC that you sought help from? What about departments? (For Persisters)

Who did you ask for help while in college? Tell me about any employees of ABC that you sought help from? What about departments? (For Non-Persisters) 
Do/did you feel comfortable at this college? Tell me a little about what parts of ABC make you feel that way?

What are/were your favorite places on campus? Are there any parts of campus you find yourself avoiding?

How do/did you come to campus? Where do/did you park, if applicable?

If I asked you to show me something in your wallet, purse or backpack that represents you, what would it be?

What three adjectives best describe you?

What motivates you? Can you share a favorite saying or quote or advice from a person important to you that you think of when you face challenges?

What other aspects of your life seem to compete with school responsibilities?

Have/did you joined/join any student groups on campus? If yes, tell me about them. If no, why not?

How many hours per week do/did you study?

Tell me about a time when you almost quit and what kept you going? (For Persisters)

Tell me about the best experiences you've had in your education?

Tell me about the worst experiences you've had in your education?

How has race, gender or culture affected your education?

Many of the students you started courses with are no longer here. What do you think made the difference for you? (For Persisters)

Why did you leave school? What would have kept you in school? (For Non-Persisters)

What advice would you give incoming freshmen starting school?

Anything else you would like to add? 


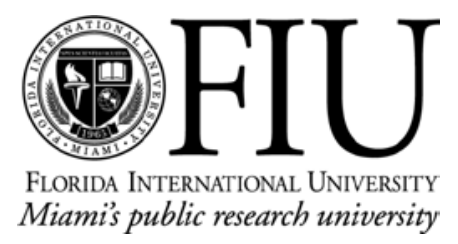

FIU IRB Approval \#121407-00

Promise of Confidentiality

This form is intended to protect the confidentiality of what members of this discussion group say during the course of this study, Perceptions of Underprepared Community College Students Regarding their Educational Achievement. Please read the following statement and sign your name indicating that you agree to comply.

Acknowledging that everyone's story is their own to tell, I promise that I will not communicate or talk about information discussed during the course of this focus group with anyone outside of my fellow focus group members and the facilitator.

Name

Signature

Facilitator Signature 


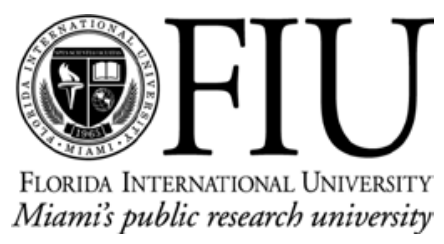

FIU IRB Approval \#121407-00

Hi, Everyone. Thanks for coming and being part of this focus group. I'm interested in learning about your experiences in college. After our personal interviews, there are some broad themes I would like us to talk about as a group. Before we begin, there's a couple of housekeeping items:

First, there are no right or wrong answers. All themes are grounded in personal experiences and perceptions which vary from one individual to another. I'm interested in understanding your perspective about overall ideas that encapsulate what you have said previously and whether you agree or disagree.

Second, based on what I just said, you do not need to agree with everyone else in this room if that's not how you really feel. It is expected that you will each have a different view. It's important that we learn about all of the views represented here. In addition, you are free to leave at any time. You should also feel free to not answer any questions.

Third, it is important for you to feel comfortable saying good things as well as critical things.

Fourth, please talk one at a time so that we can be sure to hear everyone's views and get them on tape.

Any questions? Okay let’s start with everyone introducing themselves.

One of the themes that was revealed is the importance of family support. In what ways does this statement fit with your own experiences? In what ways does the statement not fit with your experiences?

(Each theme was checked in the same way). 


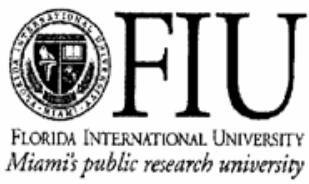

Office of Research Integrity

Research Compliance, MARC 430

\section{MEMORANDUM}
To:
Peter Barbatis
$\mathrm{CC}$ :
Dr. Ann Nevin

File

From:

Chris Grayson, CIM, Asst. Director of Research Compliance

Date:

December 18, 2007

Proposal Title: Perceptions of Underprepared Community College Students Regarding their Educational Achievement.

Approval \# 121407-00

Your study was deemed Exempt by the Institutional Review Board at Florida International University on December 14, 2007.

As a requirement of IRB approval you are required to:

1) Submit a completion report (Form B-2) upon completion of your project in order for the file to be closed.

2) Submit a proposal and receive approval for any additions or changes in the procedures involving human subjects.

3) Provide immediate written notification to the IRB of every serious or unusual or unanticipated adverse event as well as problems with the rights or welfare of the human subjects. You must confirm the receipt of serious AE reports with the IRB office.

Special Conditions: N/A

Please note your approval number is indicated above. For further information, you may contact the IRB Coordinator by email at irbiacuc@fiu.edu or visit the OSRA - Human Subjects website at www.osra.fiu.edu. 
Appendix D - Summary of Coding Procedures 
Method used for Coding

- Make a copy of transcript

- Develop tentative list of themes

- Using themes, mark transcripts, identifying information that may not fit into themes

- Review and revise list of themes to capture all transcript content

- Once themes are finalized, highlight each theme by different color

- Within each theme (color), use red pen to identify sub-themes in content

Themes for Coding

\begin{tabular}{|c|c|c|}
\hline Color & Theme & Description \\
\hline Yellow & $\begin{array}{l}\text { Pre-College } \\
\text { Characteristics and } \\
\text { Traits }\end{array}$ & $\begin{array}{l}\text { Participants share personal characteristics and } \\
\text { attributes that affect their success. } \\
\text { Code 1. Sense of Responsibility/Duty } \\
\text { Code 2. Goal Oriented } \\
\text { Code 3. Resourcefulness } \\
\text { Code 4. Determination } \\
\text { Code 5. Cultural and Racial Self-Identification } \\
\text { Code 6. Faith }\end{array}$ \\
\hline Blue & $\begin{array}{l}\text { External/Community } \\
\text { Influences }\end{array}$ & $\begin{array}{l}\text { Participants attributed their success to supportive } \\
\text { families who include parents, particularly mothers, } \\
\text { siblings, grandparents, cousin, fiancée and peers. } \\
\text { Code 1. Parents } \\
\text { Code 2. Familial Relationships } \\
\text { Code 3. Peers } \\
\text { Code 4. High School Faculty }\end{array}$ \\
\hline Green & Social Involvement & $\begin{array}{l}\text { Participants described their involvement in student } \\
\text { clubs and organizations as impacting their success } \\
\text { and giving their educational pursuits a sense of } \\
\text { purpose } \\
\text { Code 1. Student Activities/Peer Interaction }\end{array}$ \\
\hline Orange & $\begin{array}{l}\text { Academic } \\
\text { Integration }\end{array}$ & $\begin{array}{l}\text { Each participant identified faculty, campus resources } \\
\text { and time management as ways they integrated to the } \\
\text { academic community. } \\
\text { Code 1: Faculty } \\
\text { Code 2. Campus Resources } \\
\text { Code 3. Time Management } \\
\text { Code 4. Self-Reliance/Independence }\end{array}$ \\
\hline
\end{tabular}


Appendix E - Sample Interview Transcript 


\section{Sample from Interview Transcript}

Interview \#6

Peter Barbatis (P), “LeLe” (L)

February 14, 2008

11:00 a.m.

P: $\quad$ It's Valentine's Day and I'm here with "LeLe” who has graciously agreed to be part of the FYE study. Thank you for coming today.

L: $\quad$ You're welcome.

P: $\quad$ Umm, I'm going to ask a series of questions. It's going to be a

conversation. Please feel free to adlib and tell whatever stories you'd like to tell. First question, tell me about your life as a student as this college. What was it like?

L: $\quad$ Umm, I think it was great. I made a lot of friends - friends that I still have contact with now, and I ended up doing the work study here, so I got an inside of the college. I loved it. I recommend it to everyone and I tell everyone, ABC was the best years of my life. I loved it here. I wasn't as independent when I got out of high school so I wasn't ready to jump into the away-from-home college scene, but this really (pause) I didn't feel like I had anything left out. I was able to experience things that were - that other people experienced at colleges they went away to.

P: $\quad$ Tell me about your family.

L: $\quad$ Umm, my mom has five children. She has 3 girls and 2 boys. I am the second to go to college. My brother, who is 25, is ahead of me. He went out-of-state. As soon as he got out of high school, he went away to Kent State in Ohio, which is pretty far. So, he went away and, umm, I stayed back here, so, umm, and I have a little sister who is 16 and now, she is going through the whole college process of where she's trying to decide where's she's gonna go, umm, my mother attended ABC but she ended up leaving to pursue a career in something else, and she ended up having children so she never came back, but I actually convinced her to come back, so now she's back at ABC. She took, umm, a class last semester. She took environmental science and she passed with a "B", so that's really good with her. So, now she's back coming to get her 2 year degree.

P: $\quad$ You've been a role model. 
L: $\quad$ Yeah, I've been a role model. I pushed her and pushed her. I always was telling her get back in and she never did, and so finally I had to take one last class at ABC for my AA and I told her - I said, "This is the time. You can take it with me.” And she took it with me and I didn't help her. She ended up doing all her work herself - taking her notes herself and she ended up passing. That was the boost that she needed. So, now she's going - do more classes.

P: $\quad$ Let me ask you this. What is like taking a class with a parent, with your mom?

L: $\quad$ It was different because I had that person there, like, behind me, pushing me. It was like, when I would come home from work, she gets home before me so, when I get home from work, she'd be like, "LeLe, you going to study for the test?” I'm like, “Nah, I'll study later.” And, she’s like, "Well, I'm studying now, so maybe you should study now" So, it was like...she was the extra push behind me and in class, you know, she would help me out if I didn't understand and I would help her out and then the class, we ended up doing group projects and we didn't get to be in the same group...so it was different experiences for her doing a group project, being thrown into where - she's never experienced powerpoints before, and having to figure out what was a powerpoint and how to use it, and me showing her. Well, this is how you do the powerpoint and (pause) it was a good experience taking a class with her and I liked it. It was fun.

P: $\quad$ Good. Okay, there are six of you. There's five siblings and your mom, right?

L: $\quad$ Yeah.

P: $\quad$ How did they influence you going to college, in terms of your experiences?

L: Umm, my brother really was like the one to say, you know, college is the only choice. Well, even with my mother, that was - that was always instilled in us. After high school, there was no, what do I do now. There was always college. You had to go somewhere. Necessarily didn’t have to go out-of-state or upstate, but you had to go somewhere, and my sister who was older than me, before my brother, she went to a vocational school and she took up dental assisting. So, there was always you had to something else. There was no, I'm out of high school, maybe I'll jump into the workforce. There was never that. There was always, now you go off to school again. So, my mother always instilled that in us, and then when I got out of high school, I was kinda floating around - wasn't sure if I really wanted to start college right then, but my brother was the pusher 
that said, "If you don't start now, you'll never start." So, he was kinda the one that pushed me to start school and I was really grateful for that. So, it's kinda a thing - like, my sister now. She's only in $11^{\text {th }}$ grade, but now I'm telling her, you're not where you want to go, narrow it down to the schools. So, it's been really good with all of us trying to push each other to continue what we're doing.

P: $\quad$ What did he choose to go out-of-state to Ohio, because that's pretty far?

L: $\quad$ He was, umm, he played high school football, so he got recruited. He got a five year scholarship. So, that's why he chose to go to out-of-state, because if it was me, I would have never went out-of-state. But he went out-of-state and he loved it. He was able to travel all around on the football team and his major was criminal justice. So, he really enjoyed it...he liked it. Me, I'm still not ready to go out-of-state, I don't think but, that was his decision. He really enjoyed it and he wants me to go further from home because he says I would experience more, but I think I experience more still down here, closer to home.

P: $\quad$ We make our experiences where we are. So, that doesn't necessarily mean you have to leave. So, you have two older siblings, then there's you? You have a 16 year old sister?

L: $\quad$ I actually have three older siblings. I have a brother who is 34, I believe, my sister who is 29 , my brother who is 25 - me, and then my 16 year old sister.

P: $\quad$ Any barriers or obstacles from your family about going to school?

L: $\quad$ Umm, no, it really wasn't any barriers or obstacles. It was really good. Umm, I tell everyone, when I first started ABC I was very attached to my mother - very dependent on her. I didn't drive. I didn't have a license, no permit - so, she would drop me off at 7:30 in the morning, on her way to work. She'd drop me off, I'd sit here, I'd study, I'd do what I needed to do, and then slowly my friends would start coming and we'd talk. I'd go to class and then I would have to sit here until about 4:30 when she got off from work to pick me up which was kinda good in the sense that I was able to experience more of ABC because I had all that free time here. I was able to know what was open at that time, what was going on at this time. So, it made me be able to experience more, but that was one of my big barriers - not being able to drive. But, my mother, she was so great in the fact that she was willing to drop me off and willing to pick me up and willing to do this and that for me. So, there wasn't really any barriers, because everyone was able to help in a little way if they could. 
P: $\quad$ Did she go with you to orientation?

L: $\quad$ Yes, she came with me to orientation because I was actually kinda going at a slow pace and it was getting closer to the start of school and she looked at me and said, "Have you done your stuff for ABC?” And, I said, "No, I haven't done it yet, but I'm going to do it”, and she said, "No, you're going to do it now." The next day she brought me out here and I went down to Admissions and took care of everything and then she came with me to orientation. So, she was here through the whole process and she was one of the ones that pushed me. So, yes, you should do FYE because she knew it would be a different transition for me because I went from a high school where I was there from kindergarten til $12^{\text {th }}$ grade. So, there was never - I never had that experience of making new friends since I always with the same friends and we were always in the same group, so I knew I would make friends eventually, but I wasn't the outspoken person to go get friends. So, she was the one who pushed me to join and thought it would be a good thing.

P: $\quad$ Who are your closest friends?

L: $\quad$ Now, my closest friends - one of closest is "Terika", who was in FYE with me. We still talk. We don't talk as much because she goes to umm, she transferred to [local private university] and I still had a few classes out here to take, but we still talk. We meet up every chance we get or I'll go and pop up at her job to go see her. She's basically one of my closest friends. And my other friends are friends that I had from high school.

P: $\quad$ So, you said you met "Terika" here and you met your other friends in high school. Tell me why they are your friends?

L: $\quad$ They're my friends because they were - most of them were on the same journey that I was in. Like my friends from high school, we worked together all the time and most of them are education majors, so we're all in the same area that we know what's going on. Me and "Terika", we were both straight out of high school, getting into college, and I think we're still friends because she understands the hassle that it is of going to school. Like, if I can't talk to her then she knows I'm probably busy with school work or writing papers as it is the same with her. I'll know if she's busy and so, we try to make time for each other, but we understand each other's schedule more than anything else.

P: $\quad$ You might have hit on this, but in what ways, specifically your friends from [a local university], how did they affect your education in terms of going to college? Did any of them from [high school] go to ABC, too? 
L: $\quad$ Umm, none of my friends from [high school] went to ABC, but most of them stayed here locally and went to [local university]. Some went to [local university]. It was in the fact that they helped me because they knew what to expect or what to do. So, like with “Terika," when we were in FYE, we knew what to do because we were all together and we had the same work and there were times when I didn't know what was going on. I was confused - she would help me out and I would do the same with her. I would help her out. So, it was like the friends that I have now. Even today, if there's a problem with work I can call on my friend, because she's in the same area of work that I do. We're both education majors so, we're basically all in the same cluster that we can help each other out.

P: $\quad$ Okay. Tell me some of the reasons for deciding to continue your education and go to college.

L: $\quad$ Umm, I want to be a teacher. I always wanted to be a teacher since I was 7. I know that was nothing else other than college to become a teacher. After my 2 years at ABC and I got my AA, I was thinking about going to be a teacher's assistant and my mother said, “Well, if you're a teacher's assistant, you may like it too much and then you won't be a teacher and you have to follow someone else's rules and are you ready to follow someone else's rules when you think it should be this way." So, that's one of the reasons to pursue it further to receive a BA or maybe more.

P: $\quad$ Why education? You said since 7 years old, you liked that. What turned you on about being a teacher?

L: $\quad$ Umm, I think I've always had this helping nature in me - to help teach people and able to show someone something and for them to do. I've always had that in me, even as a child. My mother had my little sister when I was 6 years old, and I thought that was just the greatest thing because I learned to help take care of a baby and everything I've always done has been around children. Some of my first jobs were babysitting and it was always in me. And then when I got 11 years old, I believe I was in the $5^{\text {th }}$ grade, my school, they got a grant to start a special needs program and they had children who were autistic and ADHD and I went and volunteered in the class one day and that was like the light bulb went off that was what I wanted to do. So, when I got to ABC, my major was elementary education, but I ended up changing it to special education because I just love the whole aspect of special education. I love being able to help someone to do something that people would think they wouldn't be able to do.

P: $\quad$ So, you're a champion for the underdog? 
L: $\quad$ Yeah, that's basically what I am (light laughter). My job now, umm, when I first starting looking for jobs, I became a special needs counselor in the after-school program where I work with children who have ADHD and autism and bipolar. I had all of that and I always been an aspect of my life. I just love helping everyone out.

P: $\quad$ Are you a patient person?

L: $\quad$ It depends. It really depends. I'm patient - my mother says I'm patient with other people. When - I'm patient with most people who needs patience, but it's like, I'm not patient with my sister. It's like I try to drill things into her and she won't get it and I just get frustrated and I don't want to help her anymore. But, I try. My mother says I'm patient because she came to my job one day when I was working with special needs and she said, "You're the most patient person I know because I would loose my mind. I don't know how you can sit there and do the same things over and over and over again.” So, I guess I have a little bit of patience in me when it comes to working with children.

P: $\quad$ What factors led you to choose this community college versus going to another school?

L: Umm, my mother went here. My mother went to North Campus. She started here and that was one of the ones that - the reason why I came to North Campus. South was too far.

P: $\quad$ Central was right next to [high school].

L: $\quad$ Central was right next to [high school], but see, I stay in "Buckfield.” So, I was bused to [high school] for those 13 years that I went there. So, North was more convenient - closer to home.

P: $\quad$ Although XYZ Community College is real close to you?

L: $\quad \mathrm{XYZ}$ is very close, but (pause) I never knew that there was a XYZ college until I first came to ABC and I found out that there was a XYZ college, but $\mathrm{ABC}$ is the first choice because my mother went here. I had never stepped on the campus until the day I came out to register. I had never been here before and this is where (pause) and I was so afraid, cause I would see it from the Turnpike and I was like (pause) that's such a big campus - I'm never gonna find my way around. And then I ended up finding my way around the campus and knowing everything about it.

P: $\quad$ Why did you choose to participate in FYE? 
L: $\quad$ Umm, when I first came, I, umm, I was told I'd have to take the classes the remedial classes and they said I could test out of it. And so, I talked to my mother and she said, "Do you really want to test out of it?" She said, "If you want to test out of it, then you can test out of it, but I don't want you to test out of it and then you be too overwhelmed with it. You'll feel like you're falling behind and I don't want you to get there in your first semester there and you get discouraged." She said, "It's not going to hurt you, it can only help you.” That was one of the reasons that I really did it. And they said that you would have 25 kids that you would all go to the same classes together. And so I'm like, that's good - 25 people that you would get to know. So, that was one of the real reasons that I really joined - it was the whole - that you wouldn't have to - you would know who's going to be in your classes. You knew there would be a support system there.

P: $\quad$ In what ways did FYE fail you or disappoint you?

L: Umm, that's hard. I really can't say that it disappointed me. I'm trying to think, but I really don't think there's any way that it really disappointed me. It was really good for that year. If it could have gone on longer, that would have been great, but then, you know, but then you wouldn't be able to experience as much as you would after not being in those classes, but it was really great for the time cause we were able to continue, even though you weren't with those same people in those same classes, you were able to continue, still talk to the friends that you had and you were able to do more things. And so, it was really good in the fact in that (pause) but I wouldn’t say that it disappointed me in any way.

P: $\quad$ How did it help you?

L: $\quad$ It helped me in becoming more (pause) driven (pause) more outspoken (pause) more, it was - it became more comfortable. I was able to meet new people who I wouldn't have met otherwise. I was able to make more friends. I was able to do more things in the college. I was able to like, me and my friends, when we were in FYE, a lot of us went on the leadership trips that Student Life did, like, I would never have gone camping, we went out to the camps. We went both years. We went to Ocala once and to Lake Placid the other time. And, it was able to just build those relationships among other students.

P: $\quad$ What did you expect to encounter in college before you came? When you were in high school, what did you think college was like?

L: $\quad$ I thought college was just a lot of work and time-consuming and no time for anything else. It was just kinda like a routine. You switch from one 
class to another class and then you go home. You do work. You come back the next day and I just thought it was very routine. It wasn't (pause) I thought it was more stricter than high school, but when I got here, it was more (pause) it was more (pause) being more independent. Like, no one was going to make you. You didn't have to go to class if you didn't want to, but you knew there was going to be consequences if you didn't go to class.

P: $\quad$ So, were your expectations met? You said it wasn't going to be as much fun. Is that the way college ended up being?

L: $\quad$ College ended up being fun. I never knew that. I thought, especially at community college, I knew that more colleges did a lot of things where they had festivals and things and when I thought about community colleges, I really didn't think that it was so much more student-centered (pause) that it was more academic. It was just a stepping stone for you to go on to your next college. So I didn't think it was as student-centered. But, getting out here, I was able to experience that there was more. It was more student-centered. You were able to do things. There was festivals and there were lots of things you could participate in. So, it was much more than what I expected it to be.

P: $\quad$ Tell me about a typical professor that you had for class?

L: $\quad$ Umm, FYE professor or?

P: $\quad$ Either one. Pick a professor. What are they like?

L: $\quad$ The professors are good. My stick out was Ms. "Morrow." She was my SLS for FYE. SLS was a good class, but Ms. "Morrow" (pause) she was just so helpful and she was (pause) if there was a problem (pause) that was one of the professors that I always went to and even when I got out of FYE and I had to register for classes or I had questions. She still the professor I went to. She's the professor who wrote college recommendations for me. She's always been that professor that I've always gone back to. If I had a question, I went to her or if I needed something, I always went to her.

P: $\quad$ What classes were your favorite classes?

L: $\quad$ My favorite classes (pause) Sociology with Dr. "Stone” was my favorite. Just because I like to talk. I love to talk about anything and everything (pause) and I used to (pause) his class was centered around an open discussion. So, I would like (pause) read the paper in the day and circle things and when I'd get to his class, I'd be like, "Dr. Stone, I want to talk 
about this. What is this? I don't understand this.” And, we would talk about things from the war to laws that they were trying to pass or just (pause) we would talk about so many different things and I was always willing and ready and he was very willing and ready to talk about it with me. I think that was one of the best classes that I had - my Sociology class.

P: $\quad$ What about your least favorite classes?

L: $\quad$ Umm, Astronomy. I took Astronomy. I don’t know why. I think because I registered late, so I had to take Astronomy. That was just one of the classes that I could not grasp. As much as I studied, as many notes as I took...I just could not grasp Astronomy. It was just, (pause) I think that was one of my subjects that was not for me. Like, math has always been a struggle, but Astronomy, it was just one of those classes.

P: $\quad$ Tell me about your goals. Where do you see yourself a year from now?

L: $\quad$ A year from now, hopefully (pause), right now, I'm in the process of trying to figure out where I want to go to school. So, I don't know which school I'm going to be enrolled in. So, hopefully a year from now, I'm in school (pause) closer to graduating and closer to finishing because that's the only thing that I can see myself in a year is being more centered on school and ready to finish.

P: $\quad$ Special ed?

L: $\quad$ Special education is going to be my major, yes.

P: $\quad$ Are you working now?

L: $\quad$ Yes, I work for the YMCA - ABC County After School Care. I started working for them at 19. I saw them at a job fair here at ABC and that's one of the reasons that I started working for them. And I've been with them basically the whole time while I was at ABC.

P: $\quad$ Is this a full-time job?

L: $\quad$ It's a part-time job.

P: $\quad$ It’s Monday through Friday?

L: $\quad$ Uh-huh. 
P: $\quad$ Who helped you succeed in classes? For example, what offices or departments did you go to that you sought help from?

L: $\quad$ Umm, it was not really departments; it was more people. FYE instilled in me the people I could go to. If there was a problem, then I went to Ms. "Morrow." Like, she was the first person I would always go to (pause) and if she wasn’t available, I would go to Ms. “Gourda Johnson.” It was either her or Ms. "Morrow." Those two were the people. If I was in a class and there was no way that I was getting it. It was either those two I would go to. I didn't experience the departments as much, but Ms. "Morrow." She just always knew the answers not matter what department. If it was financial aid, she knew my financial aid answers. If it was admissions, she always knew the answers for everything. No matter what. If she didn't, she, like, come right back, and she run around, find the answer, write it down for me and she'd explain it to me and then it would be solved.

P: $\quad$ Did you feel comfortable at this college?

L: $\quad$ When I first started, I didn't feel as comfortable because I didn't know, but I would say a month into it, I was comfortable. I knew where - I knew where my classes were. I mean where to go (pause) I knew everything that was going on. I felt really comfortable with it.

P: $\quad$ So, you felt connected?

L: $\quad$ I feel connected. I would feel really connected. When I first started ABC, one of the students in the FYE program played for the basketball team, which I didn't know they had a basketball team until I was with FYE (pause) and she told me, "What's your major?”, and I said, "Education.", and she goes, "Oh, the coach for the basketball team is looking for a babysitter to babysit her son. It's only going to be for like an hour (pause) and since you're out here anyway, you might as well talk to her.” So, I think ABC had a welcome back or a welcome week. So we went there and she was there. So, I spoke to her and that was my first job with ABC - I would watch her son for maybe an hour or two while the basketball team practiced. Me and him would just walk around. I put him in a stroller and we would just walk around ABC campus. We'd go to the library. We'd go to the bookstore. We would go to Student Life. We just went wherever. I think that was one of the reasons why I was so more understanding of $\mathrm{ABC}$, because around the time when I babysat, I think it was around 1 or 2 o'clock, everyone had basically gone home and so it was slower (pause) so when we went around we was able. I was able to see more and understand (pause) like, that's the science building (pause) that's the English building (pause) was able to see much more by working for her. 
P: $\quad$ What were your favorite places on campus?

L: $\quad$ Umm, Student Life and the coffee house. The coffee house is where we would meet in the morning - where most of the FYE students would meet before class (pause) me, “Terika”, “Anekey”, and "Nataya.” We became this group that they named us the clique because I think there was seven of us. We would always hang out. If you saw one, you saw all of us, and that was our meeting place in the morning. If somebody wasn't there, we would be like, "Somebody's not here today", and we'd call them, "Where are you? Are you coming to school today?” So, that was our meeting place (pause) was the coffee house. And, Student Life was fun because when we had (pause) like when classes ended early or we didn't have class that day, we'd go in there and we'd watch a movie for that time and then we'd get up and go to class (pause) we ended up missing the FYE picture because I think our reading teacher wasn't there that day or she was late or something happened that we decided (pause) well, she's not here, we're gonna go to Student Life. So we went to Student Life and we're all sitting in there watching a movie and then it got time for our next class. So we got up to go to our next class and everyone's like, "Ms. Gourda" is looking for you guys. You guys missed the FYE picture.” And when the FYE picture came, all 7 of us, none of us were in the FYE picture because we all were in Student Life and we missed the picture. But we had fun.

P: $\quad$ Any parts of the campus that you avoided?

L: $\quad$ Umm. No, I basically did (pause) except for that building across from the library. I don’t even know.

P: $\quad$ Health Science. The Health Science Building.

L: $\quad$ Yeah, I've been there once, because they had a Saturday garage sale, but it was on the outside. I've never been in the inside that building, but I've basically been everywhere around the campus.

P: $\quad$ How many hours per week did you study?

L: $\quad$ Well, I really didn’t study that. Well, I study that much because I was here in the morning and in the afternoon. Maybe 20 hours a week I would study (pause) at the most. I would try to study before everyone started coming because then it would get noisy and hectic.

P: $\quad$ Did you do most of your studying on campus or at home? 
L: $\quad$ I did some at home, but mostly on campus because I had nothing to do, so it was better for me to study when I was here because it was quiet. There was really no one around.

P: $\quad$ I like this question, but some people have difficulty with it. If I were to ask you to show me something in your purse or backpack that represents you, what would you show me?

L: $\quad$ My phone. My phone is attached to me. My phone describes me because I try to stay connected to everyone. Like, I still have FYE people's phone numbers in my phone. I have people that I had in classes three and four semesters ago, still have their phone numbers in my phone because I try to stay connected to everyone (pause) no matter where I go, no matter what. If I leave my house and I don't have my phone, I will turn back around to go get it 'cause I try to stay connected and I want people to stay connected to me.

P: What motivates you?

L: $\quad$ Success. I think success motivates me. Someone told me success is what you make it. So, I know what I want from life and I know how to get it. So I think that's what motivates me that I (pause) for me to get what I want I have to. I know what I have to do. I have picture on my wall in my room and it's like this rock and the shore and it's one of those pictures that if you look at it, the shore is crashing against the rocks and underneath it has determination, so, I look at it everyday. Determination. I know what I have to do to get what I want. So, that's what motivates me to keep going and keep going.

P: $\quad$ Were you always that way, or is this something that happened since you graduated from high school?

L: I think I've always been that way (pause) a little bit. I fallen off a little bit, but I think I've basically always been that way. Because my mother has instilled that in me to get what you want, you have to know what you want. If you don't know what you want, how are you going to get anything? Like my brother - my brother is one of those people that motivates me the most. When my brother was in $6^{\text {th }}$ grade, he always played little league football, but when he was in the $6^{\text {th }}$ grade, he went to Alpha like me, and he told my mother one day, he said, “Mom, I’m going to play high school football. I'm going to get a scholarship to a college, but I won’t be able to do it staying at "Alpha." I need to go somewhere else that has a better football program." So, my mother told her no, but he kept telling her I need to go somewhere better because their football team is not the greatest. They don't have a good football program. So, she ended up letting him leave and go to another school. So, he went to 
another school and his senior year, his college coach came to our house and he met with my mother and my father and he met me and my sister and my brother got a 5 year scholarship. And he told my mother, "I didn't want you to pay for college and I knew that football was the way for me to go to college and make the best of what I could be.”

P: $\quad$ That's pretty good at 12 .

L: $\quad$ At 12 years old - yeah, my brother knows what to do. He got this 5 year scholarship, he went to school, and he worked hard, and when it got closer to the $5^{\text {th }}$ year, my mother asked him (pause) she said, "Are you going to try and enter the draft or are you going to be a walk-on?” His coach said he was good enough to go on, but he said, "No, I got what I wanted out of it and that was my education. I'm not going to pursue it any further (pause) it's not what I want to do anymore.” He had offers to go play Canadian ball and arena football, but that's not what he wanted to do. He got out of school, he moved. He ended up having a girlfriend in college. He ended up moving to Chicago with her and he got a job working for Tiffany's, the jeweler. He's a criminal justice major and later he did an internship with the U.S. customs while working with Tiffany's and then (pause) umm, he took a test for the government, the FBI agent test, and he ended up scoring the highest in the state of Chicago and he went to training and now he's an ICE agent. It took him a year or two to do it, but when he went to training he was the youngest in his class. His thing is don't say you can't do something. You can do whatever. There were times when my financial aid didn't give me as much money as I thought it would (pause) and I would call him and he would say that's fine, don't worry about it. I'll pay for your books. I'd say, "I'll pay you back.” No, don't worry about it. If I needed anything for school, if it was clothes or shoes or book bags, he'd get it no matter what. He always was willing to do that. He's like the role model that we look up to because he keeps giving and keeps giving and he has that determination.

P: $\quad$ He will be blessed for that. That's a great story. You said something about your dad. Talk about your dad.

L: $\quad$ My dad is from Georgia and he really didn't have the experiences that my mother had, I would say. My mother went to school in Jersey where, at the time she went to school, they were integrated. She was integrated in Jersey and then she came down here. It was segregation, like my dad. He went through the segregation and he stopped going to school, I would say around the $9^{\text {th }}$ grade. So my father still has his $9^{\text {th }}$ grade education. He didn't get his diploma, but my father's the hardest worker I know. He just works really hard. It's sad because his body - not as young as it used to be. So, he works really hard. I think that's another reason that motivates 
me because (pause) I want to succeed in the fact that I want to make enough money that I'm able to take care of myself and take care of parents. But when my mother retires, I want my father to retire. If I have to give them money every month, I will because that's what I see myself doing. He's a tire mechanic and he works really hard (light sobbing). Like, he's 56 and he gets (pause) he used to have to get epidural shots in his back because of the pain. I'm his first born girl and he'll do anything for me (crying). He does anything for me.

P: $\quad$ There's a special relationship between a father and a daughter.

L: $\quad$ I love my dad.

P: Umm, what other aspects of your life seem to compete with school?

L: $\quad$ As in, competing for my time or (pause) umm, my job competes for my time a lot. It really does.

P: $\quad$ Were you doing the YMCA when you were at ABC?

L: $\quad$ When I first started with the YMCA, I was just a counselor. It really didn't take up that much of my time and then I started moving up to where I was an assistant site coordinator, so it competed with a lot of my time because I would have to leave school sometimes early to make it to work. But, it just competed with my time. But now, as I got better with my time, it didn't compete as much. So, nothing really competed with my time, because my mother always let me know, "school was your first priority. If you had to quit your job, fine (pause) quit your job and we'll make it work."

P: $\quad$ What did you do about time management? You said that you improved your time, what did you do?

L: $\quad$ Umm, I made it better because I'm T.V. junkie. I'm a reality show junkie, so I would kinda just stop watching T.V. as much and was able to plan out how to do (pause) study for my classes and still have that leisure time for myself. And it was times when I was working for the YMCA where my children (pause) the kids would snack for 30 minutes. While they're eating snacks, I'd be reading over something. When they were doing homework, I'd be doing homework and it was really good in the fact that the kids would be seeing me do my homework. And they'd be like, "Ms. LeLe, you still in school?” and I'd say, "Yes, I'm still in school” and then I would have night classes, and certain days I would have to leave early, and they'd say, "Ms. LeLe, where are you going? You going to school tonight?” and I'd say, "Yes, I'm going to school." So, it was in the fact 
that I kinda worked it out where it worked out between school and work and then when I got home, it was kinda just reviewing the work that I had done while I was working.

P: $\quad$ So, it was something that you learned in college?

L: $\quad$ That was something that I learned in college. SLS [Student Life Skills] was a good class in the fact that it taught me time management and it taught me planning out. Ms. "Morrow" did an exercise with us which said when you get out of FYE, you pick your own classes. You're able to do that? So, she gave us this paper and it had all these lines and it said fall such and such year, and it went on, I think it was for two years planning. So, she said, "Now, plan out your classes", so I'm writing and planning out my classes and she looks at it and she corrects it and she said, "No, you shouldn't take this many classes (pause) this class is a lot of work." So, she crossed out some of them and she had us fix it and I fixed it and I still have it to this day and so I looked at it all the time. When I was ready to register for my classes, I had my little binder and I would pull it out, and I would register for this class or if that class was full, I would then switch it around with that. So, it taught me how to plan out everything before I started doing it.

P: $\quad$ Student clubs... $\quad$ did you join any?

L: $\quad$ Yes, I joined, umm, Intervarsity Christian Fellowship and I joined (pause) I think that was the only one I joined. I never joined the Education Club because their meetings were always when I was work, so I never joined that one. With Intervarsity Christian Fellowship, we went on trips and met more people. I didn't really join any major clubs, but I worked for Student Life as a workstudy. So, I was always in there. So, I didn't as many as I wish I would have, but I still experienced it because I was always there.

P: $\quad$ Tell me about a time when you almost quit and what kept you going.

L: Quit school?

P: $\quad$ Huh-huh.

L: $\quad$ When I was working for the YMCA, I had a little boy who had cerebral parsleys and he his aide was leaving and there was an opening for it, and at that time (pause) my mind was just not on school. My grades were suffering. I wasn't studying. It was after I had got out FYE and I told my mother, I said, “After this semester is over, I'm not going back.” And she said, "Why are not going to go back?" And I said, "I just feel like I want to take a break. I want to do something else and then I'll go back.” And 
she said, "You want to do the educational aide." And I said, "Yes, I'll just do it from January to the end of the school year, and then I'll go back." And then she said, "Do you think you'll really go back? You'll be working as an aide in the morning and then going to be working at the YMCA at nighttime... and that money is going to get really nice to you because you're going to have two checks coming to you and you're going to start liking that money." She said, "You're not going to go back." And I said, "Yeah, I'm going to go back. I just want to take a break." And she said, "No.” She flat out told me no. I was like, "What do you mean no? I'm just going to do it." And she said, "No, if you do it, you can only stay here until after you get that first check (pause) after that first check, you going to have to move out. If you're going to do it, you going to have to get your own place.” Then, I went looking for another job where my mother works for the schoolboard, so at her school they were looking for teachers' assistants. So, my mother knows the lady in the front office that takes all the applications and she told me, if you turn in an application, I'm going to throw it away before anyone can ever see it. So, she was telling me, "No, you can’t quit.” So, I just wanted to, but my mother never let me. She let me take breaks, but I always had to go back. Like, some summers I took off and like now, I'm taking a break, but I have to go back. There's no if, and, or but, you have to go back.

P: $\quad$ Smart woman.

L: $\quad$ Yeah, she's pretty smart. My mother's been through a lot and she knows you have to go back, cause you won't go back.

P: $\quad$ Tell me about your best experiences you've had in your education? What stands out for you?

L: $\quad$ Umm, (long pause) I want to say all of it cause (pause) well, I always tell everyone that I think [school] was the greatest school that I ever went to, because I started in kindergarten. So, I was able to experience in high school and elementary and middle school, things that other people were not able to experience. Like, I have a friend now, that I asked her (pause) that we were talking the other day and I was telling her that I wanted to have a birthday party for my goddaughter and so, she was saying about birthday parties - how she went to when she was younger and I told her that I had gone to this Bar Mitzvah and she goes, "What's a Bar Mitzvah?” and I said that's the Jewish birthday party and she's like, "What is that? I've never been to one of those." And I think that I've been to like 10 when I turned 13. So, it's crazy that she didn't (pause) she didn’t know what it was. [School] was, in my education, was so much more than just learning. We were able to experience more. We were able to know more. We had more friends than just your own special area friends. I 
always thought that's just the greatest thing. I said if I have children and I stay in Florida, I will work my hardest to get my children in [school] because it was one of those schools that you were able to meet more people than just people in your community. When my brother left [school], he went to [middle school] and [high school] and the only people that went to [middle school] and [high school] were people who stayed in [local community]. At [school], I had friends from "Arcadia” and "Australian Pines", and "Kingwood" and "Coral Gardens." It was hectic for my mother because when there was a project or I wanted to go somewhere, she was driving here, there, and everywhere, but I was able to experience so many different aspects of ABC County. It was like a little college in itself because you were able to experience people from different areas.

P: What about your worst experiences?

L: $\quad$ My worst experiences (pause), umm, (long pause) in high school, one of my worst experiences was (pause) you were on your own. Where as when you go to college, there are so many people there, that if something is going wrong, they can help you. Whereas in high school, you're on your own. There's people there to help you, but there not always there. When in college, there's people there that can help you. If not, you go to this person, this person, and this person. Whereas in high school you get one counselor and if that guidance counselor isn't there to help you, then you're kinda lost. So, when I was a senior, I really didn't have that guidance to give you (pause) to tell you do this and do that. It was more like you do it on your own and if you don't get it, then, you're kinda left behind.

P: $\quad$ Also, there are so many students that they can't build the relationships or create the time. Three adjectives that describe you, what would you say?

L: $\quad$ Three adjectives that describe me. Whew! That's hard. Is loud an adjective? Someone said I'm loud, which I think I am. Umm, I'm friendly, optimistic. Yeah, loud, optimistic, and friendly. I'll make a friend with anybody. I don't care who they are. I'll make a friend with a goat if they'll talk to me. I'm loud and I make myself known. Like even here at ABC, when I first got here, I was in my shell and then once I got comfortable, I made myself known. Optimistic, anything can happen. No matter what. If I think I can fly, probably one day I'll fly. Anything can happen.

P: $\quad$ How has your race, gender or culture affected your education? You talked a little bit about segregation with your dad. Now, you were born in Florida, right? 
L: Uh-huh.

P: $\quad$ For you, how has race, gender or culture affected you?

L: $\quad$ I think my race has affected me more because before people meet me, before people know your name, before people know anything about you, they see your race. No matter who it is, no matter what it is (pause) before anybody knows LeLe, the person, they know LeLe, the Black girl - and that's what it is. And, there are so many stereotypes of that race and that gender that you're supposed to be like this, you're supposed to be like that. You supposed to do this (pause) you're not supposed to do that.

P: $\quad$ Who sets this rule?

L: $\quad$ It is society more than anything else. Society sees us as something else and I've always wanted to break out of that mold where it's just blocking individuality. We kinda sabotage ourselves where we set ourselves back. It's just so many barriers that my mother's always trying to break out of those barriers - don't do this, don't do that. Like, I said, my adjective is I'm loud. That's the thing they say - Black women are loud and my mother's always, shhh! Don't talk so loud. So, I'm always trying to break out of that and just be LeLe - the girl you see. So, I think my race is one of the big things that differs your education. I try to not play the race card, like they say - like, I try not to say, "Well, you know, I can’t do that because I'm Black. I don't know. It's complicated. Like, I said, my mother was integrated when she was a girl in Jersey. I think she was in - she had to be in elementary school. She went to school with White children and when she came down here, she sat down, she looked around and saw that they were all Black children and she asked the girl next to her, where are the White children? And they laughed at her because the White children the White children go to the other school and we go to this school. And she just thought that was so weird that they were integrated up there but segregated down here. So, she's always showed us, this is this, and this is that. Don't let someone not allow you to do something because of your race. Don't let someone not do something because of your gender. So, it's always been do this. Do whatever you want. Just make sure you do it right. If you're going to do it, do it the best you can.

P: $\quad$ So, as an African-American woman, have you ever experienced where someone says you need to go to this school? You need to sit here?

L: $\quad$ Umm, we kinda notice things that you do. As an African-American woman, I can notice. I still do it to this day. If I go into a classroom, I feel more comfortable sitting next to an African-American person than I'd be sitting next to a Caucasian person and I try to break out of that where I'm 
trying to - no matter where I sit, I just sit somewhere. So, it kinda holds you back sometimes, but then again it sometimes makes me go forward. Like right now, one of my choices is [historically Black college]. And, I think one of the reasons I want to go there other than the fact that it's just a great school and the history is so rich, is because it's a historically Black college and I've never had that aspect where I'm in a group of AfricanAmerican students. [school] is not predominately White and it's not predominately Black. It's all just - we're all together. So, I've never been to this area where it's just predominately Black and that's one of the reasons that I want to go there because I've never had that experience. Like, my best friend in the world is Colombian. I've never had an experience where I've been in a whole cluster of all African-Americans. I think that's one of the reasons that I want to go there - to experience how was it raised up for some people and get a different aspect of my culture.

P: $\quad$ And you're open to change. You seem like the type of person that you want to experience. And you may like it and you might not. You don't know, but until you do it, you won't know.

L: $\quad$ I just want to experience so much. Like my brother going away to Ohio, he had friends from Georgia and other friends from Florida and he had friends from the east coast and the west coast. He met so many different aspects of people that it was just so amazing. He always said go off to school so that you can meet so many people. So, I'm open to meet different people and bring that back to my experience and my life...

P: $\quad$ Last question... $\quad$ many of the students you started courses with are no longer here. What do you think made the difference for you?

L: $\quad$ Umm, I'm trying to think of the term that I learned when I first started here, I think they called it "parking lot" students or from "class to parking lot.” When they come to class, they're gone as soon as they get here. It's a funny term. I think that's one of the reasons that I stayed here, because I was here so I had to experience more things. Like, there are certain people who - like I have a friend that I work with who she started here this semester. She didn't know they had a basketball team. She didn't know they have a student life. She didn't know they had all those - like today I'm meeting her at the Chocolate Festival. I'm like, you have to go to the Chocolate Festival. And there's another girl I work with that I'm making her come to the Chocolate Festival. There are so many people that don't experience so many other things that $\mathrm{ABC}$ has to offer and I tell them (pause) most of the time it's free. If you have to pay, you're not paying that much. Experience it. Because I was here all the time, I was able to experience it. There was just so many things that I was able to experience. I've been to the basketball games. I've been to the leadership retreats. I 
remember when they did the PC giveaways. I've gotten two computers from ABC. And, I tell everyone do the PC. I don't even know if they do that anymore, but do the PC giveaway. I gotten 2 computers where I've taken them and got them fixed and put everything on them and they work fine. I still use one of them and my nephew has the other one. He's nine years old and uses the other one. You have to experience it because it's so much. Don't let people make you feel that just because you go to a community college, it's less than going to [local university] or going [local university] or anywhere else. It’s the same.

P: $\quad$ Any advice you would give an incoming freshman or something you wish you had known that would help them.

L: $\quad$ Umm, be open - be open. There's so much. If you fail at ABC, you fail because you choose to fail, not because you didn't have the opportunity. You can go to tutoring, you can do so much here. If you fail, you failed on your own. Which is... a lot of my friends from FYE, they have gone on to a different college or they just stopped completely, and they're doing their own thing. I think the reason why "Terika" and I stayed so close is because we were on the same road. "Terika" and me - she knows the difference between determination. She saw, like she has older siblings who didn't go to college, which I have an older sibling who did go to college. So, we know what life is without that college education. So, "Terika" is different in the fact that she's the first and I'm the second, but we had that same path which joined us together because we knew. This is what we need to do. Even after me and "Terika" got out of FYE, we still took classes together. We took World Religion together. We took English together and then when she left and went to [local private university], I remember one day I went into the bookstore and the lady asked me, "Where's that friend that you're always with? I don't see her anymore." And, I said, "She's gone now." She left you? And I said, "Yeah, she left me. She moved at a faster pace than I did (light laughter)." But we were always together which was really great. Even though we had our group of seven, our group seven went down to like five and then it was just me and "Terika" and we worked on that same goal. But if you're a freshman coming in, be open to everything. Don't let anyone let you feel less of anything because you're going to a community college, because things you can experience somewhere else, you can experience at a community college. You just have to work for it, go to Student Life, find out everything you can about what's going on, get the calendars. There's so much that they do here, that it's ridiculous. 
VITA

\section{PETER BARBATIS}

B.A., History

University of Florida

Gainesville, Florida

1991

M.Ed., Counselor Education

University of Florida

Gainesville, Florida

1991-1995

Director of Counseling

Central Florida Community College

Ocala, Florida

1995-1997

Dean of Student Development

North Harris Montgomery Community College District Houston, Texas

1997-present

Dean of Student Affairs

ABC Community College

Southeast, United States 